University of Louisville

ThinkIR: The University of Louisville's Institutional Repository

$1-2018$

\title{
Biomechanical characterization of video-recorded short-distance falls involving children equipped with a biometric device: a pilot study.
}

Bret A Hilt

University of Louisville

Follow this and additional works at: https://ir.library.louisville.edu/etd

Part of the Biomechanical Engineering Commons

\section{Recommended Citation}

Hilt, Bret A, "Biomechanical characterization of video-recorded short-distance falls involving children equipped with a biometric device: a pilot study." (2018). Electronic Theses and Dissertations. Paper 3453. https://doi.org/10.18297/etd/3453

This Master's Thesis is brought to you for free and open access by ThinkIR: The University of Louisville's Institutional Repository. It has been accepted for inclusion in Electronic Theses and Dissertations by an authorized administrator of ThinkIR: The University of Louisville's Institutional Repository. This title appears here courtesy of the author, who has retained all other copyrights. For more information, please contact thinkir@louisville.edu. 


\title{
BIOMECHANICAL CHARACTERIZATION OF VIDEO-RECORDED SHORT-DISTANCE FALLS INVOLVING CHILDREN EQUIPPED WITH A BIOMETRIC DEVICE: A PILOT STUDY
}

\section{By}

Bret Alan Hilt

B.S., University of Louisville, 2017

\author{
A Thesis \\ Submitted to the Faculty of the \\ University of Louisville \\ J. B. Speed School of Engineering \\ as Partial Fulfillment of the Requirement \\ for the Professional Degree
}

\section{MASTER OF ENGINEERING}

Department of Bioengineering

December 2018 



\section{BIOMECHANICAL CHARACTERIZATION OF VIDEO-RECORDED SHORT-DISTANCE FALLS INVOLVING CHILDREN EQUIPPED WITH A BIOMETRIC DEVICE: A PILOT STUDY}

Submitted by:

Bret Alan Hilt

A Thesis Approved On

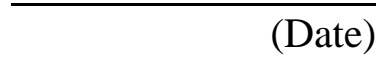

By the Following Reading and Examination Committee

Gina E. Bertocci, Thesis Director

Angela K. Thompson

Karen L. Bertocci 


\section{ACKNOWLEDGEMENTS}

This research was funded by the National Institute of Justice for research and development in forensic science for criminal justice purposes. Subjects included this study were recruited from Bluegrass Academy Childcare Center located in Louisville, Kentucky.

I would like to express my sincere gratitude to my mentor, Dr. Gina Bertocci, who provided guidance, support, and advice throughout the process. Her insight and encouragement allowed me to grow both professionally and personally. I would like to thank my examination committee, Dr. Angela Thompson and Dr. Karen Bertocci, for their guidance and valuable input. I would additionally like to thank the personnel and students at University of Louisville's iRAP Laboratory, Craig Smalley, Dr. Raymond DSouza, Dr. Nathan Brown, Keyonna McKinsey, and Danielle Cory, for their key roles and time dedication in project planning, facility installations, and data collection. Without them, this project would not have been possible. Finally, I would like to express gratitude to my friends and family for their continuing support throughout the process. 


\section{ABSTRACT}

Falls are commonly used as a false history by caregivers to conceal child abuse. Determining biomechanical compatibility is a key aspect in differentiating abuse from accident. Current forensic approaches are limited in assessing biomechanical compatibility of shortdistance falls involving children due to a lack of reliable witnessed falls with known injury outcomes. The goals of this pilot study were to characterize biomechanical measures and to examine differences in biomechanical measures based on child and fall characteristics in reliable witnessed video-recorded falls involving children. The results of this study will serve as preliminary data for an on-going larger study with the aim of improving forensic investigations with a fall history. Children between the ages of 1-3 years in a video monitored childcare center were equipped with a biometric measuring device that collected head accelerations and velocities during falls. Additionally, Head Injury Criteria (HIC) values and impact durations were determined. Video surveillance was used to capture fall dynamics and to provide reliable witnessed falls. For each fall event, whole-body impact biomechanics were determined using fall characteristics, coefficient of restitution measurements, and child anthropometric measurements. The results of the study indicate that fall characteristics had an effect on biomechanical measures. Falls with head impact were associated with greater head accelerations and shorter impact durations and thus, would be associated with an increased likelihood of injury risk compared to falls without head impacts. Head biomechanical measures also increased for falls onto stiffer surfaces than falls onto less stiff surfaces. Falls from height resulted in an increase in whole-body biomechanical measures compared to ground based falls. Fall events that resulted in head impacts with objects prior to impacting the ground were associated with greater 
biomechanical measures and injury risk than any other falls. However, no injuries requiring medical care occurred to any child and biomechanical measures obtained indicated that there was a low level of injury risk. To our knowledge, this was the first study of video-recorded pediatric falls that included biometric measurement of head biomechanics. Findings from this study address the on-going question as to whether short-distance falls can cause severe or fatal injuries, and can potentially aid forensic investigations in determining if a fall history could account for a child's presenting injuries. Future work will expand the fall sample size to further advance our understanding of fall biomechanics and injury risk in children. 


\section{TABLE OF CONTENTS}

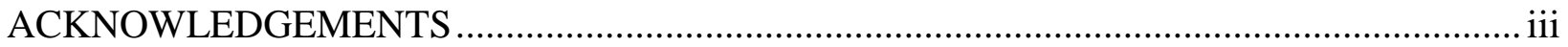

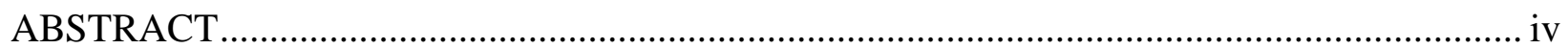

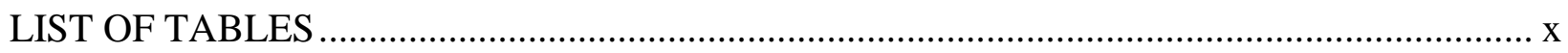

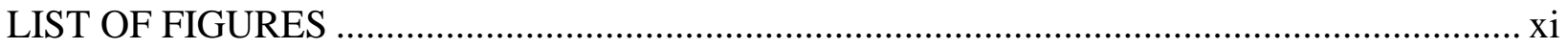

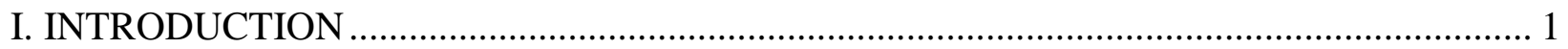

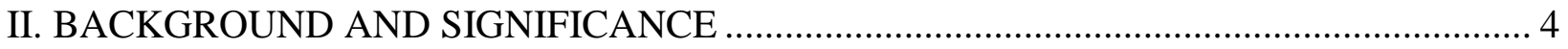

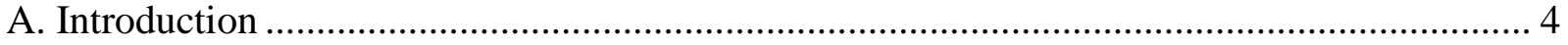

B. Abusive vs Accidental Head Injury Characteristics ...................................................... 6

C. Injuries and Fatalities Resulting from Short Falls in Children ..................................... 9

D. Pediatric Head Injury Thresholds ....................................................................... 14

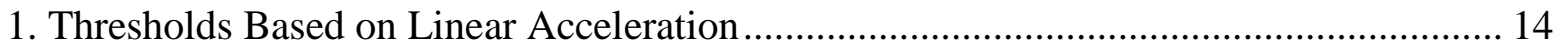

2. Thresholds Based on Rotational Acceleration.......................................................... 16

E. Biomechanical Assessment of Pediatric Injury and Injury Severity ............................. 18

1. Anthropomorphic Testing Devices in Simulated Falls.............................................. 18

2. Anthropomorphic Testing Device in Simulated Shaking ........................................... 23

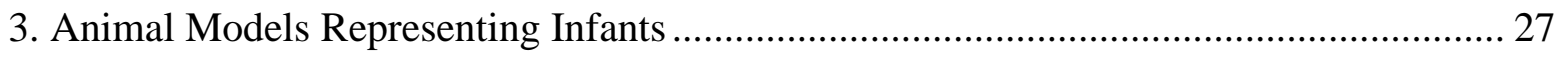

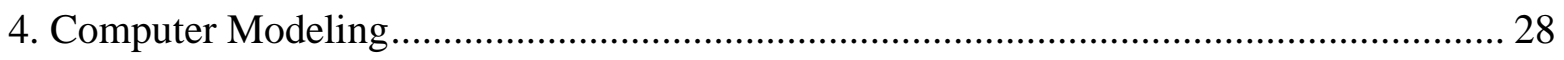

F. Methods Used to Obtain Biomechanical Measurements for Human Subjects ................... 30

1. Utilization of Biometric Sensors to Obtain Real-Time Measurements ......................... 30

2. Video Surveillance for Biomechanical Analysis ......................................................... 32

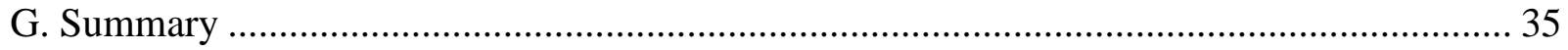

III. STUDY DESIGN AND METHODS ...................................................................... 37

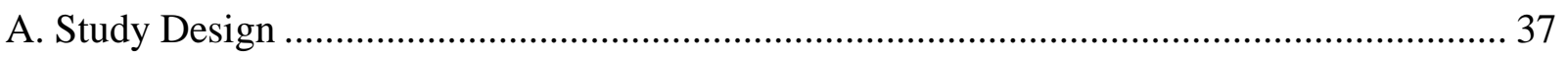

1. Inclusion/Exclusion Criteria ................................................................................... 37 
2. Fall Monitoring Duration and Sample Size ........................................................... 38

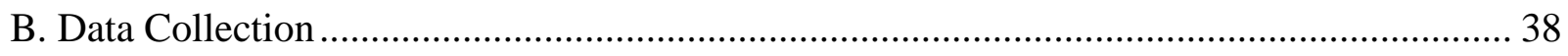

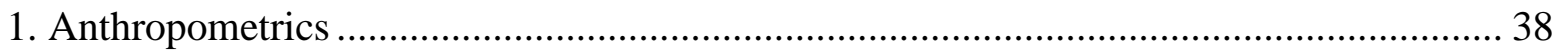

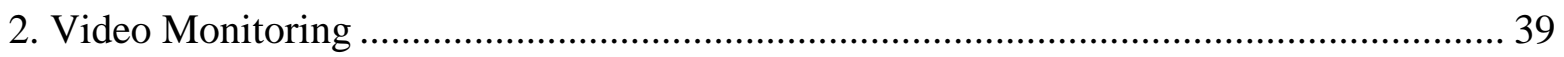

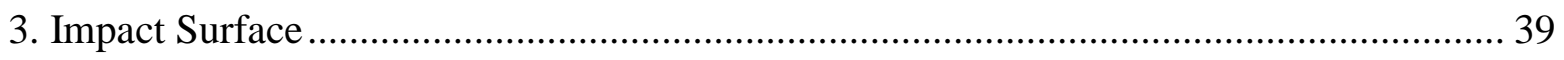

4. SIMG/SKYi System ...................................................................................... 41

C. Manual Biomechanical Calculations of Daycare Center Falls ....................................... 46

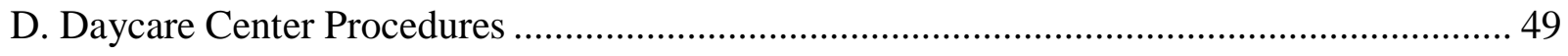

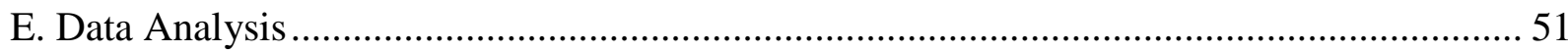

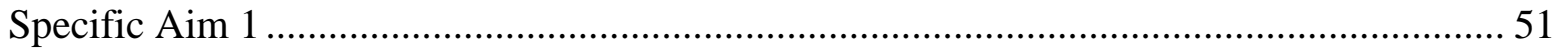

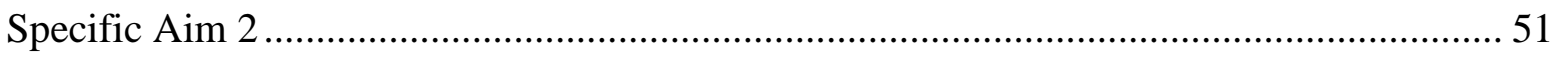

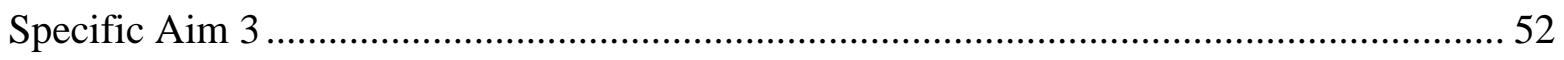

1. Differences in Biomechanical Measures Based on Child Characteristics...................... 52

2. Differences in Biomechanical Measures Based on Fall Characteristics ........................ 53

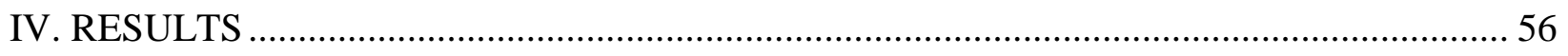

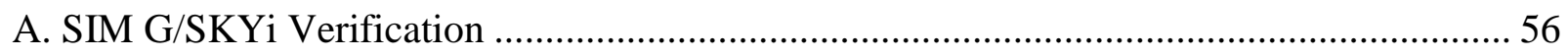

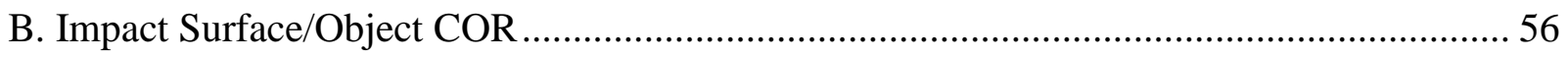

C. Video-Recorded Falls with Biomechanical Data .................................................... 57

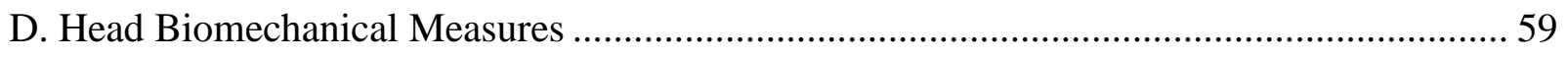

E. Whole-Body Biomechanical Measures .................................................................... 59

F. Biomechanical Measures Based on Child Characteristics ............................................ 60

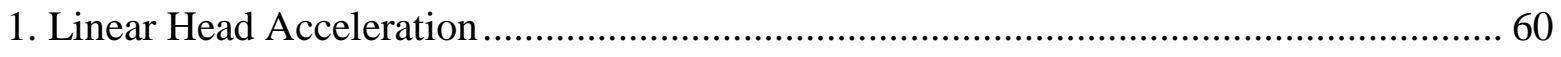

2. Rotational Head Acceleration............................................................................. 61

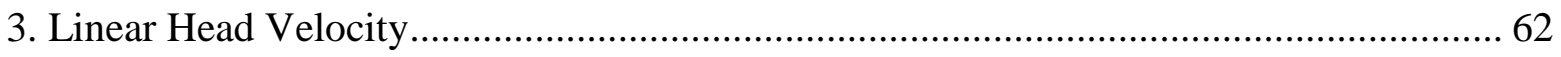

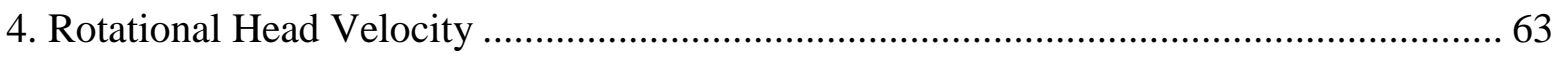




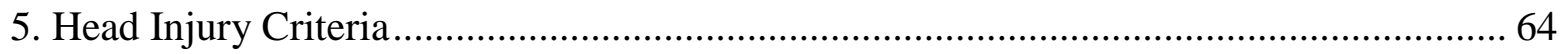

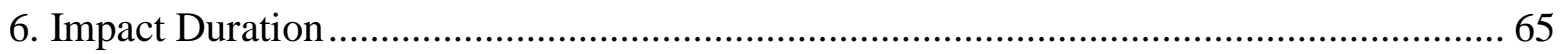

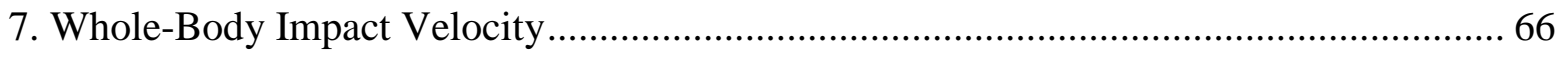

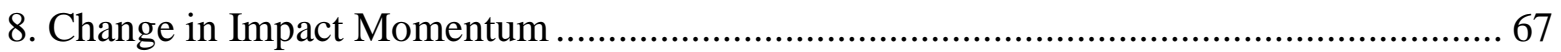

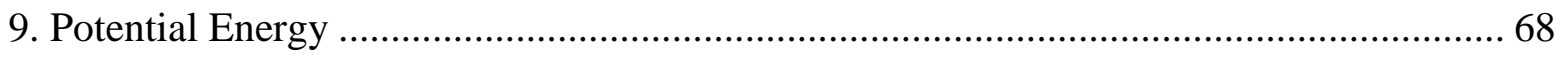

E. Biomechanical Measures Based on Fall Characteristics .................................................... 69

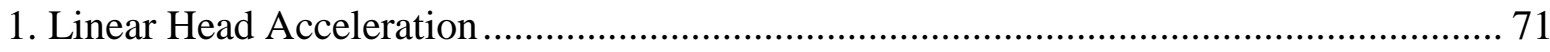

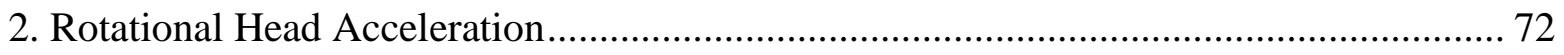

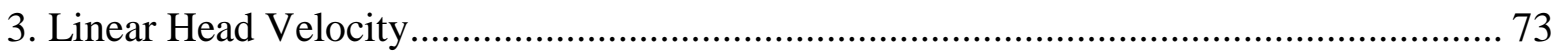

4. Rotational Head Velocity .................................................................................................. 74

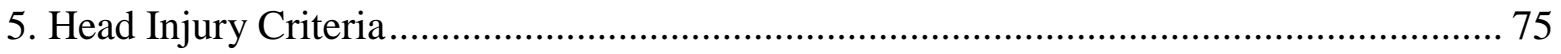

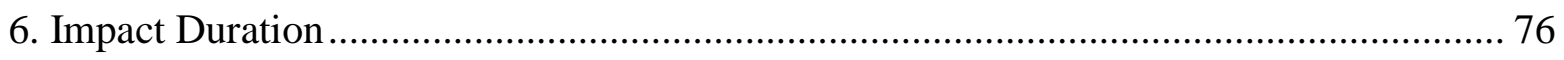

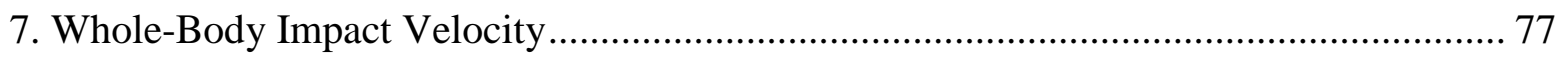

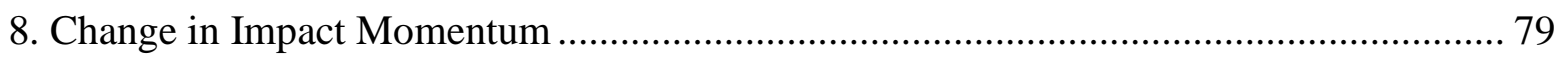

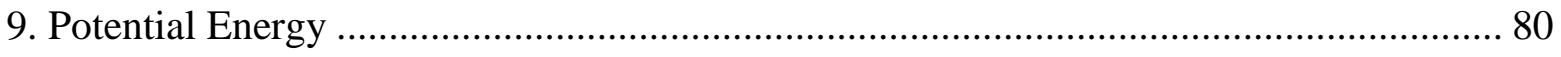

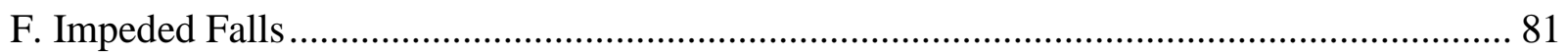

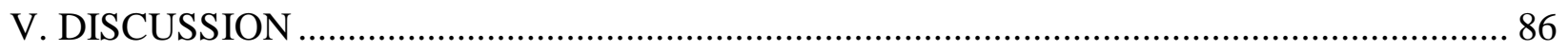

A. Head Injury Outcomes and Head Injury Risk ……………………………................... 86

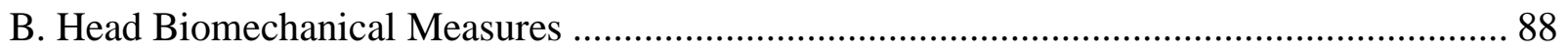

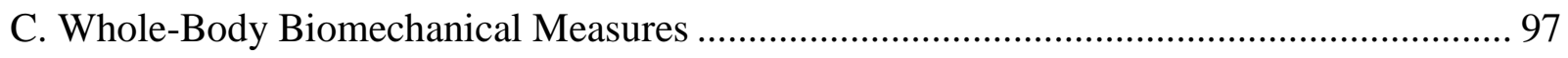

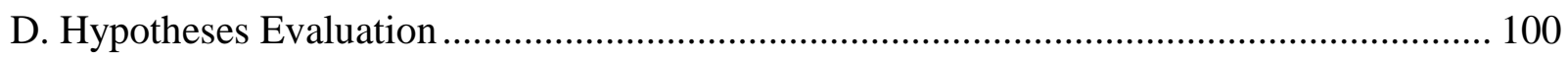

E. Clinical and Judicial Relevance.................................................................................. 102

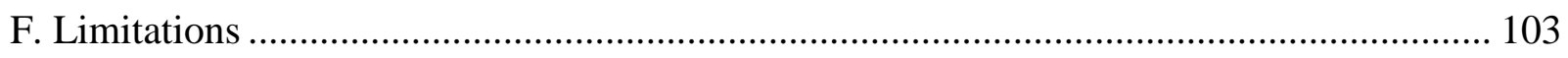

G. Future Work and Recommendations .............................................................................. 105

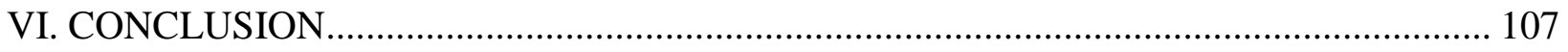




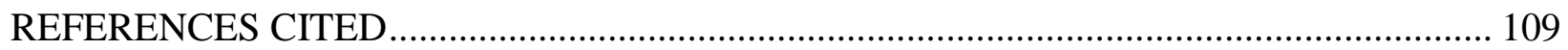

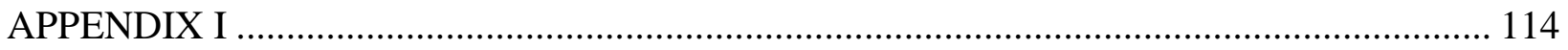

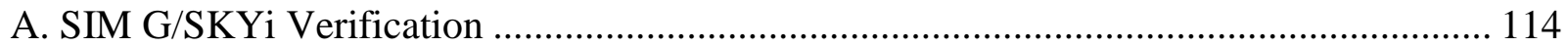

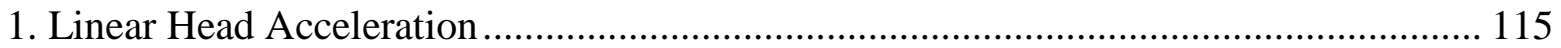

2. Rotational Head Acceleration.......................................................................... 116

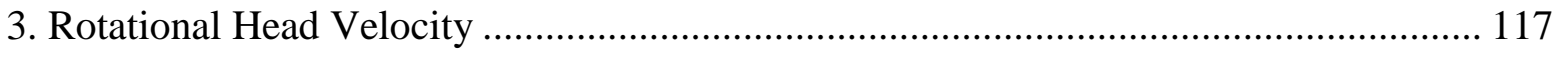

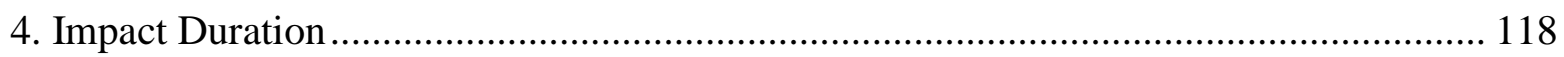

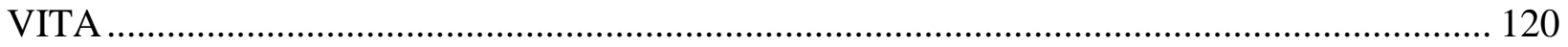




\section{LIST OF TABLES}

TABLE I COEFFICIENT OF RESTITUTION MEASUREMENTS FOR IMPACT SURFACES/OBJECTS

TABLE II MEAN HEAD BIOMECHANICAL MEASURES ACROSS ALL FALLS.

TABLE III MEAN WHOLE-BODY BIOMECHANICAL MEASURES ACROSS ALL FALLS

TABLE IV NUMBER OF FALLS FOR CHILD CHARACTERISTICS..................................... 60

TABLE V NUMBER OF FALLS FOR FALL CHARACTERISTICS …………...................... 70

TABLE VI HEAD BIOMECHANICAL MEASURES FOR IMPEDED AND NON-IMPEDED

FALLS (FREE FALLS) 83

TABLE VII COMPARISON OF MEAN HEAD BIOMECHANICAL MEASURES FROM THOMPSON'S FEET-FIRST FALL STUDY (2009)

TABLE VIII COMPARISON OF MEAN WHOLE-BODY BIOMECHANICAL MEASURES FROM THOMPSON'S HOUSEHOLD FALL STUDY (2011) 


\section{LIST OF FIGURES}

FIGURE 1 - Concussion and DAI Injury Tolerance Scaling ........................................... 17

FIGURE 2 - DAI Threshold for a Range of Brain Masses ................................................... 18

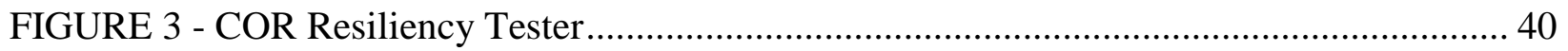

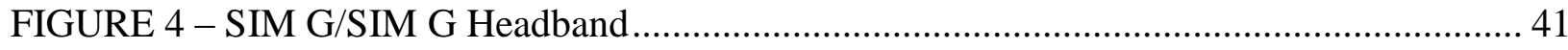

FIGURE 5 - SIM G/SKYi Receiving Monitor............................................................ 42

FIGURE 6 - Experimental Set-Up for a 0.69 m Fall ...................................................... 43

FIGURE 7- SIM G Placement on 12-Month-Old CRABI ATD ............................................ 45

FIGURE 8 - Example Acceleration Trace Indicating Impact Start Time .............................. 47

FIGURE 9 - Example Acceleration Trace Indicating Impact End Time ................................ 48

FIGURE 10 - Percentage of Video-Recorded Falls with SIM G Activation ............................ 58

FIGURE 11 - Mean Peak Resultant Linear Head Acceleration Based on Child Characteristics 61

FIGURE 12 - Mean Peak Resultant Rotational Head Acceleration Based on Child Characteristics 62

FIGURE 13 - Mean Peak Resultant Linear Head Velocity Based on Child Characteristics........ 63

FIGURE 14 - Mean Peak Resultant Rotational Head Velocity Based on Child Characteristics . 64

FIGURE 15 - Mean Peak HIC ${ }_{15}$ Based on Child Characteristics ............................................ 65

FIGURE 16 - Mean Impact Duration Based on Child Characteristics.................................... 66

FIGURE 17 - Mean Whole-Body Impact Velocity Based on Child Characteristics.................. 67

FIGURE 18 - Mean Change in Impact Momentum Based on Child Characteristics.................. 68

FIGURE 19 - Mean Potential Energy Based on Child Characteristics .................................... 69

FIGURE 20 - Mean Peak Resultant Linear Head Acceleration Based on Fall Characteristics ... 72 FIGURE 21 - Mean Peak Resultant Rotational Head Acceleration Based on Fall Characteristics.

FIGURE 22 - Mean Peak Resultant Linear Head Velocity Based on Fall Characteristics. ......... 74 
FIGURE 23 - Mean Peak Resultant Rotational Head Velocity Based on Fall Characteristics. ... 75

FIGURE 24 - Mean $\mathrm{HIC}_{15}$ Values Based on Fall Characteristics............................................ 76

FIGURE 25 - Mean Impact Duration Based on Fall Characteristics........................................ 77

FIGURE 26 - Mean Whole-Body Impact Velocity Based on Fall Characteristics. .................... 78

FIGURE 27 - Mean Change in Impact Momentum Based on Fall Characteristics ................... 80

FIGURE 28 - Mean Potential Energy Based on Fall Characteristics. .................................... 81

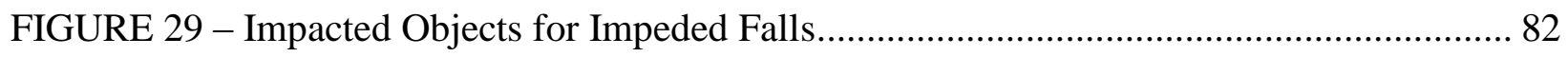

FIGURE 30 - Representative Resultant Linear Head Acceleration Time History for Impeded Fall versus Non-Impeded Fall (Free Fall) .............................................................................. 84

FIGURE 31 - Fall Event that Resulted in Maximum Peak Resultant Linear Head Acceleration 85

FIGURE 32 - Video Capture of Fall Dynamic Sequence for Replicated Falls (Top) and Previous

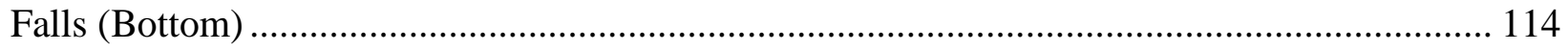

FIGURE 33 - SIM G Verificaiton: Mean Peak Resultant Linear Head Acceleration ............... 116

FIGURE 34 - SIM G Verificaiton: Mean Peak Resultant Rotational Head Acceleration ......... 117

FIGURE 35 - SIM G Verificaiton: Mean Peak Resultant Rotational Head Velocity............... 118

FIGURE 36 - SIM G Verification: Mean Impact Duration. .............................................. 119 


\section{INTRODUCTION}

Child abuse is a frequent and severe problem in today's society with a national estimate of 676,000 victims and 1,750 child deaths at a fatality rate of 2.36 per 100,000 children in 2016 (U.S. Department of Health \& Human Services, 2018). Abuse is the leading cause of childhood traumatic injury and death in the United States with abusive head trauma (AHT) accounting for $80 \%$ of deaths (Paul, 2014). In a 1990 study, it was determined that $17 \%$ of all brain injuries and $56 \%$ of serious brain injuries in children younger than one year were due to assault (Kraus, 1990). Accidental falls are the most commonly stated false scenario stated when a caregiver is concealing child abuse and there is a current need for improving differentiation between injuries resulting from abuse with a fall history and a true accidental fall (Rivara, 1988; Kraus, 1990; Coats, 2008).

Differentiation between the two is critical for abused children and can have legal ramifications for involved caregivers. The mortality rate involving young children and infants from short-distance falls has been estimated to be $<0.48$ deaths per 1 million (Chadwick, 2008). However, the lack of witnessed short-distance falls has led to uncertainties for predicting the likelihood of severe head injury and incidence of severe head injury occurring in falls involving children. Determining biomechanical compatibility of injuries with the stated cause is key in differentiating abuse from accident. The lack of evidence-based biomechanical data in reliable witnessed shortdistance falls has led to controversy in examining biomechanical outcomes such as fall dynamics, velocities, and accelerations that occur in short-distance falls involving children. Determining biomechanical compatibility of short-distance falls involving children will help differentiate between an accidental fall and a false history of a fall. 
The objective of this project was to characterize biomechanics and to determine differences in biomechanical measures based on child and fall characteristics in videorecorded short-distance falls. In this project biomechanical data was collected and analyzed in falls involving children between the ages of 1-3 years in a video monitored childcare facility. Children were equipped with a biometric measuring device that collected head acceleration and velocity measurements for fall events. In addition to the biometric device, video surveillance was used to capture fall events to describe fall dynamics and to provide reliable witnessed falls. The outcome of this project could potentially assist in forensic investigations where a fall history has been provided by providing evidence-based knowledge of biomechanical outcomes in witnessed shortdistance falls. The results of the study could be used for forensic analysis where a shortdistance fall history is in question.

The Specific Aims for this project were as follows:

Specific Aim 1: To characterize head impact biomechanics including linear and rotational head acceleration, linear and rotational head velocity, impact duration, and $\mathrm{HIC}_{15}$ associated with short-distance falls involving children between the ages of 1-3 years.

Specific Aim 2:_To characterize whole-body impact biomechanics by estimating whole-body impact velocity, change in impact momentum, and potential energy associated with short-distance falls involving children between the ages of 1-3 years. 
Specific Aim 3: To determine differences in biomechanical measures based on child age and mass, fall type, head or non-head impact, and impact surface coefficient of restitution (COR).

H01 - There will be an increase in linear and rotational head acceleration and velocity, $\mathrm{HIC}_{15}$, whole-body impact velocity, change in impact momentum, and potential energy for falls from height compared to ground based falls. H02 - There will be a decrease in impact duration and an increase in the remaining head biomechanical measures for falls onto surfaces with lower COR. H03 - There will be an increase in linear and rotational head acceleration, linear and rotational head velocity, and $\mathrm{HIC}_{15}$ for head impacts compared to non-head impacts.

This study will examine biomechanical measures for pediatric falls in a video monitored setting where the possibility of child abuse can be excluded. The findings will provide accurate evidence that has been controversial in previous studies by addressing the issue of few reliable witnessed falls through video surveillance and by obtaining direct head acceleration and velocity measurements in children through a biometric device. The findings will determine the impact biomechanical measures experienced and improve accuracy for biomechanical compatibility in short-distance falls involving children. The outcomes will have a critical role in biomechanical forensic investigations on child abuse with a stated fall history by improving accuracy for biomechanical compatibility in short-distance falls. 


\section{BACKGROUND AND SIGNIFICANCE}

\section{$\underline{\text { A. Introduction }}$}

Child abuse is a frequent and severe problem in today's society with an estimate of 676,000 victims and 1,750 child deaths at a fatality rate of 2.36 per 100,000 children in 2016 (U.S. Department of Health \& Human Services, 2018). Abuse is the leading cause of childhood traumatic injury and death in the United States with abusive head trauma (AHT) accounting for $80 \%$ of those deaths (Paul, 2014). Although abuse can occur in children of all ages, it has been found that children between the ages of zero and three are at the greatest risk of death (Feldman, 2001). In a 1990 study, it was determined that $17 \%$ of all brain injuries and 56\% of serious brain injuries in children younger than one year were due to assault (Kraus, 1990). Based upon the high percentage of injuries to children related to abuse, there is a need to focus on improving diagnosis and prevention of child abuse. Short-distance falls involving infants and young children are common, however short-distance falls are often a false history given by caregivers to conceal child abuse (Rivara, 1988; Thompson, 2011; Coats, 2008; Thompson, 2014; Kraus, 1990). There is a current need for improving differentiation between a false history of a fall provided in child abuse and a true accidental fall. The differentiation between the two can have significant consequences for abused children and legal ramifications involving caregivers. Un-witnessed short-distance falls have made it difficult for predicting the likelihood of severe head injury and the rate for severe head injuries occurring in falls involving children. The current lack of evidence-based biomechanical data in shortdistance falls and child abuse fails to provide critical biomechanical information 
including fall dynamics, impact velocities, changes in impact momentum, linear and rotational head accelerations, and rotational head velocities.

There is an economic burden related to child maltreatment with significant indirect and direct costs in the United States. Average costs can vary depending on child maltreatment being fatal or nonfatal (Fang, 2012). In 2010, estimated lifetime cost for nonfatal child abuse injuries was $\$ 210,012$, including $\$ 32,648$ in childhood health care cost, $\$ 6,747$ in criminal justice costs; and $\$ 7,999$ in special education costs. For fatal cases, the estimated average lifetime cost was $\$ 1,272,900$, including $\$ 14,100$ in medical costs and $\$ 1,258,800$ in productivity losses. In total, lifetime economic burden was approximated to be $\$ 124$ billion in the United States in 2008 and the total burden was estimated to be as large as $\$ 585$ billion. Costs related specifically to abusive head trauma have been estimated to be $\$ 47,952$ (2012) per patient for 4 years after diagnosis (Peterson, 2014). The average medical cost per hospital emergency department visit related to child abuse is $\$ 2,612$ and admission is $\$ 31,901$ (2012). Total annual nationwide medical cost of AHT hospital visits has been estimated to be $\$ 69.6$ million (Peterson, 2015).

Injury biomechanics is the field of study that examines biomechanical behaviors of the human body under injury producing conditions. Injury biomechanics seeks to understand mechanisms that can cause injury, responses of the human body resulting in a specific injury type, and determining human tolerance limits that can cause trauma or critical values for when an injury can occur. Since falls are a commonly used as an excuse for child abuse, it is important that injury biomechanics be utilized to aid in the determination of child abuse or an accidental fall. It would be useful to evaluate 
biomechanical outcomes between child abuse and falls in order to determine if the stated cause could account for the presenting injuries. Biomechanical literature related to pediatric injury and child abuse focuses on pediatric head injury thresholds, uses of anthropomorphic testing devices (ATD) to simulate falls, animal models to investigate injury mechanisms, and computer modeling studies to determine biomechanical measurements occurring in pediatric falls or abuse. The purpose of this literature review was to describe studies related to abusive vs accidental injury characteristics, injuries and fatalities from short-distance falls in children, pediatric head injury thresholds, biomechanical studies related to pediatric injuries, and methods used to obtain biomechanical measurements in human subjects.

\section{B. Abusive vs Accidental Head Injury Characteristics}

There has been a significant amount of research conducted that focused on differentiating injury characteristics between abusive and accidental injuries. An injury mechanism frequently associated with abusive head injuries is "shaken baby syndrome" (SBS). SBS was first defined by Caffey, who referred to SBS as "whiplash shaken infant syndrome"(Caffey, 1974). Caffey defined the syndrome as vigorous shaking of infants that produced intracranial and intraocular bleeding with no signs of external head trauma. Injury characteristics associated with SBS are unilateral or bilateral subdural hemorrhage (SDH), bilateral retinal hemorrhages (RH), and diffuse axonal injury (DAI) (Joyce, 2018). SBS is most common in children under two years of age and mainly seen in children under six months (Paiva, 2011). Although SBS is not the only AHT injury mechanism, the injury characteristics are commonly used to aid in the differentiation between abusive or accidental events. 
Subdural hematomas can result from contact, linear, and rotational events but are typically associated with rotational accelerations. Large rotational forces applied to the brain can cause the brain to move relative to the skull, which will ultimately lead to the shearing of bridging veins that connect the brain to the skull, resulting in SDH (Nadarasa, 2014). SDHs have been found to be the most common injury characteristic in abused children (Karibe, 2016). Betchel conducted a study to distinguish injuries between accidental and abusive head injuries in children younger than 24 months of age (Bechtel, 2004). A total of 87 children were included in the study, 15 children were classified as having abusive head injury and 72 were classified as having accidental head injury. Betchel found that $80 \%$ of abusive head trauma and $27 \%$ of accidental head injuries resulted in SDH. Roach also found that patients with abusive head trauma had higher rates of SDH compared to patients with accidental head injuries (76\% vs 23\%) (Roach, 2014). Accidental head injuries that result in SDHs typically either result from falls at great heights or from motor vehicle accidents. In a study conducted by Billmire, 19 infants were found to have SDH, 18 of those SDHs resulted from abuse and 1 was a result of a motor vehicle accident (Billmire, 1985). Barlow conducted a study to associate injuries with great fall heights in children and found that 1 out of 14 fatal injuries resulted in a SDH from a fall height greater than three stories (Barlow, 1983).

The presence of bilateral RHs raise a strong possibility of abuse (Kivlin, 2001). Maguire conducted a systematic review on abusive and accidental head injuries and found that RHs were found in 78\% of abusive head injuries and only 5\% of accidental head injuries (Maguire, 2009). 83\% of the abusive head injuries that resulted in RHs were bilateral, while only $8.3 \%$ of the accidental head injuries were bilateral. Betchel found 
that RHs occurred in $60 \%$ of abused children and only $10 \%$ in accidental head injuries. RHs were mostly bilateral in abused children and mostly unilateral in accidental cases. In addition, Geddes found that $71 \%$ of abusive head injuries resulted in RHs (Geddes, 2001). Duhaime found 10 cases of RHs out of 100 children less than two years of age (Duhaime, 1992). Of the 10 cases, 9 cases of RHs were a result of abusive head injuries, while one case was a result from a motor vehicle accident.

Diffuse axonal injury is a severe diffuse brain injury that causes disruption of axons within the cerebral hemisphere and can result in hemorrhages in the corpus callosum. DAI can result in a loss of consciousness lasting days or weeks and can cause sever disability or death. Roach found that patients with abusive head injuries had higher rates of DAI than accidental head injury patients (14\% vs $8 \%$ ). Geddes reported that $5 \%$ of abusive head trauma injuries resulted in severe DAI (Geddes, 2001). Although severe DAI has a low probability of occurring, Concussions are frequently present in both abusive and accidental head injuries. Billmire found concussions in 13 out of 54 cases of accidental head injuries and 7 out of 30 cases for abusive head injuries.

Skull fractures have been found in both abusive and accidental events. Roach found that accidental head injuries resulted in higher rates of skull fracture than abusive head injuries (52\% vs 21\%). Billmire found that 43 of 54 accidental head injuries included skull fractures, while 12 out of 30 abusive head injuries resulted in skull fracture. Billmire also found that $87 \%$ of skull fractures were linear fractures. However, there were four cases of complex fractures with intracranial hemorrhage and all four cases were a result from abuse. 


\section{Injuries and Fatalities Resulting from Short Falls in Children}

Case-based studies have been conducted to determine injuries that resulted in either Emergency Department (ED) visits or fatalities involving children. Helfer performed a case-study that focused on resulting injuries to children who fell out of a bed (Helfer, 1977). The purpose of this study was to determine the likelihood and seriousness of injuries to children 5-years-old or younger falling from the height of a bed or sofa (less than $90 \mathrm{~cm}$ ). The study included a total of 246 children and data was obtained by having parents fill out questionnaires regarding the fall incident and by obtaining incident fall reports from a large children's hospital. From the fall questionnaires, 161 children fell out of a bed or sofa on one or more occasion. Of those falls, $80 \%$ resulted in no observable injuries, $17 \%$ resulted in nonserious injuries (bumps, scratches, and bruises), and 3\% resulted in more serious injuries (clavicle, humerus, and skull fracture). However, none of the 161 children suffered any serious or life-threatening injuries. From the hospital incident reports, 85 reports of children who fell to the floor from heights of approximately $90 \mathrm{~cm}$ were obtained. Of the 85 incidents, 57 had no apparent injury and only one child obtained a skull fracture. The remaining incidents resulted in nonserious injuries such as bruises and cuts. The child that obtained the skull fracture had no serious ramifications. The results show that for most fall incidents from beds or sofas in children do not result in serious head injury. None of the fractures seen were bilateral, diastatic, or greater than $1 \mathrm{~mm}$ in width. Helfer states that physicians should be extremely suspicious of child abuse when the child has serious head injuries, with or without skull fracture, from a reported fall from a bed, sofa, or crib. This study concluded that severe head 
injuries and damage to the central nervous system is extremely rare from falls out of a bed in children aged 5-years-old and younger.

An additional case study that focuses on determining the likelihood of injuries to children occurring in bed falls came from Lyons \& Oates (Lyons, 1993). The researchers wanted to determine how likely serious injuries to children such as a SDH, skull fracture, or broken limbs could occur from a relatively low fall height. Data was obtained by fall incident reports occurring at a children's hospital over a nine-year period. Children included in this study were 6-years-old and younger. Using the estimated height of the fall and weight of the child, the momentum of impact was calculated and compared between injured and non-injured children. The study obtained 207 fall incident reports with the majority of falls occurring in boys and children between the ages of 1 and 2years-old. The heights of the falls were obtained by measuring crib and bed heights. Children under the age of 36 months slept in cribs. Cribs with the sides down were 0.81 $\mathrm{m}$ high and were $1.37 \mathrm{~m}$ with the sides up. The average bed height was $0.64 \mathrm{~m}$. Of the 207 falls, 31 resulted in injuries. Of the 31 injuries, 29 were trivial (contusions or small lacerations) and the other two were a fractured clavicle and a skull fracture. There was no loss of consciousness reported in any of the falls. The fractured clavicle occurred in a 21month-old child who fell after climbing over the crib rails and the skull fracture occurred in a 10-month-old who fell from a crib. The skull fracture was a simple linear fracture and the child had no contusions. The impact momentum between the injured and noninjured group showed no statistical significance between the two. The study concludes that bed falls are relatively benign where only $15 \%$ of children showed visible evidence of trauma. Lyons \& Oates discuss that most serious brain injuries are a result from 
rotational accelerations, where the brain moves within the skull. The result of high rotational accelerations could lead to the tearing of bridging veins and cause bleeding. Typically, falls from short distances produce mainly linear forces to the head. Linear forces can result in simple fractures but are only clinically significant when an epidural hematoma is present. The study was relevant because it shows that falls from short heights do not produce life-threatening injuries and that clinically significant injuries are uncommon. The study concludes that when given a history of a minor fall as the cause of life-threatening, multiple, or severe injuries, the history should be questioned.

Another study that focused on determining the risk of death resulting from short falls among young children was conducted by Chadwick (Chadwick, 2008). The purpose of this study was to develop an estimate of the risk of death in children between 0 and 5years-old from falls less than $1.5 \mathrm{~m}$. A review of published materials and public databases on injuries due to child falls was performed. The review included five book chapters, two medical society statements, seven major literature reviews, three public injury databases, and 177 peer-reviewed publish articles. The quantitative estimate was based on the California EPIC database from 1999 to 2003. Specific conditions that cause death in infants and young children in California were prematurity (165/1 million), congenital malformations (316/1 million), neoplasms (33/1 million), respiratory diseases (38/1 million), accidents (121/1 million), short falls (0.48/1 million), and homicide (22/1 million). The study states that it is almost impossible in any case to determine the accuracy of the history given. The study concludes that the current evidence indicates that the risk of death from short-distance falls in infants or young children per year is 0.48 per 1 million. The study provides an estimated risk of short falls that result in death and 
shows that the likelihood of fatalities from short-distance falls in children is extremely rare.

Thompson conducted a study to determine the severity of injuries that result from accidental short-distance household falls in children between the ages of 0 and 4 -yearsold (Thompson, 2011). Detailed case-based biomechanical assessments of short-distance household falls for children presenting to the ED were used to determine the types and severity of injuries and to investigate the influence of fall environment and biomechanical measures on injury outcomes. Caregivers were interviewed to obtain information regarding fall histories and fall dynamics. The study included household falls from beds, sofas, or similar height furniture. Any children that were suspected of being abused were excluded from the study. Information obtained from household falls included subject age, weight, demographics, height, and anthropomorphic measures, along with furniture height, fall description, and impact surface. The coefficient of restitution (COR) was determined using a resiliency tester. Injury assessment was determined using the Abbreviated Injury Scale (AIS). AIS is a 6-point scale used to define injury severity ( $1=$ minor, $2=$ moderate, $3=$ serious, $4=$ severe, $5=$ critical, $6=$ fatal) based on body region, type, and severity. The biomechanical measures determined included impact velocity, potential energy, and change in momentum during impact. Statistical analysis was used to determine whether biomechanical outcomes were related to injury severity with the independent variables being impact velocity, energy, change in momentum, fall height, and COR, and child factors including mass, age, and body mass index (BMI). From the 79 subjects, 15 had no injuries, 45 had AIS 1 injuries, 17 had AIS 2 injuries, 2 had AIS 3 injuries, and no subjects had AIS 4 or higher injuries. Children with AIS 2 or 3 injuries 
tended to have fallen from greater heights with greater impact velocities while also having a lower BMI. The authors of this study found that no children had moderate or serious injuries to multiple body regions and that children involved in short-distance household falls did not sustain severe or life-threatening injuries. This study provides evidence that children between the ages of 0 and 4-years-old who experience shortdistance household falls should not sustain severe or life-threatening injuries. Limitations of this study include the possibility of overestimating injury severity by only including ED visits, small sample size, estimates of fall heights based on caregiver information, and the potential of miss identified abuse cases contaminating the results. In addition, the study includes un-witnessed falls and questionable fall histories. Our study will provide video surveillance of falls in order to provide evidence for fall histories.

Plunkett wanted to determine if accidental short-distance falls could be fatal in order to determine potential lethality of a short-distance fall (Plunkett, 2001).The study reviewed the United States Consumer Product Safety Commission database for head injury associated with use of playground equipment from 1988 through 1999. Primary source data was obtained for all fatalities involving a fall. From the search, the author found 18 deaths due to head injury from falls. The falls that resulted in fatalities included falls from ladders, swings, stationary platforms, a see-saw, a slide, and a retaining wall. From the total 18 falls, five occurred at the child's home while the remaining falls occurred at a school or public playground. The mean age was 5.2 years with the oldest being 13-years-old and the youngest being 12-months-old. The distance of the fall could be determined in 10 cases; the fall height ranged from 0.6 to $3.0 \mathrm{~m}$ (measured from feet to ground). Of the 18 falls, 12 were witnessed by a non-caregiver or were videotaped. 
The author reported that 12 falls resulted in a lucid interval between 5 minutes and 48 hours and when funduscopic examination was performed, four of the six children had bilateral RHs. The study discussed the injury results associated with linear and rotational acceleration and how there is controversy for fall heights that can lead to fatalities. The author states that SDH, lucid intervals, bilateral RHs can occur in falls. Limitations of this study include that not all of the falls were witnessed, exact height of falls could not be determined in seven cases, and a minimum impact velocity sufficient to cause fatal brain injury could not be determined. There are also limitations when using national databases, which have the possibility of inaccurate recalls of details, insufficient number of cases, and variability from different sources. The author concluded that every fall is a complex event where biomechanical analysis is essential, RHs cannot be used to determine the ultimate injury mechanism, axonal damage is unlikely the cause for lethal injuries in falls, and a fall less than $3 \mathrm{~m}$ in an infant or child may cause fatal head injuries. The study has controversial findings compared to the previous studies due to the conclusion that short-distance falls can be fatal to infants and children. However, over the dates and number of cases included in this study, the likelihood of short-distance falls in children that result in fatalities is still rare.

\section{Pediatric Head Injury Thresholds}

\section{Thresholds Based on Linear Acceleration}

Linear acceleration has been used as a measurement and predictive tool in estimating injury severities in child head injuries. It has been associated with focal type injuries and is examined in numerous studies. A method used to assess the head injury tolerance limits for children is to examine the peak resultant linear head acceleration 
experienced during an impact. Sturtz utilized scaling of adult head injury thresholds for pedestrian accidents (Stürtz, 1980). For 3 ms impact durations, Sturtz found injury threshold values of $86.1 \mathrm{~g}$ for 3-year-olds and $82.1 \mathrm{~g}$ for 6-year-olds. Mohan conducted a study that focused on head-first falls in children between the ages of 1-10-years-old (Mohan, 1979). The study included case-based data, experiments with an ATD, and computer simulations to examine biomechanical measures. From the study, the results showed that the threshold for skull fracture for head-first falls in children 18 months and younger occurred between $1.22-3.05 \mathrm{~m}$. The study also concluded that the head injury tolerance limit for children between the ages of 1-10-years-old for peak resultant linear acceleration was between 200 and $250 \mathrm{~g}$. Cory provided an overview of head injury models (HIMs) and how they are used to determine forces involved in child head injuries from impacts (Cory, 2001). Cory proposed head injury tolerance limits for children between 50-200 g, where values over $200 \mathrm{~g}$ are considered to result in a fatal injury.

Head Injury Criteria (HIC) is a measure of injury potential that accounts for linear acceleration and impact duration. The National Highway Traffic Safety Administration (NHTSA) developed improved injury criteria for the assessment of advanced automotive restraint systems (Eppinger, 1999). Cory defined HIC as the current "state of the art" HIM and should be utilized for assessing head impact injury in child abuse cases. HIC can be defined as

$$
H I C=\left(t_{2}-t_{1}\right)\left[\frac{1}{\left(t_{2}-t_{1}\right)} \int_{t_{1}}^{t_{2}} a(t) d t\right]^{2.5}
$$


where $\left(t_{2}-t_{1}\right)$ is the sliding window in $s$ and $a(t)$ is the resultant head acceleration in $g$. The maximum critical time intervals used in the calculation of HIC can be 36 or 15 msec. Injury thresholds for different sized children are provided for a 6-year-old, 3-year-old, and 1-year-old child. The $\mathrm{HIC}_{15}$ limits established for the 6, 3, and 1-year-old are 700, 570, and 390 respectively. These thresholds are frequently used by researchers in order to assess the head injury probability in children based on linear acceleration values. When the child's calculated HIC value is under the HIC threshold established, it can be considered as low probability of severe childhood focal head injury (Thompson, 2009).

\section{Thresholds Based on Rotational Acceleration}

Rotational head acceleration has been associated with diffuse head injuries such as concussion and diffuse axonal injury. Ommaya focused on understanding biomechanics in age-related traumatic brain injury (Ommaya, 2002). This study referred back to a previous study, where three sub-human primate species were subjected to experimental head impact and whiplash injuries to obtain tolerance thresholds for onset of cerebral concussion (Ommaya, 1971). The results from the primate experiments were scaled to estimate injury thresholds in humans. Ommaya proposed injury tolerance thresholds for concussion and severe DAI for adults and children (FIGURE 1). Estimated values for concussion were $4,500 \mathrm{rad} / \mathrm{s}^{2}$ for adults and $10,000 \mathrm{rad} / \mathrm{s}^{2}$ for infants. Estimated values for severe DAI were $18,000 \mathrm{rad} / \mathrm{s}^{2}$ and $40,000 \mathrm{rad} / \mathrm{s}^{2}$ for infants. 


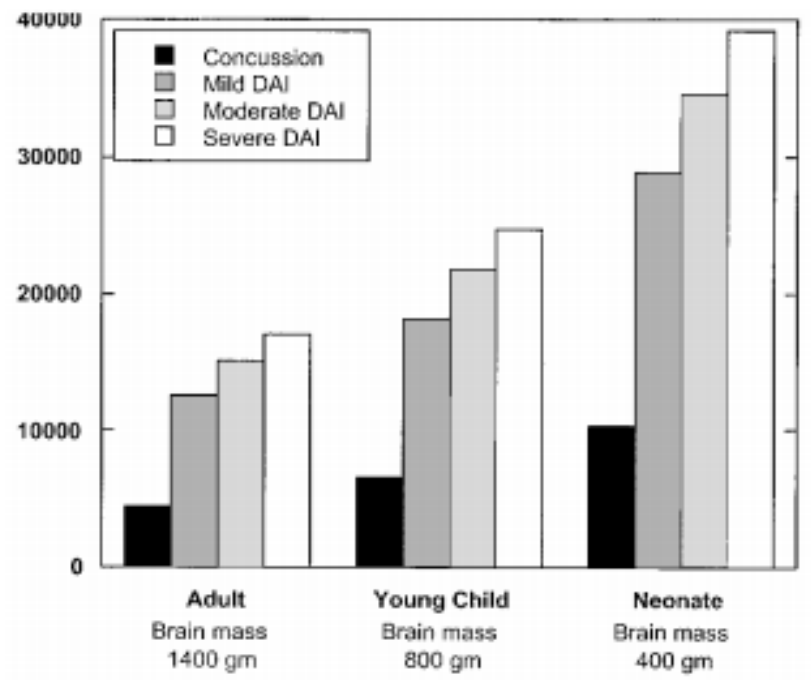

FIGURE 1 - Concussion and DAI Injury Tolerance Scaling in Adult, Child, and Neonate (Ommaya, 2002)

Ommaya's 2002 study was original in establishing injury thresholds for children subjected to rotational acceleration. However, the accuracy of scaling animal models to human infants is questionable due to differences in brain and skull geometry, brain composition, and biomechanical characteristics. In addition to proposing peak resultant linear acceleration injury thresholds, Sturtz proposed peak rotational acceleration thresholds in children that would result in $50 \%$ probability of serious brain injury. For a direct impact with impact durations of $3 \mathrm{~ms}$, the proposed threshold established was 9100 $\mathrm{rad} / \mathrm{s}^{2}$ and for $10 \mathrm{~ms}$ impact durations, the proposed threshold established was 2,008 $\mathrm{rad} / \mathrm{s}^{2}$. Margulies and Thibault focused on injury thresholds for DAI instead of HIC due to HIC not being injury specific, not relating to injury severity, and not accounting for varying brain masses (Margulies, 1992). Through the use of animal experiments, physical model experiments, and computer modeling simulations to determine kinematics of DAI in subhuman primates and scaling results to obtain human values, the study estimated 
tolerance curves for DAI with different brain masses based on peak rotational acceleration and peak rotational velocity (FIGURE 2).

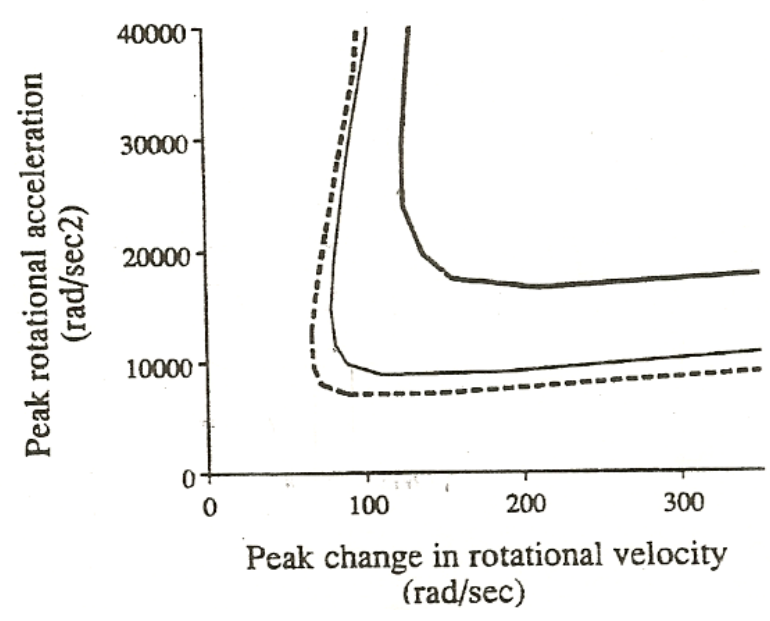

FIGURE 2 - DAI Threshold for a Range of Brain Masses (500g Infant Heavy Solid Line, 1067 Adult Solid Line, 1400g Dashed Line) (Margulies, 1992)

\section{E. Biomechanical Assessment of Pediatric Injury and Injury Severity}

\section{Anthropomorphic Testing Devices in Simulated Falls}

There have been a significant amount of studies that used an ATD equipped with instrumentation to study pediatric head injuries. Bertocci used an ATD to conduct experiments related to pediatric injury risk related to short-distance falls (Bertocci, 2003). The purpose of this study was to assess biomechanics associated with simulated shortdistance falls in children and to investigate the effect of impact surface type on injury risk. The ATD used for the experiments was an instrumented Hybrid II 3-year-old test dummy and repeated simulated fall experiments were conducted from a bed height of $0.68 \mathrm{~m}$. The authors focused on several biomechanical measures including head acceleration and HIC. Data was collected using three uniaxial accelerometers located in the ATD's head. A LabVIEW program was developed for data acquisition with a 
sampling rate of $1,000 \mathrm{~Hz}$ and filtered using a $1.6 \mathrm{kHz}$ Butterworth filter. Head acceleration data was used to calculate $\mathrm{HIC}_{15}$ and $\mathrm{HIC}_{36}$ for each fall scenario. The ATD fell three times on each surface (wood, padded carpet, linoleum, and playground foam). Relating to head biomechanics, the authors found that there were significant differences for $\mathrm{HIC}_{15}$ in comparison of carpet with linoleum, carpet with wood, and playground foam with wood. $\mathrm{HIC}_{36}$ was found to be significantly different in comparison of linoleum and playground foam and wood and playground foam. Playground foam resulted in the lowest $\mathrm{HIC}_{15}$ (mean, 53), $\mathrm{HIC}_{36}$ (mean, 55), and peak resultant linear head acceleration (114 g). Wood impact surface resulted in the highest $\mathrm{HIC}_{15}$ (mean, 313), $\mathrm{HIC}_{36}$ (mean, 418), and peak resultant linear head acceleration (245 g). Linoleum had the second greatest head biomechanical measures. The study concludes that impact surface can significantly affect head injury risk and that there is a need for detailed clinical histories when attempting to differentiate between abusive and accidental injuries. The authors also conclude that the simulated falls with the ATD presented a low risk of head injury. Examining the different biomechanical values obtained from different impact surfaces is important in determining associated biomechanical measures for a provided history. When investigating a fall event, head acceleration values can be assumed to be greater for falls onto wood surfaces than carpet. The authors determined that despite the different surface impacts, that there is still a low probability of injury to a 3-year-old child from a fall height of $0.68 \mathrm{~m}$ or less.

Another study that used an ATD that represented a different age group came from Thompson (Thompson, 2009). The purpose of the study was to determine the risk of head injury for a 12-month-old child in feet-first short-distance falls. The ATD used for the 
experiments was a 50th percentile 12-month-old Child Restraint Air Bag Interaction (CRABI) instrumented with four accelerometers within the head. Three of the accelerometers were placed tri-axially at the ATD head's center of mass and the fourth was located posterior to center of mass for rotational head acceleration calculations. The ATD was suspended from a rope wrapped around the inferior portion of the head from three different drop heights $(0.46,0.69$, and $1.19 \mathrm{~m})$ and dropped onto five different impact surfaces (linoleum over wood, linoleum over concrete, playground foam, padded carpet, and wood). Different drop heights corresponded to different fall scenarios, the $0.46 \mathrm{~m}$ drop height was considered to be ground based and the other heights were considered to be falls from a chair or stool. Data was collected via a LabVIEW program that had a sampling rate of $10,000 \mathrm{~Hz}$ and was filtered at $1,000 \mathrm{~Hz}$ with a Butterworth filter. Linear head acceleration was used to calculate $\mathrm{HIC}_{15}$ values. The study showed that there were different fall dynamics occurring from different drop heights. Average peak resultant linear head acceleration across all trials was $52.2 \mathrm{~g}$ with a max of $130.6 \mathrm{~g}$ occurring at a $0.46 \mathrm{~m}$ drop onto linoleum over concrete. $\mathrm{HIC}_{15}$ mean across all trials was 67 with a max of 173 occurring at a $0.46 \mathrm{~m}$ drop onto linoleum over concrete. The max $\mathrm{HIC}_{15}$ value was below the injury assessment reference value of 390 for a 12-month-old ATD. Mean peak anterior-posterior (AP) rotational acceleration across all trials was $4,246 \mathrm{rad} / \mathrm{s}^{2}$ with a max of $11,804 \mathrm{rad} / \mathrm{s}^{2}$ occurring at a $0.46 \mathrm{~m}$ drop onto linoleum over concrete. Mean impact duration was $19.9 \mathrm{~ms}$. Lower fall heights showed greater linear and AP rotational head acceleration and shorter head impact durations than the two greater fall heights which is counterintuitive to similar studies that report an increase in head injury risk with increasing fall height (Prange, 2003). Thompson contributed the 
difference in findings to different fall dynamics and initial position of the ATD. The initial position in Thompson's study focused on feet-first falls, while Prange et al. investigated falls from a supine position. The authors discuss previous established injury thresholds for linear head acceleration, HIC, and rotational head acceleration. In the conclusion, the authors determine that the risk is low for severe head injury in feet-first falls. Findings from this study are important because it associates head injury risk values to short-distance falls from different heights and onto different surfaces. The results could be useful when investigating biomechanical measures from a proclaimed fall scenario from a caregiver.

Another study focused on short-distance falls in children came from Ibrahim, who conducted experiments with a custom developed 18-month-old toddler surrogate to determine biomechanics of the toddler head during low-height falls (Ibrahim, 2010). This study focused on identifying potential age-dependent mechanical load factors between toddlers and infants. This study provides useful biomechanical head information between children of different ages and falls from different heights. The authors state that they developed a novel biofidelic surrogate based on published anthropometry to compare results with a 6-week-old surrogate. A 9-accelerometer array was placed in the surrogate's head center of mass to measure rotational accelerations. Rotational velocity was measured with an angular velocity transducer in the same location. Data was filtered with a Butterworth filer at $1,650 \mathrm{~Hz}$. The largest peak rotational head acceleration over all three directions and the mid-location of the cervical spine as the center of rotation was used to calculate the impact force. Fifty-three drops were conducted from three heights $(0.30,0.61$, and $0.91 \mathrm{~m})$ onto two surfaces (carpet and concrete). Peak rotational head 
acceleration values were different based on fall orientation and were found to be greatest in the sagittal and horizontal directions. Increased fall heights corresponded to a significant increase in peak rotational head acceleration. Impact surfaces had a difference in rotational head acceleration and duration of impacts, where the concrete surface produced larger peak rotational head accelerations and shorter impact durations. Toddler head accelerations and impact forces were greater than infant head accelerations and impact forces from the same height and surface. In the discussion, the authors focus on previously established thresholds and related studies. They also discuss the importance of focusing on rotational acceleration instead of HIC which is related to linear acceleration. However, they do mention that the study produced $\mathrm{HIC}_{36}$ values ranging from 4.7 to 42.4 . Based on the results, the authors conclude that there is a less likely chance of skull fracture in toddlers due to having a thicker skull than infants, but toddlers are more vulnerable to neurological impairment based on higher peak rotational head accelerations. This study is useful in comparing different injury biomechanics between different child age groups and how the effect of a developing human skull can alter injury biomechanics.

Coats \& Margulies studied accelerations at low fall heights using an anthropomorphic infant surrogate (Coats, 2008).The low height falls were between 0.3 and $0.9 \mathrm{~m}$ and the ATD was dropped onto three different surfaces which included a mattress, carpet pad, and concrete. The researchers developed a 1.5-month-old ATD and claimed it consisted of a realistic skull case, neck, and had appropriate weight distributions. The head and skull for the ATD consisted of five copolymer polypropylene plates attached together with silicone rubber and the authors claim that the stiffness is 
similar to that of a human infant. The skull case was attached to a "You \& Me" doll via brass screws and an accelerometer mount composed of nine linear accelerometers was placed in the center of the head. The neck of the surrogate was designed to be flexible in three directions with no fixed center of rotation. Flexion and extension properties for the developed neck were compared with unpublished human infant data. Extremities consisted of hollow metal rods with lead balls and were covered with cotton cloth. All extremity joints had ball-and-socket joints for attachment to the wood torso frame. The surrogate was dropped from an initial supine position a total of 90 times and the maximum peak rotational head acceleration, maximum peak-to-peak change in rotational head velocity, and maximum time interval for peak-to-peak rotational head velocity was determined. The results showed that an increase in height resulted in an increased peak rotational head acceleration, change in peak rotational head velocity, time duration, and peak impact force for drops onto concrete and carpet. However, the results showed that increasing height from 0.6 to $0.9 \mathrm{~m}$ didn't result in any significant changes to outcome measurements. The authors conclude that linear fractures may occur in an infant from head-first fall from $0.9 \mathrm{~m}$ onto carpet or onto concrete from $0.6-0.9 \mathrm{~m}$. This is another study that examined injury potential for short-distance falls in children where the initial drop position was from a supine position.

\section{Anthropomorphic Testing Device in Simulated Shaking}

In addition to using ATDs for simulated falls, ATDs have been used to determine biomechanical measures for simulated shaking. Duhaime conducted a study to examine SBS and attempted to determine the injury mechanisms behind it (Duhaime, 1987). The study included forty-eight cases of infants and young children diagnosed with shaken 
baby syndrome. It also included a biomechanical component using a custom-developed ATD to evaluate shaking and impacts. Biofidelity and validation of this surrogate were not demonstrated in the study. The ATD was developed from an unreferenced "Just Born Doll" and the brain was composed of cotton and water. Three different neck models were used in the study. One neck model was a hinge model with zero resistance, while the other two were rubber neck models with little or moderate neck resistance. Shaking episodes and impacts were conducted on the different ATD models by male and female experimenters. However, the force and duration of the shaking wasn't specified. Accelerations found from the shaking and impacts using the ATDs were compared to rotational head acceleration thresholds of $35,000 \mathrm{rad} / \mathrm{s}^{2}$ for SDH and $40,000 \mathrm{rad} / \mathrm{s}^{2}$ for DAI. The authors concluded that shaking alone cannot cause a fatal head injury, but shaking with an impact can result in fatal injuries. The authors also state that shaking may play a role in SBS, but blunt impact is likely the major cause. There are serious questions related to the validation of the ATDs and other literature typically has conflicts with this study.

Cory's "Can shaking alone cause fatal injuries" (Cory, 2003) attempted to replicate Duhaime's findings. Their study used a surrogate representing a 1-month-old to compare the findings by Duhaime to assess if shaking alone can cause fatal head injuries. The authors believe that the Duhaime surrogate contained variations in certain design parameters that could affect rotational head acceleration values. Cory's ATD parameters varied from Duhaime's by neck joint design, torso design, and mass distribution of the surrogate. From the change in parameters, the results showed that greater peak rotational head accelerations occurred during shaking alone compared to Duhaime's results. The 
head accelerations found by Cory also exceeded concussion thresholds and were closer to SDH tolerance limits. Maximum values obtained for rotational head acceleration, angular velocity, and peak linear head acceleration were $10,216 \mathrm{rad} / \mathrm{s}^{2}, 61 \mathrm{rad} / \mathrm{s}$, and $177 \mathrm{~g}$ respectively. HIC values for 7 out of 10 impact tests showed values exceeding the tolerance limits suggested for children. The authors concluded that further studies are needed in order to assess the veracity of Duhaime's findings. This study is able to show the variability in biomechanical findings based on differences in certain ATD parameters and biofidelity. Our study will avoid controversy on ATD biofidelity, due to the use of human subjects.

In addition to Duhaime and Corey, Prange also performed experiments with an ATD for simulated falls, shakes, and inflicted impacts (Prange, 2003). The objective of the study was to compare rotational deceleration values sustained by the head among free falls with those sustained during shaking and inflicted impacts. A 1.5-month-old anthropomorphic surrogate was constructed and used to simulate falls from $0.30,0.91$, and $1.52 \mathrm{~m}$, as well as shaking and inflicted head impacts. Rotational head velocity, maximum change in rotational head velocity, and the peak rotational head acceleration values were recorded. The surrogate's neck design consisted of a hinged design which allowed for movement for only extension and flexion. The hinge was a heavy duty stainless strap hinge and was connected to the skull material of the surrogate's head and torso. The authors make an important note that there is an absence of infant neck kinematics and that they assume that there is no resistance. Drop tests were conducted via a custom-designed apparatus for consistent drops from varying heights. The drops were conducted with the surrogate in the horizontal position so the impact would occur at the 
head first. In order to recreate shaking and inflicted impact events, volunteers were instructed to shake the surrogate with maximum effort. Volunteers firmly gripped the torso and held it at chest level. All shaking episodes included at least five shakes, with the final shake concluding with an inflicted impact of the surrogate's head to different materials. Falls onto harder surfaces and from greater heights resulted in significant increases in the change in rotational head velocity and peak rotational head acceleration. Change in rotational head velocity and rotational head acceleration during inflicted impacts were greater than those measured during shaking events and had shorter average impact durations than shaking events. Inflicted impacts resulted in 39 times greater peak rotational head acceleration, three times greater change in rotational head velocity, and 53 times shorter impact duration than shaking. Shaking was similar to $0.3 \mathrm{~m}$ falls with change in rotational head velocity and had significantly longer impact duration than any of the fall events. The authors suggest that inflicted impacts against hard surfaces may be more frequently associated with clinically significant inertial brain injuries than shaking or falls less than $1.5 \mathrm{~m}$. The study also concludes that there was no data that showed change in rotational head velocity and peak rotational head acceleration during shaking and inflicted impacts against unencased foam could cause SDHs or primary traumatic axonal injuries (TAI) in infants. This study is unique due to its biomechanical comparison between falls, shakes, and inflicted impacts. However, the ATD was a simplified representation of a real infant head and neck which could diminish accuracy. No ATD is completely biofidelic, especially regarding infants who lack kinematical data. As mentioned previously, our study will collect biomechanical data on real children where the issue of biofidelity can be disregarded. 


\section{Animal Models Representing Infants}

Animal models have also been used in biomechanical studies involving infants and children. Previously discussed was Ommaya \& Hirsch, who used three subhuman primate species in impact and whiplash experiments. An additional animal study came from Raghupathi, which focused on determining traumatic axonal injury after closed head injury in a 3-5-day-old piglet which represented an infant less than 3 months of age (Raghupathi, 2002). The purpose of this study was to better understand the mechanical environment in pediatric closed head injuries. The piglets were subjected to vigorous non-impact rotations in the axial plane with the center of rotation located at the cervical spine. A pneumatic actuator that generates rotational motion and a snout clamp was used to achieve rotational motion without impacts. The rotational velocity was scaled from previous adult pigs and the target rotational velocity was $272 \mathrm{rad} / \mathrm{s}$. In $10-12 \mathrm{~ms}$ the full desired rotational excursion was achieved. A coma scale developed by Smith et al. (Smith, 2000) was used to evaluate injury after each rotational event. Scores between 0 and 1 represented severe coma, 2 and 3 moderate coma, 4 and 5 mild coma, and 6 and 8 represented emergence from coma. An average peak rotational velocity of $250 \pm 9 \mathrm{rad} / \mathrm{s}$ and a load duration of $11.4 \pm 0.8$ sec caused 5 out of 7 piglets to become apneic with an absence of pupillary, corneal, and pain reflexes. All 7 piglets had a 0 - 1 severe coma immediately post injury but recovered to a score of 8 six h post injury. Blood was present on the frontal lobes, cerebellum, and brainstem, and subarachnoid hemorrhage was evident in the frontal cortex. This study demonstrates that rapid rotation alone without head impact can produce subarachnoid hemorrhage (SAH) and traumatic axonal injury 
(TAI). This study was able to demonstrate that shaking alone can produce severe injuries in neonatal pigs that represent children less than 3 months of age.

\section{Computer Modeling}

A different method used to investigate biomechanics of pediatric head injury is the use of computer modeling. Thompson (Thompson, 2014) conducted a study to investigate fall environment and child surrogate parameters on fall dynamics and outcomes related to injury potential with a validated bed fall computer simulation model of an 12-month-old child ATD (Thompson, 2013). The model displays the ATD in an initial lying position on the edge of a $0.61 \mathrm{~m}$ horizontal surface above the ground. Validation of the model included visual comparison of fall dynamics and quantitative comparison of outcome measures with the predictive capability of the model assessed by changing impact surfaces. The fall parameters included fall height, impact surface stiffness, and initial force used to initiate the fall and the child surrogate parameters included overall mass, head stiffness, neck stiffness, and stiffness for other body segments. A parametric sensitivity analysis was conducted to analyze the relationships between model parameters and outcome measures related to injury potential. The study examined horizontal surface height where the baseline surface height was $608 \mathrm{~mm}$, the minimum height was $330 \mathrm{~mm}$, and the maximum was $890 \mathrm{~mm}$. Surface stiffness in the bassline model corresponded with playground foam and was adjusted to match linoleum over a wood subfloor. Baseline velocity was $0.52 \mathrm{~m} / \mathrm{s}$ and baseline force was $140 \mathrm{~N}$. Surrogate mass represented a $50^{\text {th }}$ percentile 12-month-old child, incremental mass changes, $5^{\text {th }}$, and $95^{\text {th }}$ percentile were evaluated. In addition, skull, neck, and body segment stiffness properties were evaluated within the model. Sensitivity analysis was 
used to define the ratio of change in the outcome measure over the change in the input parameter and the mean sensitivity index for each parameter was determined and used for parameter sensitivity comparisons. The study found that changes in fall height, initial velocity and force, and surrogate mass caused changes in fall dynamics and impact orientation. Changes in surrogate mass caused the greatest change in peak linear head acceleration. Injury outcome measures were more sensitive to environmental parameters such as bed height, impact surface stiffness, and initiating force than surrogate parameters. Limitations of this study include using an ATD to represent a child with limited biofidelity and that computer models are a discrete representation of real-world events. Other limitations of the computer model were that there were limited surface representations and changes in surrogate mass did not include changes in anthropometrics. The study concludes that fall dynamics and impact orientation play a key role in head and neck injury potential. This study is particularly useful to compare different fall environmental parameters and child parameters when assessing injury potential related to short-distance falls.

Another study that utilizes computer modeling came from Wolfson, who utilized rigid body modeling (RBM) to investigate the effect of neck stiffness on head motion and head torso impacts as a possible mechanism of injury for a 12-month-old child (Wolfson, 2005). The purpose of this study was to produce a more accurate mechanical representation of the shaken baby syndrome and to determine associated injury levels. Volunteers were recruited to shake a developed ATD and the linear acceleration values obtained were used in the RBM simulations for SBS. The authors examined the effect of neck stiffness on head motion and the effect of head-torso impacts. Peak rotational 
acceleration and peak rotational velocity were determined from each simulation. The study concludes that impact-type characteristics were required for head accelerations to exceed established injury criteria for concussion. Impacts to the torso as a result from shaking were only sufficient to exceed the lower injury criteria for concussion. However, the model used in this study hasn't been validated. This study provides useful information regarding SBS in comparison with previous studies.

\section{$\underline{\text { F. Methods Used to Obtain Biomechanical Measurements for Human Subjects }}$}

\section{Utilization of Biometric Sensors to Obtain Real-Time Measurements}

Biometric sensors have been previously used as a tool to obtain real time measurements of head accelerations and velocities from different impact types. Most studies use biometric sensors such as accelerometer-gyro sensors in order to determine peak linear acceleration, peak rotational acceleration, peak rotational velocity, impact duration, and impact location with regards to head impacts. The accelerometer-gyro sensors have been used in studies to obtain head biomechanical measures experienced during American Football. Kelley conducted a study to evaluate frequency, magnitude, and location of head impacts for a youth football team with wearable sensors (Kelley, 2017). Head impact data was collected with Head Impact Telemetry (HIT) systems to obtain head acceleration measurements. The HIT system was instrumented in the football helmets and video surveillance was conducted to verify head impacts and to assign impacts to each drill. The HIT system consists of six spring-mounted single axis accelerometers. Data is recorded once an impact is over $10 \mathrm{~g}$ and records for a total of 40 ms with $8 \mathrm{~ms}$ of pre-trigger data. The HIT system has a sampling rate of $1,000 \mathrm{~Hz}$ and data is transmitted to a side-line base unit via radio-wave transmission. Data obtained 
from measurements were used to obtain the resultant peak linear head acceleration, resultant peak rotational head accelerations, and impact locations. Nine athletes with a mean age of $11.1 \pm 0.6$ years were included in this study and a total of 2,125 impacts were record over 30 contact practices. This study demonstrates the use and capability of wearable biometric sensors to obtain peak head linear acceleration, peak head rotational acceleration, and impact locations during head impacts.

Another study that used a similar method came from Duma, who conducted a study to measure and analyze head accelerations during American collegiate football practices and games (Duma, 2005). The study used a HIT system designed to fit inside of a player's helmet which consisted of six linear accelerometers, a wireless transceiver, onboard memory, and data acquisition capabilities. Data was collected for $40 \mathrm{~ms}$ when the system detects an acceleration that exceeds a threshold of $10 \mathrm{~g}$. The total $40 \mathrm{~ms}$ of data collection consisted of $12 \mathrm{~ms}$ of stored pre-trigger with $28 \mathrm{~ms}$ post-trigger. Acceleration data is time-stamped and wirelessly transmitted $(903-927 \mathrm{MHz})$ to a sideline controller interfaced to a laptop. An algorithm used the data obtained from the six accelerometers to determine the head acceleration and impact location. Peak linear head center of gravity time history, impact location, Gadd Severity Index (GSI), HIC, and sagittal and later peak rotational accelerations were calculated. The HIT system was validated using a series of impact tests with a helmet equipped Hybrid III dummy instrumented with a 3-2-2-2 head accelerometer array. The correlation was $\mathrm{R}^{2}=0.97$ with $\pm 4 \%$ error for linear and rotational acceleration and HIC. Linear drop tests were also performing using a twin wire drop tower with a National Operating Committee on Standards for Athletic Equipment (NOCSAE) instrumented headform. The average impact location error for both azimuth 
and elevation was $\pm 1.2 \mathrm{~cm}$. The setup for data collection had the sideline receiver placed on the 20-yard line with approximately an 80-yard range. The sideline unit and the interface laptop show the current impact location, impact location history, acceleration verse time graph, acceleration magnitude history. Video footage was also obtained to provide insight into injury mechanisms for different impacts. In the study a total of 3,312 head impacts were recorded for 38 different players. Average peak head acceleration was $32 \mathrm{~g} \pm 25 \mathrm{~g}$, with a range between 1 and $200 \mathrm{~g} .89 \%$ of impacts were below $60 \mathrm{~g}$. Average GSI was $36 \pm 91$ and average HIC was $26 \pm 64$. The average rotational accelerations about the $\mathrm{x}$-axis were $905 \mathrm{rad} / \mathrm{s}^{2} \pm 1,075 \mathrm{rad} / \mathrm{s}^{2}$ and about the $\mathrm{y}$-axis were $2,020 \mathrm{rad} / \mathrm{s}^{2} \pm 2,042$ $\mathrm{rad} / \mathrm{s}^{2}$. Impact durations were associated with varying types of positions. This study demonstrates the capabilities of accelerometer systems to obtain real time biomechanical measure for human subjects.

\section{Video Surveillance for Biomechanical Analysis}

In addition to the use of biometric sensors, video surveillance has been previously used in studies to provide analysis with respect to falls. Kakara used child test subjects equipped with wearable acceleration-gyro sensors and video-surveillance system to develop a fall motion database for children between the ages of 0 and 4 years (Kakara, 2013). The study was completed in an ordinary apartment and data was collected in one of the rooms. There were a total of 12 surveillance cameras used to ensure that multiple angles of the fall incident were recorded. The acceleration-gyro sensor was placed inside a wearable vest and equipped on the children to obtain measurements. The sensor was developed by Wireless Technologies, Inc. and had a sampling rate of $167 \mathrm{~Hz}$ and data was collected to a PC via Bluetooth. Of the 12 cameras, 11 had normal lenses (angle of 
view $43.36 \times 33.24)$ and one was positioned at the center of ceiling and had a fish-eye lens (angel of view $185 \times 185$ ). A frame rate of $30 \mathrm{~Hz}$ was used for all cameras. A total of 19 children were included in this study and a total of 105 fall events were observed. Fall events were never initiated, but occurred while the children were playing. From the data obtained, a fall motion database was developed which included child attributes (age, height, and weight), fall situation (landing body site, action immediately before the fall, and the cause of the fall), and fall dynamics data. Data searches allowed for the users to visualize probabilistic distributions of fall data, fall videos, outputs time-variable motion data, and 3D head motion. From the database, two kinds of fall simulations were used to analyze injury risks. Simulations using the multibody model were used to calculate HIC and simulations from finite element model were used to calculate the von Mises stress to the head. The authors conclude that the database developed will provide more accurate estimates for the range of injury risks associated from common falls in children. The database allows for worst-case analyses and analyses based on probabilistic distributions. Overall it has the potential to facilitate injury risk reduction in household environments. This study is useful because it has shown viability of collecting data from real children with acceleration-gyro sensors and through video surveillance.

Choi conducted a study through kinematic analysis with real-life falls in older adults captured on video (Choi, 2015). The study was conducted at two long-term care facilities. Video was recorded from cameras placed in common areas such as dining rooms, hallways, and lounges. Video was recorded at 30 frames per second and with a resolution of either 640 by 480 pixels, or 720 by 480 pixels. Fall videos were analyzed to determine the cause of fall, activity at time of fall, direction, and landing configuration. 
Fall duration was determined by estimating the exact video frames between the onset of imbalance and initial impact to the body part including descent duration. Impact velocities were estimated by using a Matlab routine that digitized each frame from the fall initiation to after impact. Two-dimensional direct linear transform was used to reconstruct landmark body parts as position coordinates. Finite difference methods were used to obtain time-varying vertical and horizontal velocities. The method for calculating velocities was tested to determine the accuracy with an inverted pendulum and a human participant. Over a six-year period, the study captured 813 falls experienced by 306 individuals. A total of 788 falls were excluded from their study based on their exclusion criteria. For the 25 remaining falls, the most common fall direction were backward falls, cause of imbalance was incorrect weight shifting, and activity was standing. Head impact occurred in $48 \%$ and hand impact occurred in $84 \%$. Average vertical velocity was 0.26 $\mathrm{m} / \mathrm{s}$ for forward falls and $0.06 \mathrm{~m} / \mathrm{s}$ in backward falls. Horizontal velocity was $0.15 \mathrm{~m} / \mathrm{s}$ for forward falls and $0.16 \mathrm{~m} / \mathrm{s}$ in backward falls. Average impact velocity for the pelvis was $2.14 \mathrm{~m} / \mathrm{s}, 2.91 \mathrm{~m} / \mathrm{s}$ for the head, and $2.87 \mathrm{~m} / \mathrm{s}$ for the hand. Total fall duration averaged $1,271 \mathrm{~ms}$ for the pelvis, $1,730 \mathrm{~ms}$ for the head, and 1,188 $\mathrm{ms}$ for the hand. Using regression analysis, the study found that fall height associated with the vertical impact velocity of the head, but not the pelvis. The authors claim that this is the first study to report impact velocities and fall duration from real-life falls in older adults. The results of the study suggest that the faller is able to use mechanisms to absorb energy by stepping for balance or by using hands to brace themselves during descent to reduce impact velocity. Limitations in this study include only analysis of older adults and small sample 
size. This study is unique for determining kinematic profiles such as impact velocities and fall durations in real-life falls from video captured falls.

\section{G. Summary}

It is crucial that injury biomechanics related to abuse and falls involving children becomes better understood. There needs to be better differentiation between an accidental fall and child abuse in order to protect children and to have appropriate legal ramifications for caregivers. Based on current literature, there are conflicting findings on established head injury thresholds in children. Specifically, shaking baby syndrome is a topic that results in conflicting conclusions on whether shaking alone can cause fatal injury as seen in Duhaime and Cory. These articles are often used in child abuse legal cases as supporting arguments, which is an issue based on the accuracy of the findings due to the lack of validation of the studies. With regards with ATDs, applying established injury assessment reference values accurately may be directly limited to the biofidelity of the ATD used for experiments (Pierce, 2006). Specifically, ATDs used to represent children have to address several concerns due to the lack of knowledge of pediatric physical properties such as neck stiffness. Inaccurate representations of children could lead to inaccurate results. Some of the head injury thresholds in children established are conflicting, due to scaled animal models from Ommaya \& Hirsh. There are questions relating to whether a primate is an accurate representation of a human child based on skull geometry, brain material properties, and neck stiffness. From the literature review, there is a current need to advance the understanding of pediatric injury and pediatric injury thresholds in order to have greater accuracy in distinguishing between abuse and accident. There are common limitations that occur while investigating pediatric 
biomechanics such as limitations with ATD biofidelity, computer modeling validation, variability between animal models and human infants, and reliability of unwitnessed case-based falls. Our study was able to avoid these limitations through the use of human subjects and video surveillance, which had no issues with biofidelity and provided video evidence of fall events. 


\section{STUDY DESIGN AND METHODS}

\section{A. Study Design}

The purpose of this prospective study was to investigate biomechanical measures associated with common short-distance falls involving children. The effects of child age and mass, fall type, impact location (head or non-head impact), and surface type on biomechanical measures were examined. To accomplish this, children were equipped with biometric sensors in a video monitored childcare facility and observed for falls. Head biomechanical measures were obtained via the biometric sensors, while video surveillance provided fall dynamics. This study has been approved by the University of Louisville IRB \#16.1030.

\section{$\underline{\text { 1. Inclusion/Exclusion Criteria }}$}

The children included in this study were between the ages of 1-3-years, located in a video monitored room at the childcare center, and enrolled at Bluegrass Academy Childcare Center (BGACC) located in Louisville, Kentucky. Caregiver written informed consent was provided for participation in the study. If a child included in the study exceeded 3-years of age during the study, the subject was "aged out" and was no longer eligible for data collection. The video monitored rooms were Explorers 1, Explorers 2, Twos 1, and Twos 2. Explorer classrooms contained children between the ages of 1 and 2 years and Twos classrooms ("Twos $1 \& 2$ ") contained children between the ages of 2 and 3 years. Any child that had a musculoskeletal disorder or any disease that impeded subject mobility was excluded from this study. 


\section{Fall Monitoring Duration and Sample Size}

A total of 22 subjects met the eligibility criteria and were monitored for falls.

Data was collected at BGACC over a 1.5- $2 \mathrm{~h}$ period, three times per week. Fall events that contained video and biomechanical data were used for analysis. Data was collected for 11 weeks to obtain a minimum of 100 video-recorded falls with biomechanical data.

\section{B. Data Collection}

\section{$\underline{1 . \text { Anthropometrics }}$}

After the subject's caregiver provided consent to participate in the study, anthropometric measurements were recorded for each subject for use in calculations. The child's mass, height, head circumference, shoulder breadth, hip breadth, chin to sole length, hip to sole length, knee to sole length, and chest depth were measured. The subject's weight was obtained by using a Baby and Toddler Scale (Health o meter, McCook, Illinois) and was measured in $\mathrm{kg}$. Subject height, chin to sole length, hip to sole length, and knee to sole length was determined by using a Hopkins Road Rod Portable Stadiometer (Hopkins Medical Products, Caledonia, Michigan). All height and length measurements were measured in $\mathrm{cm}$. Height measurements were rounded to nearest 0.1 $\mathrm{cm}$, while chin to sole, hip to sole, and knee to sole lengths were rounded to the nearest $0.5 \mathrm{~cm}$. Head circumference was measured with a Gulick tape measure (Patterson Companies, Saint Paul, Minnesota). The tape measure was wrapped around the widest circumference of the subject's head, just above the supraorbital ridge and just above the superior aspect of the pinna to the most prominent aspect of the posterior head. Head circumference measurements were rounded to the nearest $0.1 \mathrm{~cm}$. Shoulder breadth, hip 
breadth, and chest depth were measured by breadth calipers (Baseline, White Plains, New York) and were recorded to the nearest $0.1 \mathrm{~cm}$.

\section{Video Monitoring}

Cameras were installed to capture videos of falls from enrolled subjects wearing SIM G biometric devices. There were a total of 16 cameras across 4 rooms and a playground at BGACC (Explorers $1=3$ cameras, Explorers $2=3$ cameras, Twos $1=3$ cameras, Twos $2=4$ cameras, and playground $=3$ cameras). For each room and playground, cameras were placed at multiple locations and varying angles to ensure that the entirety of the room can be visualized and that all falls could be captured. The wallmounted cameras (Lorex Technology, Markham, Canada) recorded at 1080p and 30 frames per second. All 16 camera feeds were transmitted to a network video recording (NVR) system (Lorex Technology, Markham, Canada) located in an isolated room at BGACC.

\section{Impact Surface}

The coefficient of restitution (COR) was determined by using a resiliency tester (IDM instruments, Victoria, Australia) (FIGURE 3). 


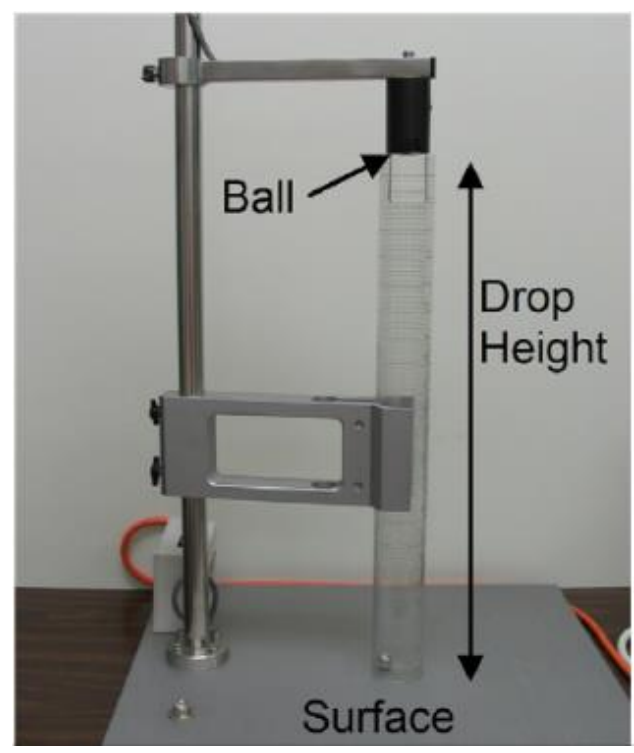

FIGURE 3 - COR Resiliency Tester

The COR value was obtained by dropping a steel ball from a known height onto an impact surface and recording the bounce height. COR was determined for each drop height by using equation 2 .

$$
e=\sqrt{\frac{h_{f}}{h_{i}}}
$$

Where e is COR, $h_{f}$ is the final height, and $h_{i}$ is the initial height. COR values were obtained for every surface type in each data collection room and playground (linoleum, carpet, area rug, and playground synthetic mulch). For each surface in every collection room, COR was determined in at least three separate locations. For each location, there were at least three trials. Additionally, COR measurements for objects that children came into contact with during a subset of falls were obtained. The mean CORs and standard deviation for each surface type were determined for use in calculations. 


\section{SIMG/SKYi System}

For data collection, children were assigned to wear a headband containing a triaxial accelerometer-gyroscope Smart Impact Monitoring (SIM G) device (Triax Technologies, Norwalk, Connecticut). The SIM G is $0.34 \mathrm{oz}$ and 1" x 1.33 " x 0.29 " with 3.3" antenna and was designed to fit tightly inside a headband in a posterior pouch (FIGURE 4).
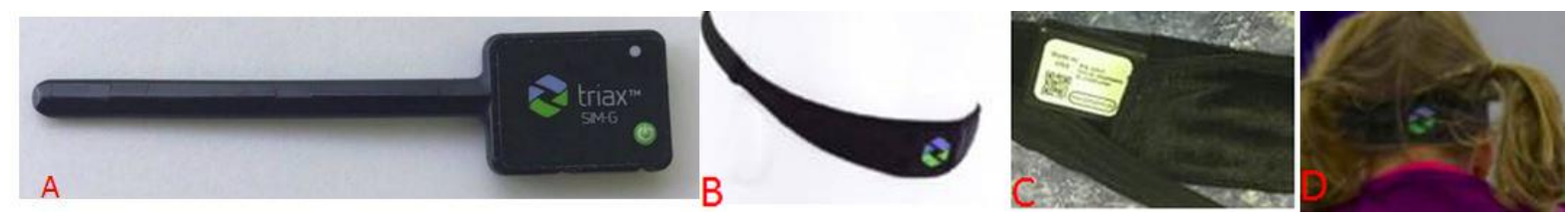

FIGURE 4 - (A) SIM G Sensor, (B) Headband, (C) SIM G Inserted in headband, (D) Child Wearing Headband with SIM G

The lengths of the headbands have been modified to provide a snug fit on children between the ages of $1-3$ years $(43,47$, and $51 \mathrm{~cm})$. The headbands were placed on the children so that the SIM G was positioned at the posterior head and above the base of the skull. The SIM G collected data at $1,000 \mathrm{~Hz}$ when an impact with a resultant linear head acceleration was over a threshold of $12 \mathrm{~g}$. Impacts were recorded for a total of $62 \mathrm{~ms}$ when activated, where $10 \mathrm{~ms}$ consisted of pre-trigger data and $52 \mathrm{~ms}$ was post-trigger data. When an impact was detected, the SIM G recorded $\mathrm{x}, \mathrm{y}, \mathrm{z}$, and resultant measurements for linear head acceleration $(\mathrm{g})$, rotational head acceleration $\left(\mathrm{krad} / \mathrm{s}^{2}\right)$, and rotational head velocity $(\mathrm{rad} / \mathrm{s})$. In addition to recording acceleration and velocity data, the SIM G also displayed head impact locations on a 3D head model. Signals from the SIM G were transmitted via a $900 \mathrm{MHz}$ radio frequency to a SKYi aggregator receiver (FIGURE 5). 


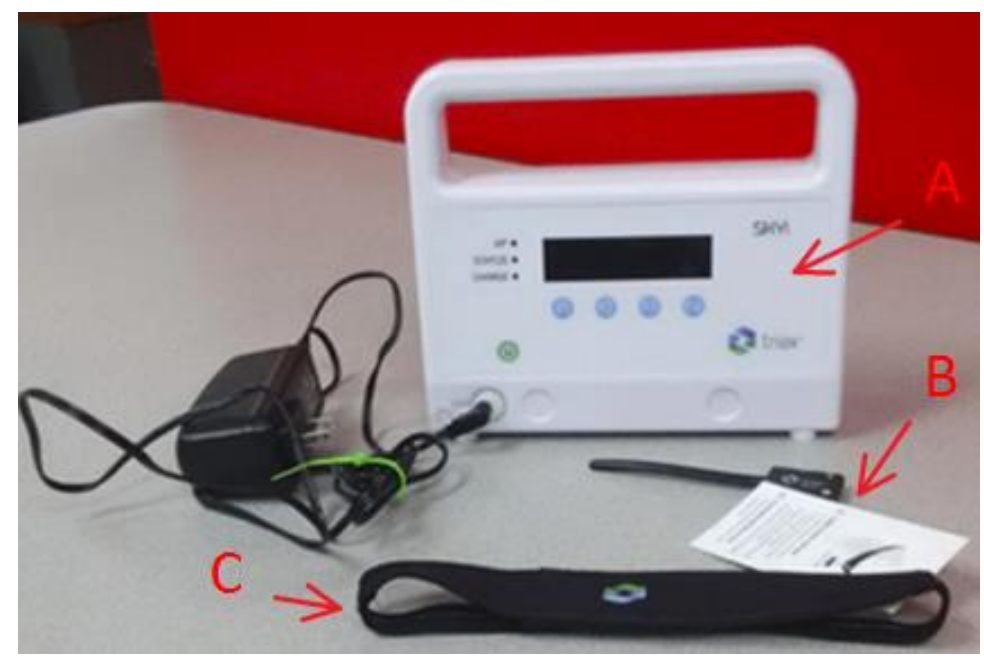

FIGURE 5 - (A) SKYi Receiving Monitor, (B) SIM G, (C) Headband

Signals could be transmitted to the SKYi up to a distance of $137 \mathrm{~m}$. Data was recorded in real time and onboard software recorded and processed registered impacts.

a. Verification of SIM G/SKYi System. The SIM G/SKYi system was tested for accuracy by comparing head acceleration data from a previous ATD study (Thompson, 2018). Thompson's study examined femur loading but also obtained head acceleration data from 12-month-old CRABI ATD (First Technology Safety Systems, Plymouth, Michigan) onboard tri-axial head accelerometers and rotational velocity sensors during feet first falls. Experimental replicate falls with the SIM G were conducted to obtain SIM $\mathrm{G}$ head acceleration data. The purpose of the tests was to determine SIM G accuracy for resultant linear head acceleration, rotational head acceleration, rotational head velocity, and impact duration. In previous and replicated experiments, the ATD was suspended from a rope attached to a release mechanism and dropped onto linoleum and carpet surfaces at heights of $0.69 \mathrm{~m}$ and $1.19 \mathrm{~m}$ (FIGURE 6). The fall height was measured from impact surface to the center of mass of the ATD. 


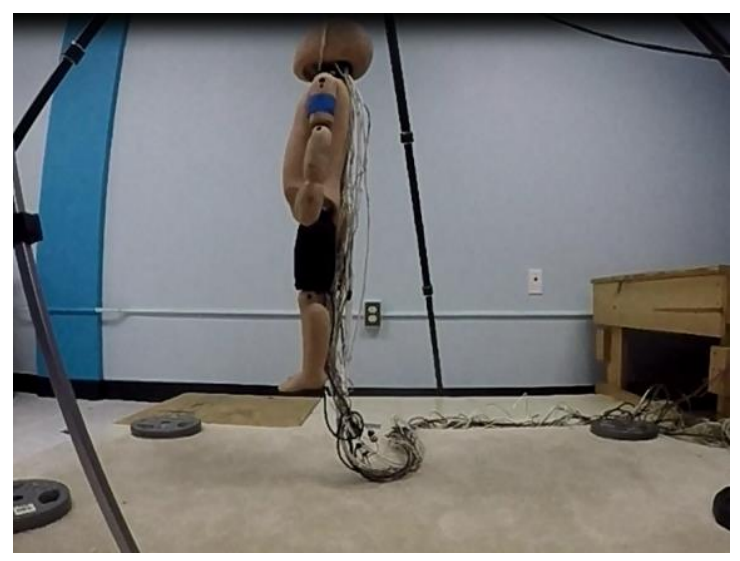

FIGURE 6 - Experimental Set-Up for a 0.69 m Fall

Head acceleration data from the previous falls at $0.69 \mathrm{~m}$ for falls onto carpet $(n=13)$ and onto linoleum $(n=13)$ were obtained. The onboard accelerometers were located at the ATD head center of mass and had a sampling rate of 10,000 Hz. $x, y$, and z linear head acceleration, anterior-posterior (AP) rotational head velocity, and mediallateral (ML) rotational head velocity were measured in the previous fall experiments. Rotational acceleration was determined for both AP and ML rotational head acceleration by using equation 3 .

$$
\alpha=\frac{\omega_{f}-\omega_{i}}{t_{f}-t_{i}}\left(\frac{1}{1000}\right)
$$

Where $\alpha$ is rotational acceleration $\left(\mathrm{krad} / \mathrm{s}^{2}\right), \omega_{\mathrm{f}}$ is the final velocity $(\mathrm{rad} / \mathrm{s}), \omega_{\mathrm{i}}$ is the initial velocity $(\mathrm{rad} / \mathrm{s}), \mathrm{t}_{\mathrm{f}}$ is final time $(\mathrm{s}), \mathrm{t}_{\mathrm{i}}$ is initial time (s), and dividing by 1000 is the conversation to $\mathrm{krad} / \mathrm{s}^{2}$. Head resultant linear head acceleration was determined by using equation 4.

$$
A_{r}=\sqrt{A_{X}^{2}+A_{Y}^{2}+A_{Z}^{2}}
$$


Where $A_{r}$ is resultant linear head acceleration $(g), A_{x}$ is linear head acceleration about the $\mathrm{x}$-axis $(\mathrm{g}), \mathrm{A}_{\mathrm{y}}$ is linear head acceleration about the $\mathrm{y}$-axis $(\mathrm{g})$, and $\mathrm{A}_{\mathrm{z}}$ is linear acceleration about the z-axis (g). Resultant rotational head velocity was determined by using equation 5.

$$
\omega_{r}=\sqrt{\omega_{A P}^{2}+\omega_{M L}^{2}}
$$

Where $\omega_{\mathrm{r}}$ is resultant rotational head velocity $(\mathrm{rad} / \mathrm{s}), \omega_{\mathrm{AP}}$ is anterior-posterior rotational head velocity $(\mathrm{rad} / \mathrm{s})$, and $\omega_{\mathrm{ML}}$ is medial-lateral rotational head velocity ( $\left.\mathrm{rad} / \mathrm{s}\right)$. Resultant rotational head acceleration was determined by using equation 6 .

$$
\alpha_{r}=\sqrt{\alpha_{A P}^{2}+\alpha_{M L}^{2}}
$$

Where $\alpha_{\mathrm{r}}$ is resultant rotational head acceleration $\left(\mathrm{krad} / \mathrm{s}^{2}\right), \alpha_{\mathrm{AP}}$ is anterior-posterior rotational head acceleration $\left(\mathrm{krad} / \mathrm{s}^{2}\right)$, and $\alpha_{\mathrm{ML}}$ is medial-lateral rotational head acceleration $\left(\mathrm{krad} / \mathrm{s}^{2}\right)$.

For replicated falls, the SIM G was positioned on the same 12-month-old CRABI ATD head within a headband. The SIM G was at the anterior aspect of the head to protect the sensor from direct impacts with the surface (FIGURE 7). 


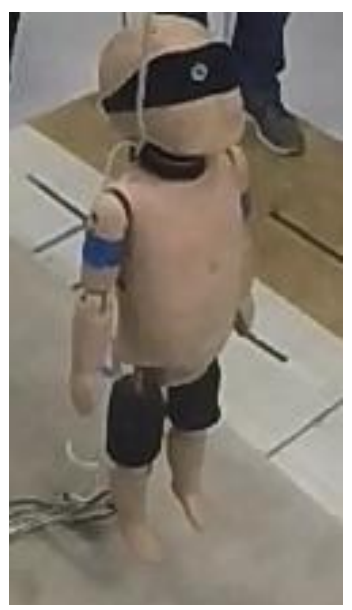

FIGURE 7 - SIM G Placement on 12-Month-Old CRABI ATD

Replicate falls with the SIM G were conducted onto linoleum $(n=7)$ and carpet surfaces $(\mathrm{n}=7)$ from $0.69 \mathrm{~m}$ with the same support mechanism (rope) position and releasing mechanism. Replicated falls were video-recorded with 2 HERO4 Silver cameras (GoPro, San Mateo, California) at 240 frames per second to visualize the ATD fall dynamics and to compare to previous fall experiments. SIM G and onboard accelerometers data having the same fall dynamics were compared.

Peak resultant linear head acceleration, rotational head acceleration, and rotational head velocity values were compared between the onboard accelerometer and the SIM G. In addition to comparing acceleration and velocity measurements, impact duration between the SIM G and onboard accelerometer was compared. Means and standard deviations for each measurement were generated to visualize similarities and differences between the SIM G and onboard accelerometer. Statistical analysis was conducted to determine if acceleration, velocity, and impact duration values were significantly different between the ATD onboard accelerometers and the SIM G. Each set of data was checked for normal distribution, if the data was normally distributed a two sample t-test 
was conducted with a $95 \%$ confidence interval for each of the variables. Before running the two-sample t-tests, the variance between the two samples was checked to determine if the variances could have been assumed to be equal. If the data was not normally distributed, a Mann-Whitney U-Test (non-parametric equivalent) was used.

\section{Manual Biomechanical Calculations of Daycare Center Falls}

For each fall event that had SIM G data, manual calculations were conducted to obtain head and whole-body biomechanical measures. Head impact biomechanics were obtained or calculated from SIM G data. The SIM G recorded resultant linear head acceleration, rotational head acceleration, and rotational head velocity data for fall events when the linear acceleration threshold of $12 \mathrm{~g}$ was exceeded. Linear head velocity was calculated by applying the trapezoidal rule to peak linear head acceleration data (equation 7).

$$
\int_{t 1}^{t 2} a(t) d t
$$

Where $\mathrm{a}(\mathrm{t})$ is linear head acceleration in $\mathrm{m} / \mathrm{s}^{2}$. Linear head velocity was calculated in the $\mathrm{x}, \mathrm{y}, \mathrm{z}$-directions and the resultant linear head velocity was determined $(\mathrm{m} / \mathrm{s})$. $\mathrm{HIC}_{15}$ was calculated based on the resultant linear acceleration and impact duration data obtained from the SIM G/SKYi system. HIC $_{15}$ was calculated using equation 8

$$
H I C=\left(t_{2}-t_{1}\right)\left[\frac{1}{\left(t_{2}-t_{1}\right)} \int_{t_{1}}^{t_{2}} a(t) d t\right]^{2.5}
$$


where $\left(\mathrm{t}_{2}-\mathrm{t}_{1}\right)$ is the sliding window $(0.015 \mathrm{~s})$ and $\mathrm{a}(\mathrm{t})$ is the resultant linear head acceleration in $\mathrm{g}$. The impact duration was determined by plotting time vs. resultant linear head acceleration. From the plot, the impact start time was determined by locating the time point were the acceleration begins towards the peak and the impact end time was determined by locating the time point were the linear acceleration returns to the initial value (FIGURE 8 and FIGURE 9).

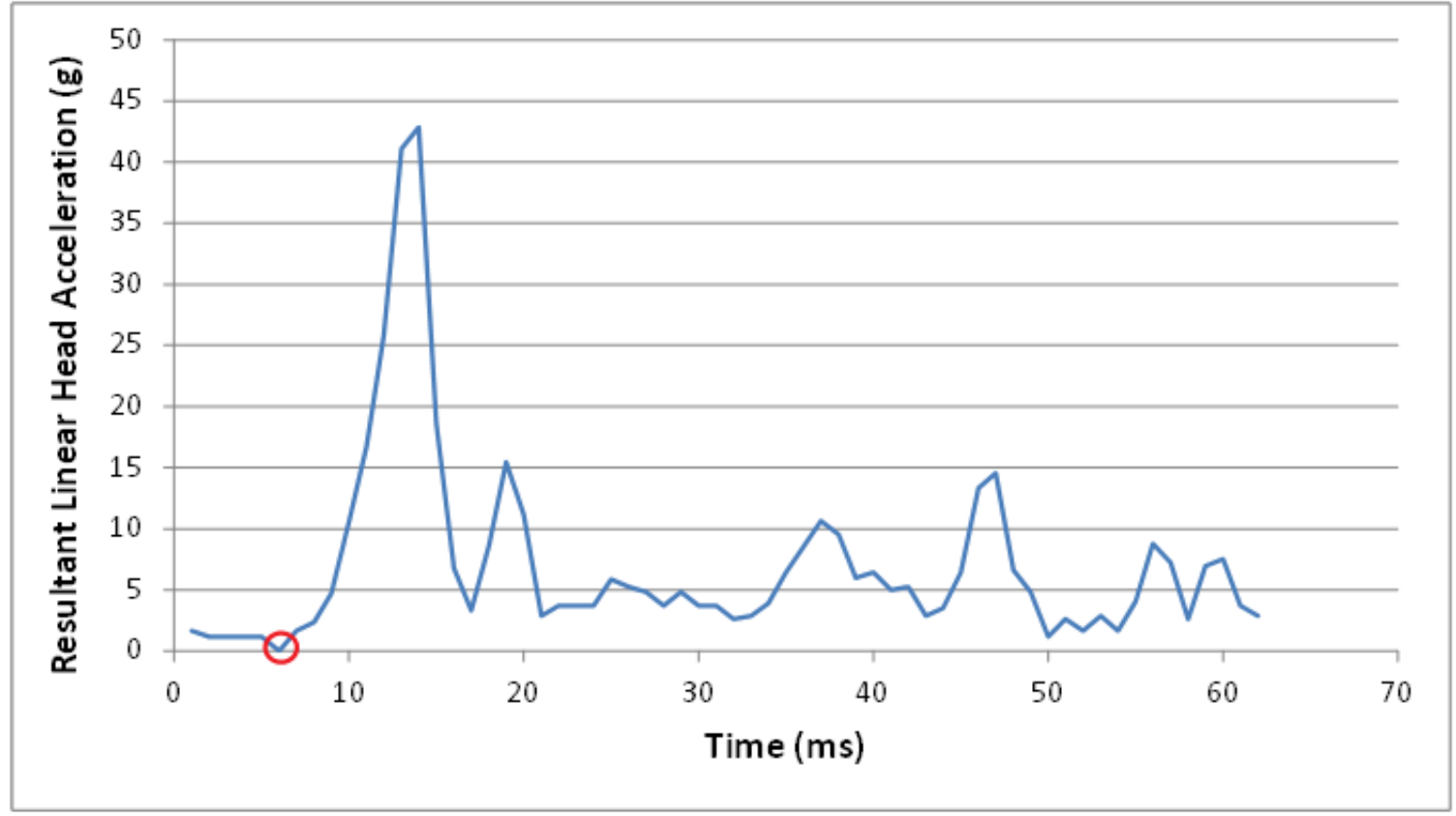

FIGURE 8 - Example Acceleration Trace Indicating Impact Start Time 


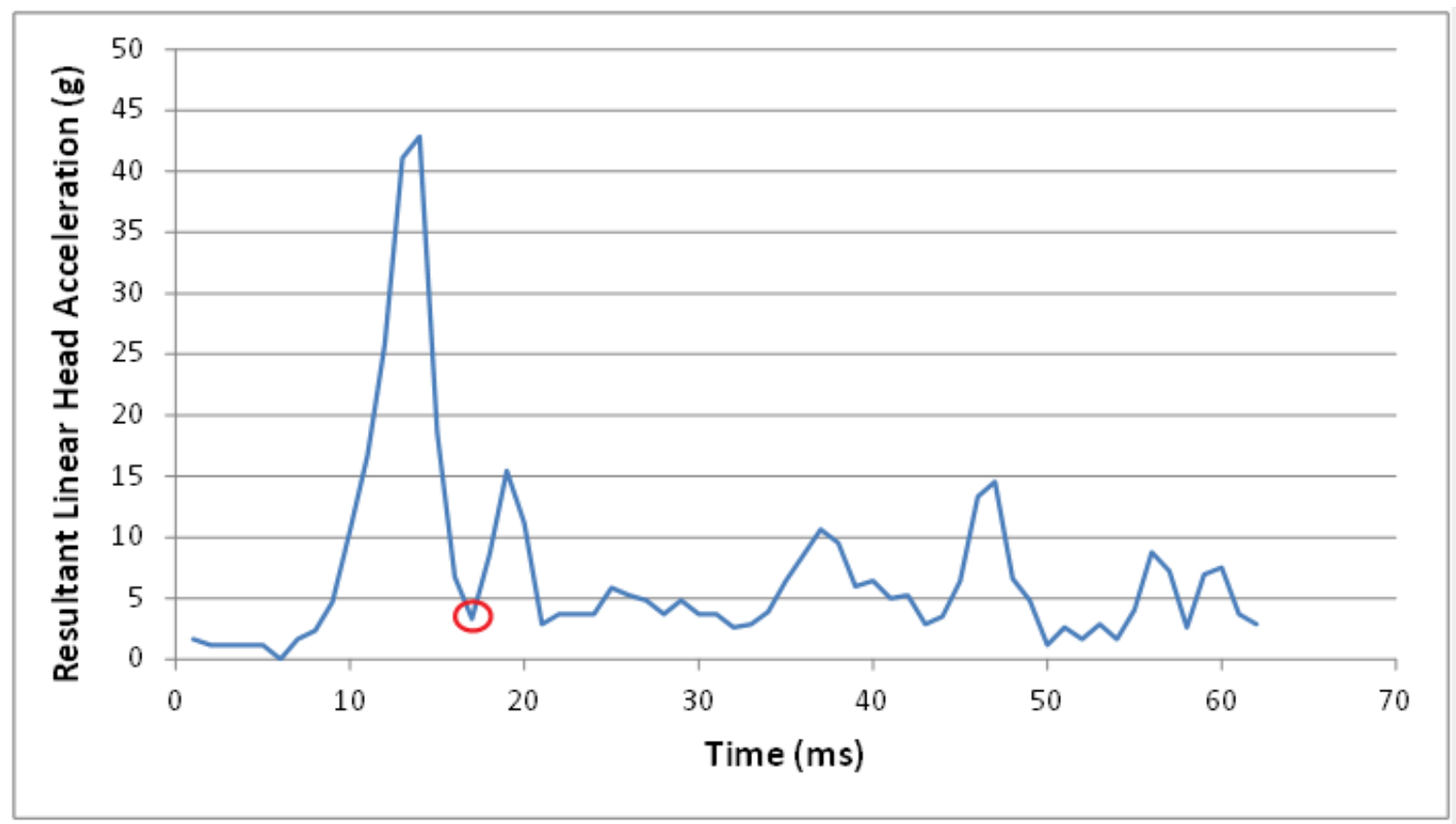

FIGURE 9 - Example Acceleration Trace Indicating Impact End Time

Whole-body impact biomechanics were calculated by using fall characteristics, COR measurements, and child anthropometric measurements. For whole-body calculations, the child was modeled as a lumped mass. Biomechanical measures that were calculated and examined included whole-body impact velocity, change in impact momentum, and potential energy. Whole-body impact velocity was determined by using equation 9 .

$$
V=\sqrt{2 g h}
$$

where $\mathrm{V}$ is whole-body impact velocity $(\mathrm{m} / \mathrm{s}), \mathrm{g}$ is the force of gravity $\left(9.81 \mathrm{~m} / \mathrm{s}^{2}\right)$, and $\mathrm{h}$ is the fall height (m). Fall height was defined as the distance from the child's center of mass at the start of the fall to the child's center of mass at the end of the fall. Height was estimated based on the height of the furniture surface that the child fell from, the position 
of the child just prior to the fall, and anthropometric measures of the child. Potential energy for each fall event was determined by using equation 10 .

$$
E=m g h
$$

where $\mathrm{E}$ is potential energy $(\mathrm{Nm}), \mathrm{m}$ is the child's mass $(\mathrm{kg}), \mathrm{g}$ is the force of gravity $\left(9.81 \mathrm{~m} / \mathrm{s}^{2}\right)$, and $\mathrm{h}$ is the fall height. Change in impact momentum for each fall event was determined by using equation 11 .

$$
M=m V(C O R+1)
$$

where $\mathrm{M}$ is the change in impact momentum $(\mathrm{kgm} / \mathrm{s}), \mathrm{m}$ is the child's mass $(\mathrm{kg}), \mathrm{V}$ is whole-body impact velocity $(\mathrm{m} / \mathrm{s})$, and COR is the resiliency of the impact surface. Video capture of falls provided information regarding fall characteristics and dynamics. For calculations, child measurements including mass and height were obtained and for falls from heights, the furniture heights were measured and child anthropometrics were used to determine fall heights.

\section{Daycare Center Procedures}

Data collection sessions were scheduled to monitor children while they were in their corresponding rooms and during a 30 min playground session. For data collection sessions, either explorer's or Two's rooms were observed. Based on the room's subjects SIM G's ( $\mathrm{n}=17)$ were assigned to specific subjects. SIM G's were turned on and placed inside of an appropriate sized headband for the subject based on head circumference 
measurements. Once the SIM G's were in the headband, the SIM G's were activated through the SKYi aggregator. Research team members worked with the BGACC staff to position the headbands containing the SIM G's on children. Before data collection began, a mirror drive was connected to the NVR system to backup video recordings of the data collection session. Three research team members were present for each data collection session. A researcher was present in each room where a headband was equipped and one researcher monitored the NVR and SIM G/SKYi system. Research team members monitored the children to ensure that the headbands were not tampered with and recorded fall characteristics and dynamics onto a data collection sheet. The data collection sheet contained sections that indicate time of impact, subject ID, fall type (ground based or from height), pre-fall condition (running, standing, walking, pushed, or other), and a notes section for documenting specific details for fall events. For each fall event, the research team member filled out the collection sheet to aid in locating the fall video and describing fall dynamics and characteristics. After data collection sessions were completed, the SIM G's were deactivated and the headbands were removed from the children. The mirror drive was disconnected and transported to the Injury Risk Assessment and Prevention (iRAP) Laboratory where an additional NVR System was located. The mirror drive was connected to the iRAP's NVR system where video recordings were reviewed. All falls that occurred during the data collection were located, captured, and stored. Biomechanical data was linked to the associated video-recorded falls by using location identifiers, time, and filled data collection sheets. For each fall event, a total of 10 seconds ( 5 seconds pre-fall and 5 seconds post fall) was clipped by the NVR system. After the 10 seconds of video containing the fall was clipped, the video was 
exported to a USB drive and was saved on an iRAP data storing computer. Fall videos were archived to provide fall characteristics and dynamics.

\section{E. Data Analysis}

Specific Aim 1: To characterize head impact biomechanics including linear and rotational head acceleration, linear and rotational head velocity, impact duration, and $\mathrm{HIC}_{15}$ associated with short-distance falls involving children between the ages of 1-3 years.

Head biomechanical data was obtained by providing children with SIM G wearable accelerometer-gyroscope devices. SIM G recorded peak resultant linear head acceleration, peak resultant rotational head acceleration, and peak resultant rotational head velocity. Impact duration, peak resultant linear head velocity, and $\mathrm{HIC}_{15}$ were calculated from SIM G Data. To characterize head impact biomechanical measures, the mean, max, min, and standard deviations for peak resultant linear and rotational head acceleration, peak resultant linear and rotational head velocity, $\mathrm{HIC}_{15}$, and impact duration were reported.

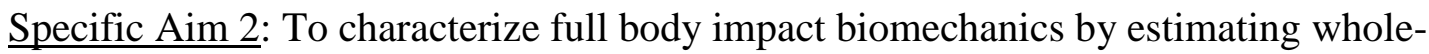
body impact velocity, change in impact momentum, and potential energy associated with short-distance falls involving children between the ages of 1-3 years.

Whole-body biomechanical data was obtained by examining video recordings. For each fall event, whole-body impact biomechanics were calculated. Whole-body impact velocity, change in impact momentum, and potential energy were calculated by using fall characteristics, COR measurements, and child anthropometric measurements. To characterize whole-body impact biomechanical measures, the mean, max, min, and 
standard deviations for whole-body impact velocity, change in impact momentum, and potential energy were reported.

$\underline{\text { Specific Aim 3: }}$ To determine differences for biomechanical measures based on child age and mass, fall type, head or non-head impact, and impact surface COR.

1. Differences in Biomechanical Measures Based on Child Characteristics

Subject age was recorded at the time of enrollment and age in months of the subject was known when a fall event had occurred. Child age was categorized into $<24$ months and $\geq 24$ months based on the median age value for eligible subjects. Subject mass was measured and recorded during anthropometric measurements. Child mass was categorized into $\geq 12.36 \mathrm{~kg}$ or $<12.36 \mathrm{~kg} .12 .36 \mathrm{~kg}$ is the average of $50^{\text {th }}$ percentile measurements for 2-year-old males and females (Center for Disease Control and Prevention). Multiple 2-factorial analysis of variance (ANOVA) tests were conducted to compare the main effects of child age and child mass and the interaction effect between child age and child mass on peak resultant linear and peak resultant rotational head acceleration, peak resultant linear and peak resultant rotational head velocity, $\mathrm{HIC}_{15}$, impact duration, whole-body impact velocity, change in impact momentum, and potential energy. Each outcome measure was analyzed independently. Child age had two levels (< 24 months, $\geq 24$ months $)$ and child mass had two levels $(<12.36 \mathrm{~kg}, \geq 12.36 \mathrm{~kg})$. All data was tested for normal distribution and homogeneity of variance. For non-normal data, Box-Cox transformations were performed to meet ANOVA assumptions. However, there were a few measures that could not be transformed to meet ANOVA assumptions of normal distribution and homogeneity of variance. For measures that didn't meet ANOVA 
assumptions, the ANOVA was still conducted and was considered a limitation of this study. Statistical Significance was set at $\mathrm{p}<0.05$.

\section{Differences in Biomechanical Measures Based on Fall Characteristics}

Fall type was categorized into ground based or from height. Fall type was determined by examining video recordings of fall events to determine if the fall was ground based or from height. From the video, if the fall was from height the fall height was determined. Video recordings and data collection log sheets were used to determine head or non-head impact and impact surface for each fall event. COR measurements were used to categorize each surface type into greater than or less than $0.43(0.43$ is the median COR across all BGACC surfaces). Multiple factorial ANOVA tests were conducted to compare the main effects of fall type, head or non-head impact, and impact surface COR and the interaction effect between fall type and head or non-head head impact, fall type and impact surface COR, head or non-head impact and impact surface COR, and fall type, head or non-head impact, and impact surface COR on each of the biomechanical measures. Fall type had two levels (ground based, from height), head or non-head impact had two levels (non-head impact, head impact), and impact surface COR had two levels $(\mathrm{COR}<0.43, \mathrm{COR} \geq 0.43)$. All data was tested for normal distribution and homogeneity of variance. For non-normal data, Box-Cox transformations were performed to meet ANOVA assumptions. However, there were a few measures that could not be transformed to meet ANOVA assumptions of normal distribution and homogeneity of variance. For measures that didn't meet ANOVA assumptions, the ANOVA was still conducted and was considered a limitation of this study. Post hoc tests were not conducted for fall characteristic interactions due to low sample sizes for certain factor 
combinations. Statistical significance was defined as $p<0.05$. Statistical analysis was performed using Minitab 18.1.0.0.

a. H01: There will be an increase in linear and rotational head acceleration and velocity, $H_{15}$, whole-body impact velocity, change in impact momentum, and potential energy for falls from height compared to ground based falls. Falls were categorized into either ground based, or from height through video recordings and filled log sheets. Differences in biomechanical measures based on fall type were determined by conducting multiple factorial ANOVA tests. The results of the tests determined which outcome measure(s) was significantly greater for falls from height compared to ground based falls. b. H02: There will be a decrease in impact duration and an increase in the remaining head biomechanical measures for falls onto surfaces with lower COR. Falls were categorized into either onto surfaces with low COR $(<0.43)$, or onto surfaces with high COR $(\geq 0.43)$ by examining video recordings and filled log sheets. Differences in biomechanical measures based on impact surface COR were determined by conducting multiple factorial ANOVA tests. The results of the tests determined which outcome measure(s) was significantly greater for falls onto surfaces with low COR compared to falls onto surface with high COR.

c. H03: There will be an increase in linear and rotational head acceleration, linear and rotational head velocity, and $\mathrm{HIC}_{15}$ for head impacts compared to non-head impacts.

Falls were categorized into either falls with head impacts, or falls without head impacts by examining video recordings and filled log sheets. Differences in biomechanical measures based on head or non-head impacts were determined by conducting multiple factorial ANOVA tests. The results of the tests determined which outcome measure(s) 
was significantly greater for falls with head impacts compared to falls without head impacts. 


\section{RESULTS}

\section{A. SIM G/SKYi Verification}

Replicate fall experiments of Thompson's ATD feet first falls study (Thompson, 2018) have been conducted to assess SIM G accuracy. SIM G values were found to be consistent with the values obtained from ATD onboard instrumentation. There were no significant differences in peak linear head acceleration $(\mathrm{p}=0.571)$, peak rotational head acceleration $(\mathrm{p}=0.270)$, peak rotational head velocity $(\mathrm{p}=0.574)$, or impact duration $(\mathrm{p}$ $=0.734)$. The results from testing confirmed SIM G accuracy and the SIM G was determined to be acceptable for use as a biometric sensor to obtain head acceleration measurements for falls involving children. Details and results of the SIM G accuracy testing can be seen in APPENDIX I.

\section{B. Impact Surface/Object COR}

Coefficient of restitution (COR) values were obtained to characterize potential impact surfaces in each data interior room (e.g. linoleum, carpet, area rugs over linoleum or carpet) and playground synthetic mulch. Additionally, COR measurements for objects that children contacted during a subset of fall events were obtained. Mean CORs and standard deviation (SD) for each surface/object type were determined (TABLE I). 
TABLE I

COEFFICIENT OF RESTITUTION MEASUREMENTS FOR IMPACT

SURFACES/OBJECTS

\begin{tabular}{|l|c|c|c|}
\hline \multicolumn{1}{|c|}{ Impact Surface } & N & $\begin{array}{c}\text { Coefficient of Restitution } \\
\text { Mean } \pm \text { SD }\end{array}$ & COR Classification \\
\hline Linoleum & 7 & $0.45 \pm 0.01$ & High \\
\hline Carpet & 32 & $0.41 \pm 0.02$ & Low \\
\hline $\begin{array}{l}\text { Area rug over } \\
\text { linoleum }\end{array}$ & 1 & $0.45 \pm 0.01$ & High \\
\hline $\begin{array}{l}\text { Area rug over } \\
\text { carpet }\end{array}$ & 11 & $0.55 \pm 0.02$ & High \\
\hline $\begin{array}{l}\text { Playground } \\
\text { synthetic mulch }\end{array}$ & 42 & $0.57 \pm 0.03$ & Low \\
\hline Drywall & 1 & $0.26 \pm 0.01$ & Low \\
\hline Wood Furniture & 2 & $0.40 \pm 0.01$ & Low \\
\hline Playground Slide & 4 & $0.23 \pm 0.01$ & High \\
\hline $\begin{array}{l}\text { Playground } \\
\text { "Mushrooms" } \\
\text { (FIGURE 29) }\end{array}$ & 1 & $0.54 \pm 0.01$ & Low \\
\hline $\begin{array}{l}\text { Slide Structural } \\
\text { Support Pole }\end{array}$ & 1 & $0.24 \pm 0.04$ & \\
\hline
\end{tabular}

The median surface COR (0.43) was used to delineate between surfaces/objects with "high" versus "low" COR. Surfaces associated with "high" COR were playground synthetic mulch, area rug over linoleum, area rug over carpet, linoleum, and the playground "mushrooms." Carpet, drywall, wood furniture, playground slide, and the slide structural support pole were associated with "low" COR.

\section{Video-Recorded Falls with Biomechanical Data}

A total of 102 video-recorded falls with SIM G head biomechanical data were obtained. There were a total of 1,176 video-recorded falls and the SIM G equipped 
headband was worn by children for 558 falls. However, the SIM G system was activated for 102 falls; data from these falls were used for analysis (FIGURE 10).

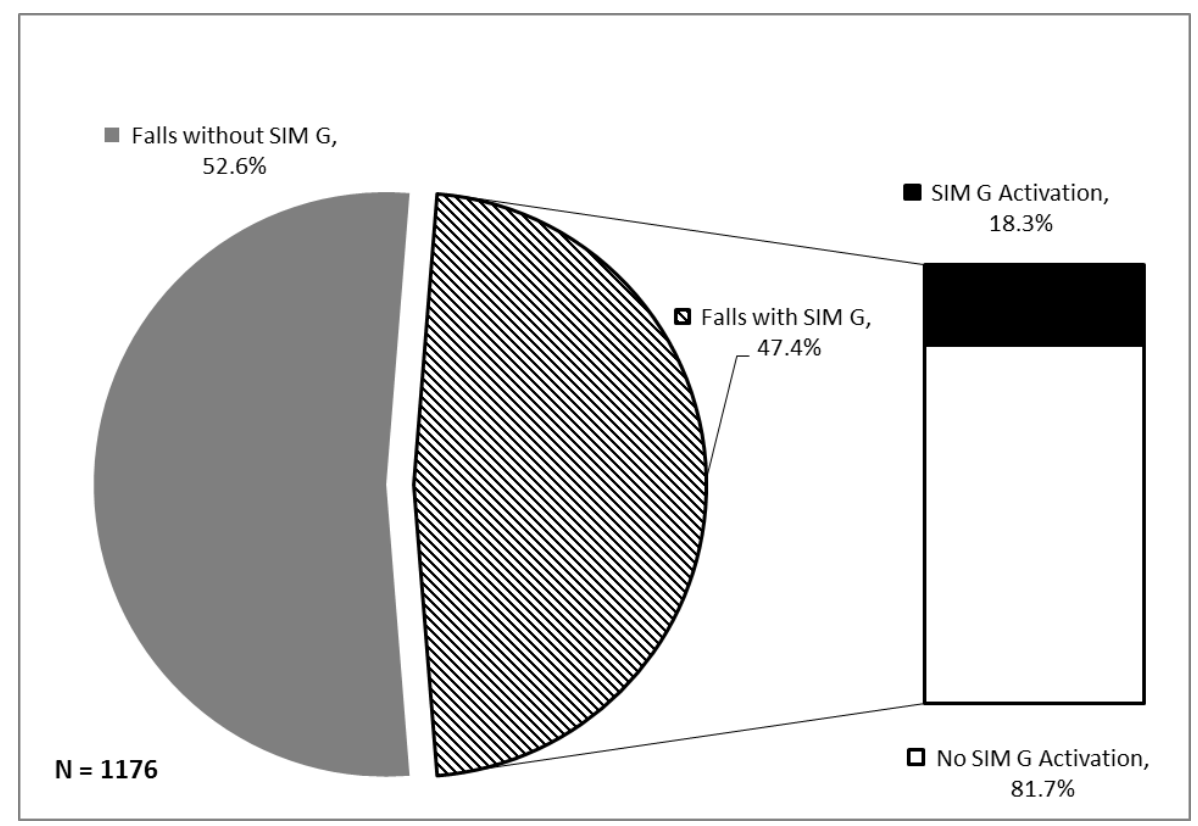

FIGURE 10 - Percentage of Video-Recorded Falls with SIM G Activation. Only Falls with SIM G Activation Record Head Biomechanical Data were Included in Study.

Data was collected at the daycare center for $1.5-2$ hours/day for a total of 32 days over 11 weeks. Data was collected in the Explorers rooms for 23 days and in the Twos rooms for 9 days. A total of 19 subjects had falls with recorded biomechanical data. Of the 19 subjects, 9 subjects were male and 10 subjects were female. The mean age of the subjects was 20.42 months $( \pm$ SD) ( \pm 5.91 months). The mean child mass was 12.49 $\mathrm{kg}( \pm 1.71 \mathrm{~kg})$. Of the 102 falls, $43(42.2 \%)$ were located in the Explorers 1 room, 10 (9.8\%) were located in Explorers 2 room, no falls occurred in the Twos 1 room, $1(1.0 \%)$ occurred in the Twos 2 room, and 48 (47.1\%) were located on the playground (includes both Explorers and Twos subjects). There were 87 ground based falls (85.3\%) and 15 falls from height (14.7\%). Head impact occurred in 26 fall events $(25.5 \%)$. There were 41 
falls onto surfaces associated with having a low COR (40.2\%) and 61 falls onto surfaces associated with having a high COR $(59.8 \%)$.

\section{$\underline{\text { D. Head Biomechanical Measures }}$}

Means, SD, and ranges for head biomechanical measures across all falls can be seen in TABLE II.

TABLE II

MEAN HEAD BIOMECHANICAL MEASURES ACROSS ALL FALLS

\begin{tabular}{|c|c|c|}
\hline $\begin{array}{c}\text { Head Biomechanical } \\
\text { Measures }\end{array}$ & Mean \pm SD & Range \\
\hline $\begin{array}{c}\text { Peak Linear Head } \\
\text { Acceleration (g) }\end{array}$ & $16.77 \pm 5.51$ & $12.00-50.20$ \\
\hline $\begin{array}{c}\text { Peak Rotational Head } \\
\left.\text { Acceleration (rad/s }{ }^{2}\right)\end{array}$ & $1819.61 \pm 1018.93$ & $500.00-6800.00$ \\
\hline $\begin{array}{c}\text { Peak Linear Head Velocity } \\
(\mathrm{m} / \mathrm{s})\end{array}$ & $1.95 \pm 0.72$ & $0.50-3.80$ \\
\hline $\begin{array}{c}\text { Peak Rotational Head } \\
\text { Velocity (rad/s) }\end{array}$ & $9.78 \pm 4.50$ & $2.60-23.50$ \\
\hline HIC15 & $8.30 \pm 5.13$ & $1.30-34.90$ \\
\hline Impact Duration (ms) & $21.03 \pm 6.29$ & $6.00-33.00$ \\
\hline
\end{tabular}

E. Whole-Body Biomechanical Measures

Means, SD, and ranges for whole-body biomechanical measures across all falls can be seen in TABLE III. 
TABLE III

MEAN WHOLE-BODY BIOMECHANICAL MEASURES ACROSS ALL FALLS

\begin{tabular}{|c|c|c|}
\hline $\begin{array}{c}\text { Whole-Body } \\
\text { Biomechanical Measure }\end{array}$ & Mean \pm SD & Range \\
\hline $\begin{array}{c}\text { Whole-Body Impact } \\
\text { Velocity (m/s) }\end{array}$ & $2.40 \pm 0.51$ & $1.27-4.04$ \\
\hline $\begin{array}{c}\text { Whole-Body Change in } \\
\text { Impact Momentum } \\
\text { (kgm/s) }\end{array}$ & $43.06 \pm 10.83$ & $24.31-72.30$ \\
\hline $\begin{array}{c}\text { Whole-Body Potential } \\
\text { Energy (Nm) }\end{array}$ & $36.09 \pm 16.15$ & $9.85-93.02$ \\
\hline
\end{tabular}

$\underline{\text { F. Biomechanical Measures Based on Child Characteristics }}$

The number of falls for child characteristic factors and interactions can be seen in TABLE IV.

\section{TABLE IV}

NUMBER OF FALLS FOR CHILD CHARACTERISTICS

\begin{tabular}{|c|c|c|}
\hline Child Characteristics & Group & $\mathrm{N}$ \\
\hline \multirow{3}{*}{ Child Age } & $<24$ months & 89 \\
\cline { 2 - 3 } & $\geq 24$ months & 13 \\
\hline \multirow{3}{*}{ Child Mass } & $<12.36 \mathrm{~kg}$ & 86 \\
\cline { 2 - 3 } & $\geq 12.36 \mathrm{~kg}$ & 16 \\
\hline \multirow{4}{*}{ Child Age and Child Mass } & 80 \\
\cline { 2 - 3 } & $<24$ months, $<12.36 \mathrm{~kg}$ & 9 \\
\cline { 2 - 3 } & $<24$ months, $\geq 12.36 \mathrm{~kg}$ & 6 \\
\cline { 2 - 3 } & $\geq 24$ months, $<12.36 \mathrm{~kg}$ & 7 \\
\cline { 2 - 3 } & $\geq 24$ months, $\geq 12.36 \mathrm{~kg}$ & \\
\hline
\end{tabular}

\section{Linear Head Acceleration}

Mean peak resultant linear head acceleration based on child age and mass can be seen in FIGURE 11. Child age did not have an effect on peak resultant linear acceleration 
$\mathrm{F}(1,98)=1.08, \mathrm{p}=0.302$ indicating that there was no significant difference between children younger than 24-months (Mean=16.93 g \pm 5.78$)$ and children 24-months and older (Mean=15.70 g \pm 3.14 ). Child mass did not have an effect on peak linear head acceleration $\mathrm{F}(1,98)=0.379, \mathrm{p}=0.379$. Mean peak linear head acceleration for children less than $12.36 \mathrm{~kg}$ was $16.65 \mathrm{~g}( \pm 5.24 \mathrm{~g})$ and mean peak linear head acceleration for children greater than or equal to $12.36 \mathrm{~kg}$ was $17.44 \mathrm{~g}( \pm 6.97 \mathrm{~g})$. When considered together, child characteristics did not have an effect on peak resultant linear head acceleration $\mathrm{F}(1,98)=0.01(\mathrm{p}=0.927)$.

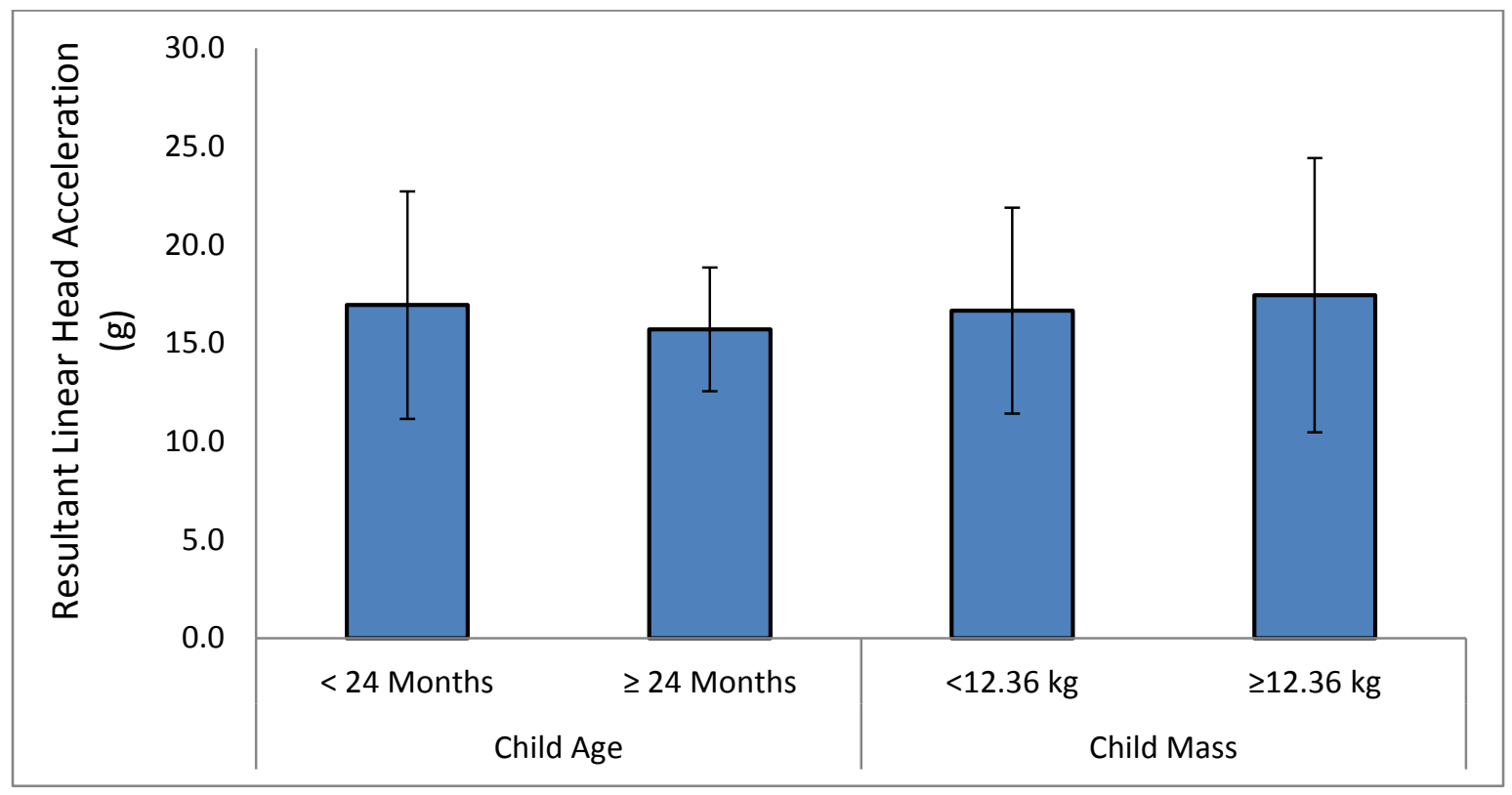

FIGURE 11 - Mean Peak Resultant Linear Head Acceleration Based on Child Characteristics. Error Bars Represent \pm SD

\section{Rotational Head Acceleration}

Mean peak resultant rotational head acceleration based on child age and mass can be seen in FIGURE 12. Child age did not have an effect on peak resultant rotational head acceleration $\mathrm{F}(1,98)=0.03, \mathrm{p}=0.871$ indicating that there was no significant difference 
between children younger than 24-months (Mean $\left.=1,813 \mathrm{rad} / \mathrm{s}^{2} \pm 1,016\right)$ and children 24 months and older (Mean $\left.=1,831 \mathrm{rad} / \mathrm{s}^{2} \pm 1,001\right)$. Child mass did not have an effect on peak rotational head acceleration $\mathrm{F}(1,98)=0.43, \mathrm{p}=0.512$. Mean peak rotational head acceleration for children less than $12.36 \mathrm{~kg}$ was $1,811 \mathrm{rad} / \mathrm{s}^{2}\left( \pm 920 \mathrm{rad} / \mathrm{s}^{2}\right)$ and mean peak rotational head acceleration for children greater than or equal to $12.36 \mathrm{~kg}$ was 1,844 $\mathrm{rad} / \mathrm{s}^{2}\left( \pm 1436 \mathrm{rad} / \mathrm{s}^{2}\right)$. When considered together, child characteristics did not have an effect on peak resultant rotational head acceleration $\mathrm{F}(1,98)=1.12, \mathrm{p}=0.292$.

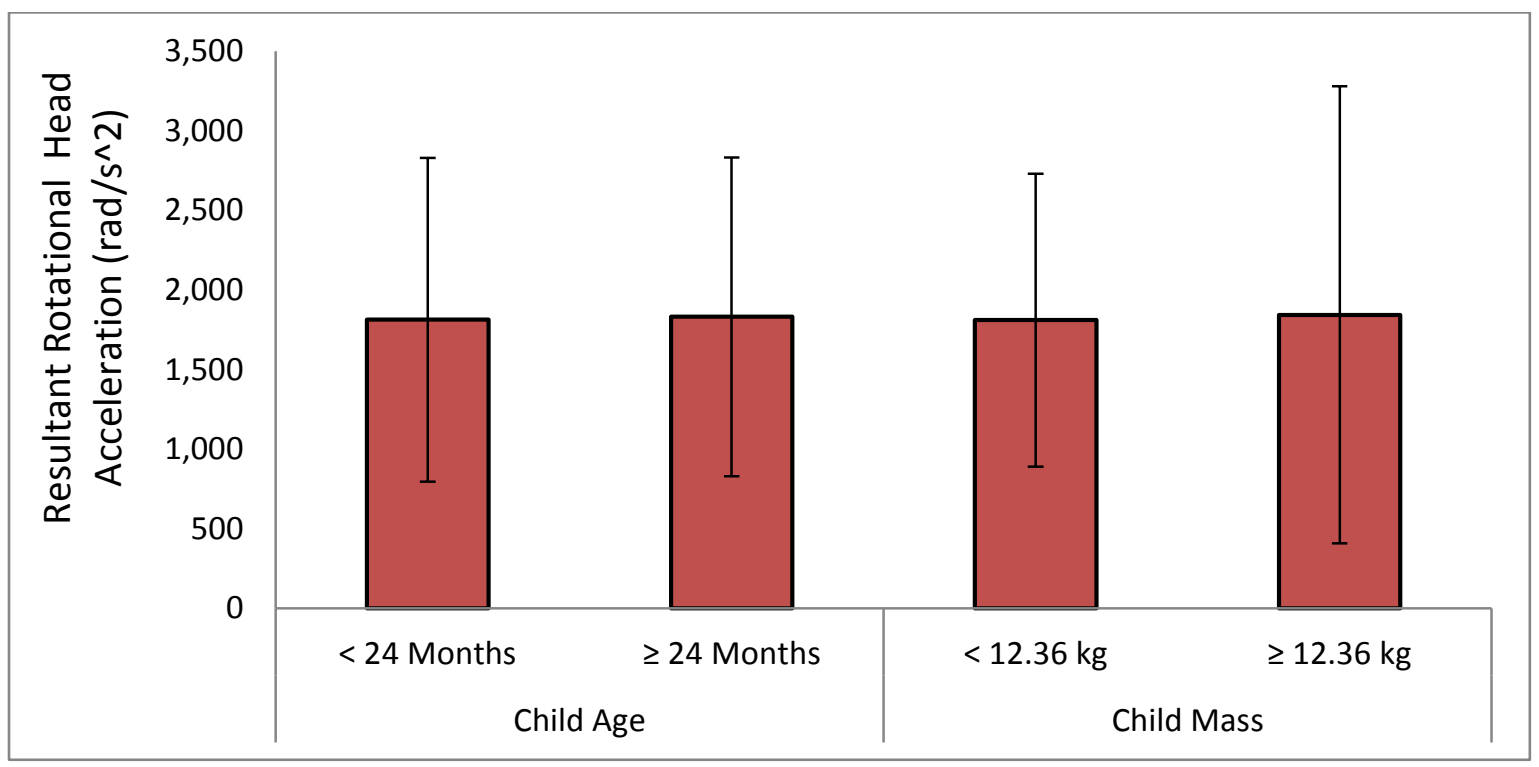

FIGURE 12 - Mean Peak Resultant Rotational Head Acceleration Based on Child Characteristics. Error Bars Represent \pm SD

\section{Linear Head Velocity}

Mean peak resultant linear head velocity based on child age and mass can be seen in FIGURE 13. Child age did not have an effect on peak resultant linear head velocity $F(1,98)=0.19, p=0.666$ indicating that there was no significant difference between children younger than 24-months (Mean=1.97 m/s \pm 0.72 ) and children 24-months and older (Mean $=1.82 \mathrm{~m} / \mathrm{s} \pm 0.74$ ). Child mass did not have an effect on peak linear head 
velocity $F(1,98)=0.51, p=0.476$. Mean peak linear head velocity for children less than $12.36 \mathrm{~kg}$ was $1.96 \mathrm{~m} / \mathrm{s}( \pm 0.73 \mathrm{~m} / \mathrm{s})$ and mean peak linear head velocity for children greater than or equal to $12.36 \mathrm{~kg}$ was $1.93 \mathrm{~m} / \mathrm{s}( \pm 0.68 \mathrm{~m} / \mathrm{s})$. When considered together, child characteristics did not have an effect on peak linear head velocity $F(1,98)=2.03$, $p$ $=0.158$.

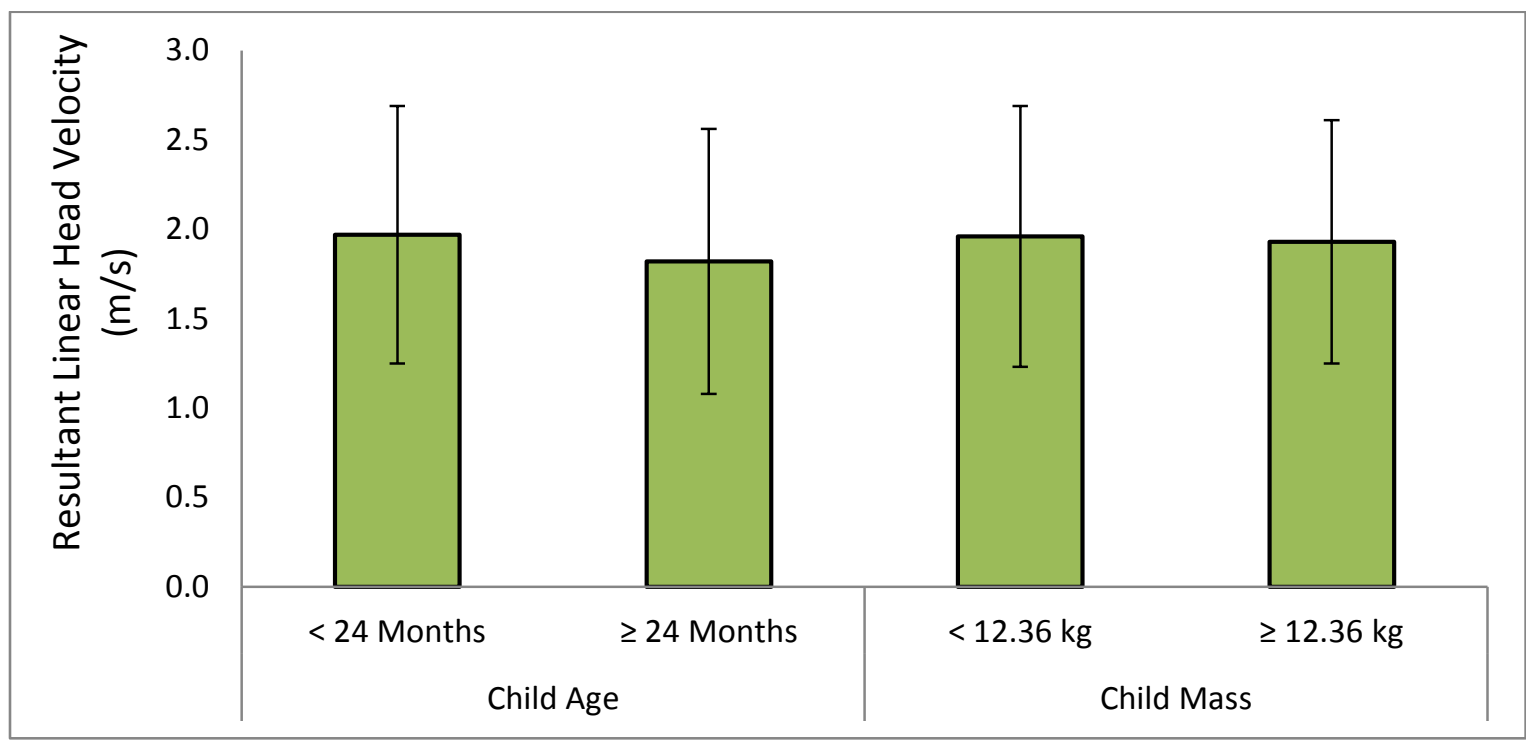

FIGURE 13 - Mean Peak Resultant Linear Head Velocity Based on Child Characteristics. Error Bars Represent \pm SD

\section{Rotational Head Velocity}

Mean peak resultant rotational head velocity based on child age and mass can be seen in FIGURE 14. Child age did not have an effect on peak resultant rotational head velocity $F(1,98)<0.01, p=0.946$ indicating that there was no significant difference between children younger than 24-months (Mean=9.69 rad/s \pm 4.35$)$ and children 24months and older (Mean=10.28 rad/s \pm 5.34$)$. Child mass did not have an effect on peak rotational head velocity $F(1,98)=0.45, p=0.503$. Mean peak rotational head velocity for children less than $12.36 \mathrm{~kg}$ was $9.80 \mathrm{rad} / \mathrm{s}( \pm 4.35 \mathrm{rad} / \mathrm{s})$ and mean peak rotational head 
velocity for children greater than or equal to $12.36 \mathrm{~kg}$ was $9.54 \mathrm{rad} / \mathrm{s}( \pm 5.16 \mathrm{rad} / \mathrm{s})$. When considered together, child characteristics did not have an effect on peak rotational head velocity $\mathrm{F}(1,98)=0.54, \mathrm{p}=0.462$.

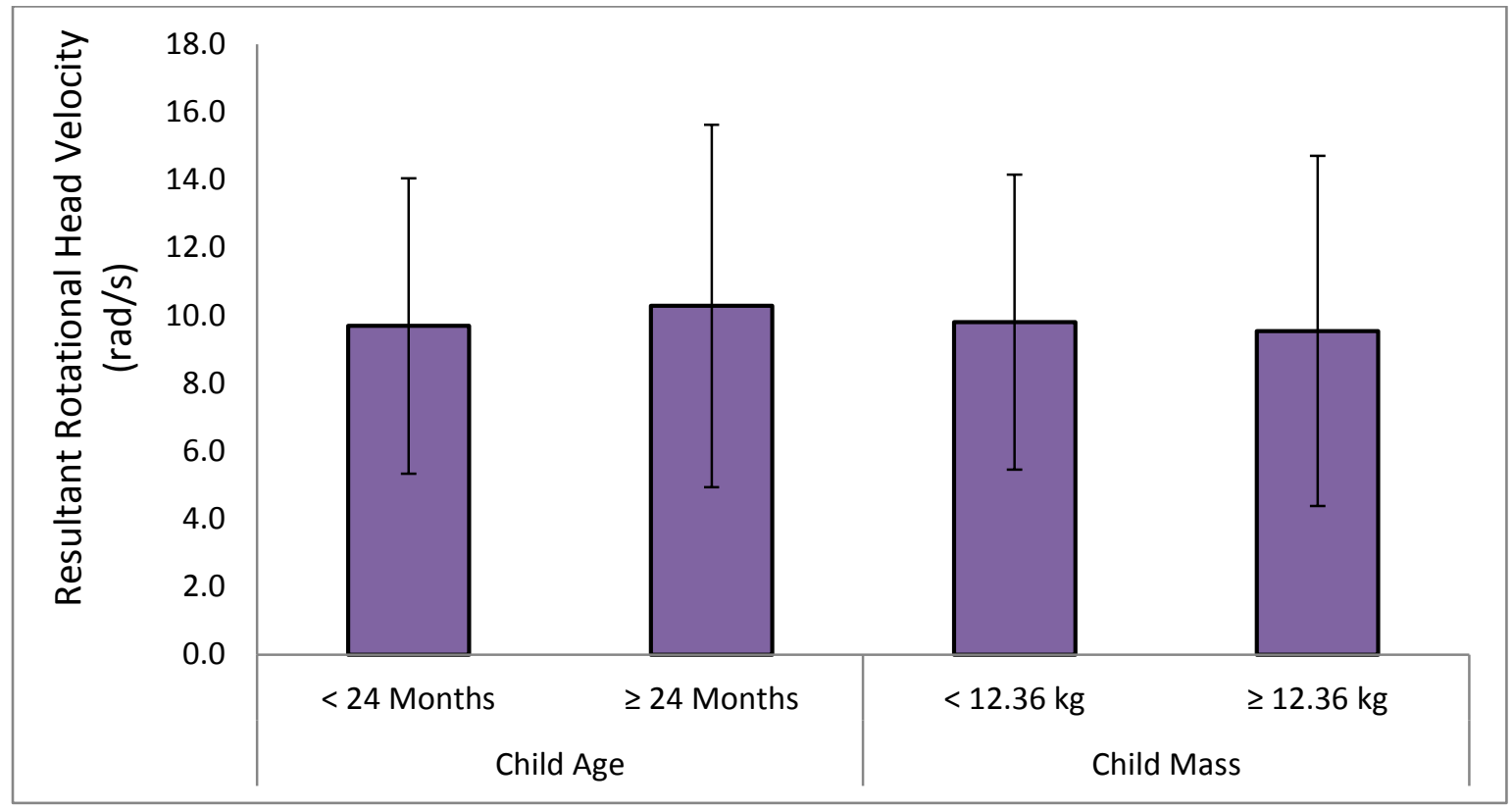

FIGURE 14 - Mean Peak Resultant Rotational Head Velocity Based on Child Characteristics. Error Bars Represent \pm SD

\section{Head Injury Criteria}

Mean $\mathrm{HIC}_{15}$ values based on child age and mass can be seen in FIGURE 15. Child age did not have an effect on $\mathrm{HIC}_{15} \mathrm{~F}(1,98)=0.09, \mathrm{p}=0.763$ indicating that there was no significant difference between children younger than 24-months (Mean=8.38 \pm 5.33 ) and children 24-months and older (Mean=7.70 \pm 3.55 ). Child mass did not have an effect on $\mathrm{HIC}_{15} \mathrm{~F}(1,98)=1.82, \mathrm{p}=0.180$. Mean $\mathrm{HIC}_{15}$ for children less than $12.36 \mathrm{~kg}$ was 8.09 $( \pm 4.60)$ and mean $\mathrm{HIC}_{15}$ for children greater than or equal to $12.36 \mathrm{~kg}$ was $9.42( \pm 7.44)$. When considered together, child characteristics did not have an effect on $\mathrm{HIC}_{15} \mathrm{~F}(1,98)=$ $1.10, \mathrm{p}=0.297$ 


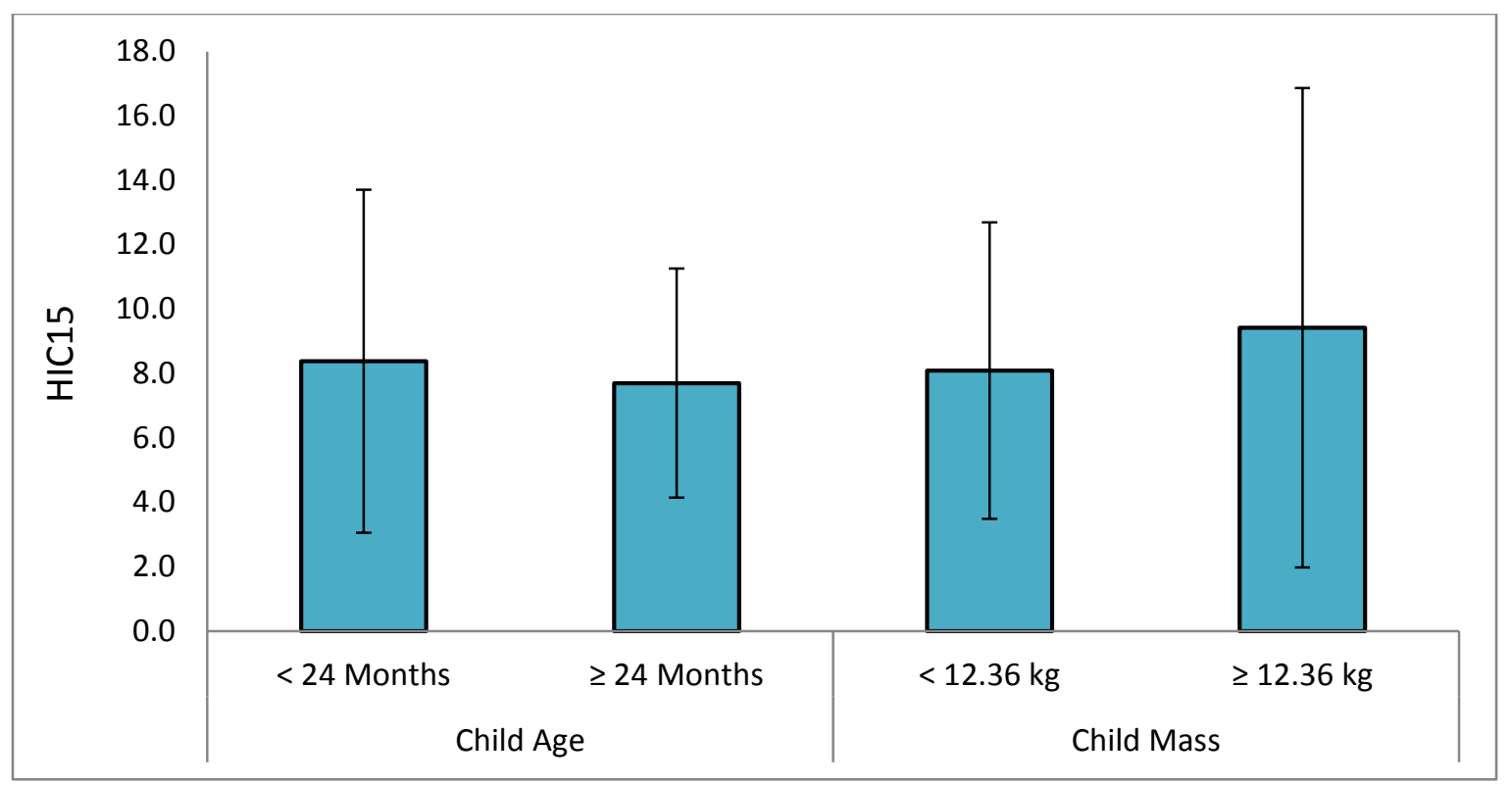

FIGURE 15 - Mean Peak $\mathrm{HIC}_{15}$ Based on Child Characteristics. Error Bars Represent \pm SD

\section{$\underline{\text { 6. Impact Duration }}$}

Mean impact duration based on child age and mass can be seen in FIGURE 16. Child age did not have an effect on impact duration $\mathrm{F}(1,98)=0.55, \mathrm{p}=0.461$ indicating that there was no significant difference between children younger than 24-months (Mean=21.26 $\mathrm{ms} \pm 6.09$ ) and children 24-months and older (Mean=19.46 ms \pm 7.63 ).

Child mass did not have an effect on impact duration $\mathrm{F}(1,98)=0.50, \mathrm{p}=0.483$. Mean impact duration for children less than $12.36 \mathrm{~kg}$ was $21.08 \mathrm{~ms}( \pm 6.21 \mathrm{~ms})$ and mean impact duration for children greater than or equal to $12.36 \mathrm{~kg}$ was $20.75 \mathrm{~ms}( \pm 6.92 \mathrm{~ms})$. When considered together, child characteristics did not have an effect on impact duration $\mathrm{F}(1,98)=1.44, \mathrm{p}=0.233$. 


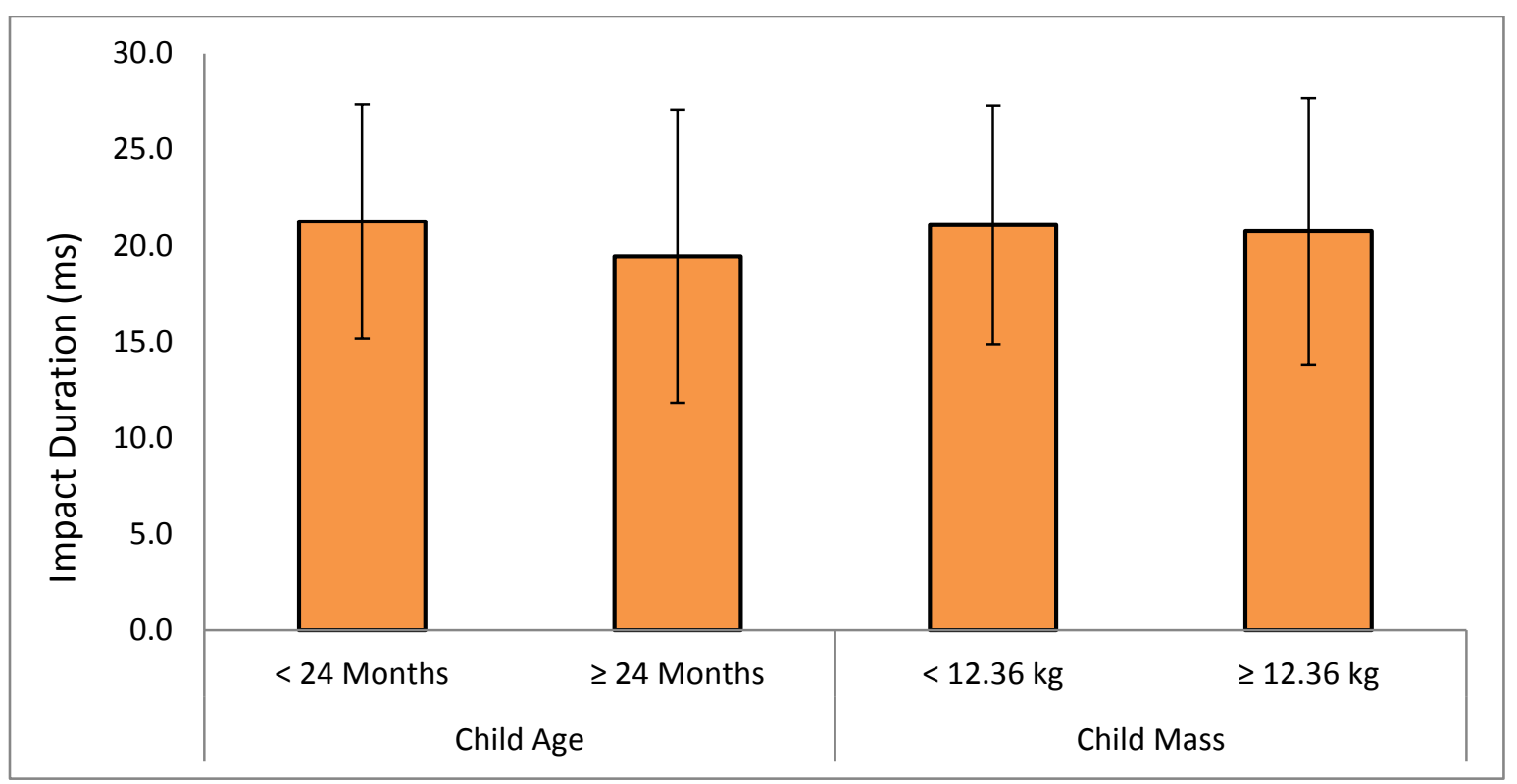

FIGURE 16 - Mean Impact Duration Based on Child Characteristics. Error Bars Represent \pm SD

\section{Whole-Body Impact Velocity}

Mean whole-body impact velocity based on child age and mass can be seen in FIGURE 17. Child age did not have an effect on whole-body impact velocity $F(1,98)=$ $0.43, p=0.512$ indicating that there was no significant difference between children younger than 24-months $($ Mean=2.39 m/s \pm 0.52$)$ and children 24-months and older (Mean=2.50 m/s \pm 0.49 ). Child mass did not have an effect on whole-body impact velocity $\mathrm{F}(1,98)=2.18, \mathrm{p}=0.143$. Mean whole-body impact velocity for children less than $12.36 \mathrm{~kg}$ was $2.41 \mathrm{~m} / \mathrm{s}( \pm 0.51 \mathrm{~m} / \mathrm{s})$ and mean whole-body impact velocity for children greater than or equal to $12.36 \mathrm{~kg}$ was $2.37 \mathrm{~m} / \mathrm{s}( \pm 0.51 \mathrm{~m} / \mathrm{s})$. When considered together, child characteristics did not have an effect on whole-body impact velocity $\mathrm{F}$ $(1,98)=3.39, \mathrm{p}=0.069$. 


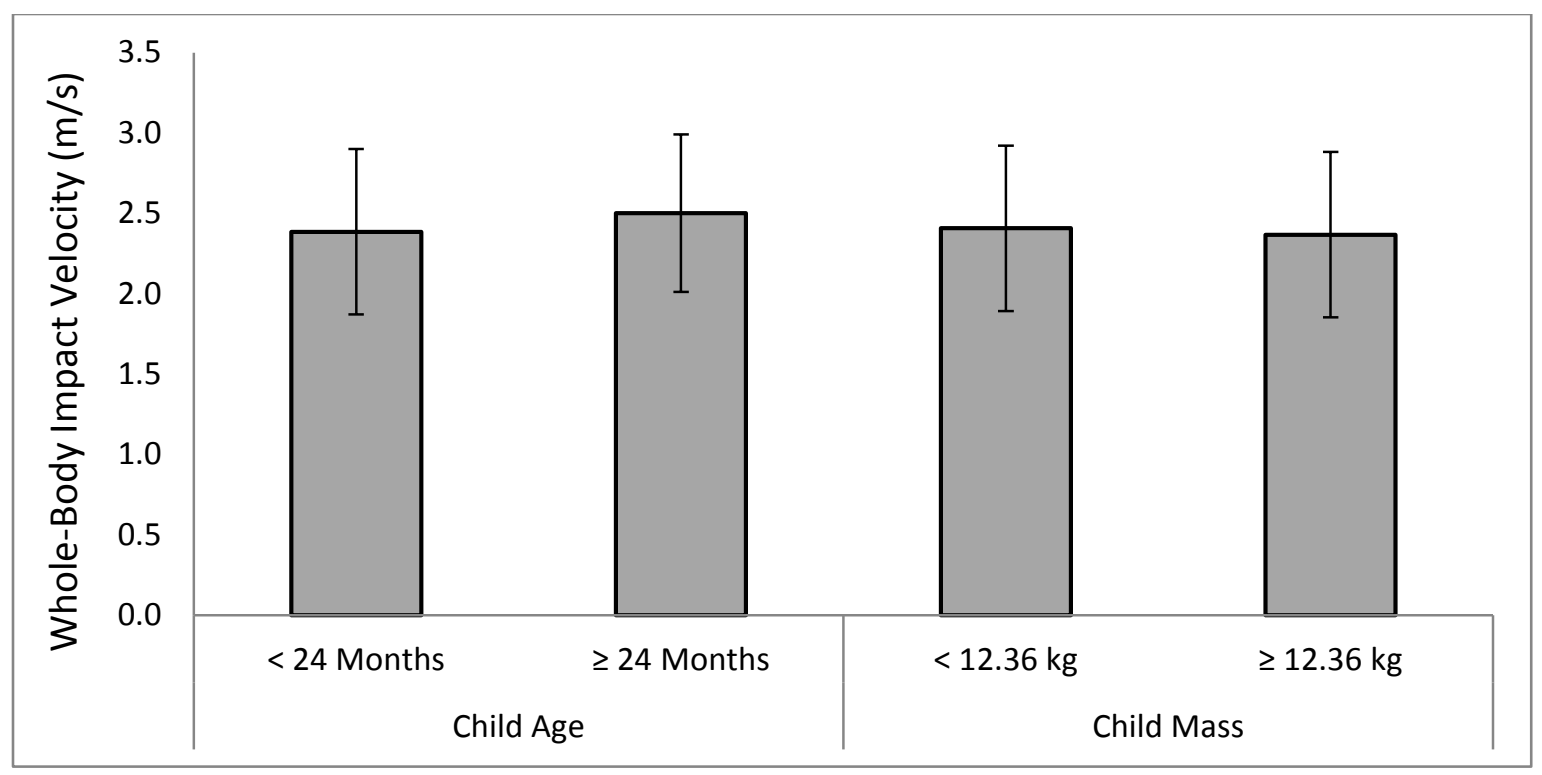

FIGURE 17 - Mean Whole-Body Impact Velocity Based on Child Characteristics. Error Bars Represent \pm SD

\section{$\underline{\text { 8. Change in Impact Momentum }}$}

Mean change in impact momentum based on child age and mass can be seen in FIGURE 18. Child age did not have an effect on change in impact momentum $F(1,98)=$ 2.57, $\mathrm{p}=0.112$ indicating that there was no significant difference between children younger than 24-months (Mean=41.98 kgm/s \pm 10.51$)$ and children 24 -months and older (Mean $=50.44 \mathrm{kgm} / \mathrm{s} \pm 10.46$ ). Child mass did not have an effect on change in impact momentum $\mathrm{F}(1,98)=0.21, \mathrm{p}=0.646$. Mean change in impact momentum for children less than $12.36 \mathrm{~kg}$ was $41.92 \mathrm{kgm} / \mathrm{s}( \pm 10.11 \mathrm{kgm} / \mathrm{s})$ and mean change in impact momentum for children greater than or equal to $12.36 \mathrm{~kg}$ was $49.18 \mathrm{kgm} / \mathrm{s}( \pm 12.75$ $\mathrm{kgm} / \mathrm{s}$ ). When considered together, child characteristics did not have an effect on change in impact momentum $\mathrm{F}(1,98)=3.14, \mathrm{p}=0.079$. 


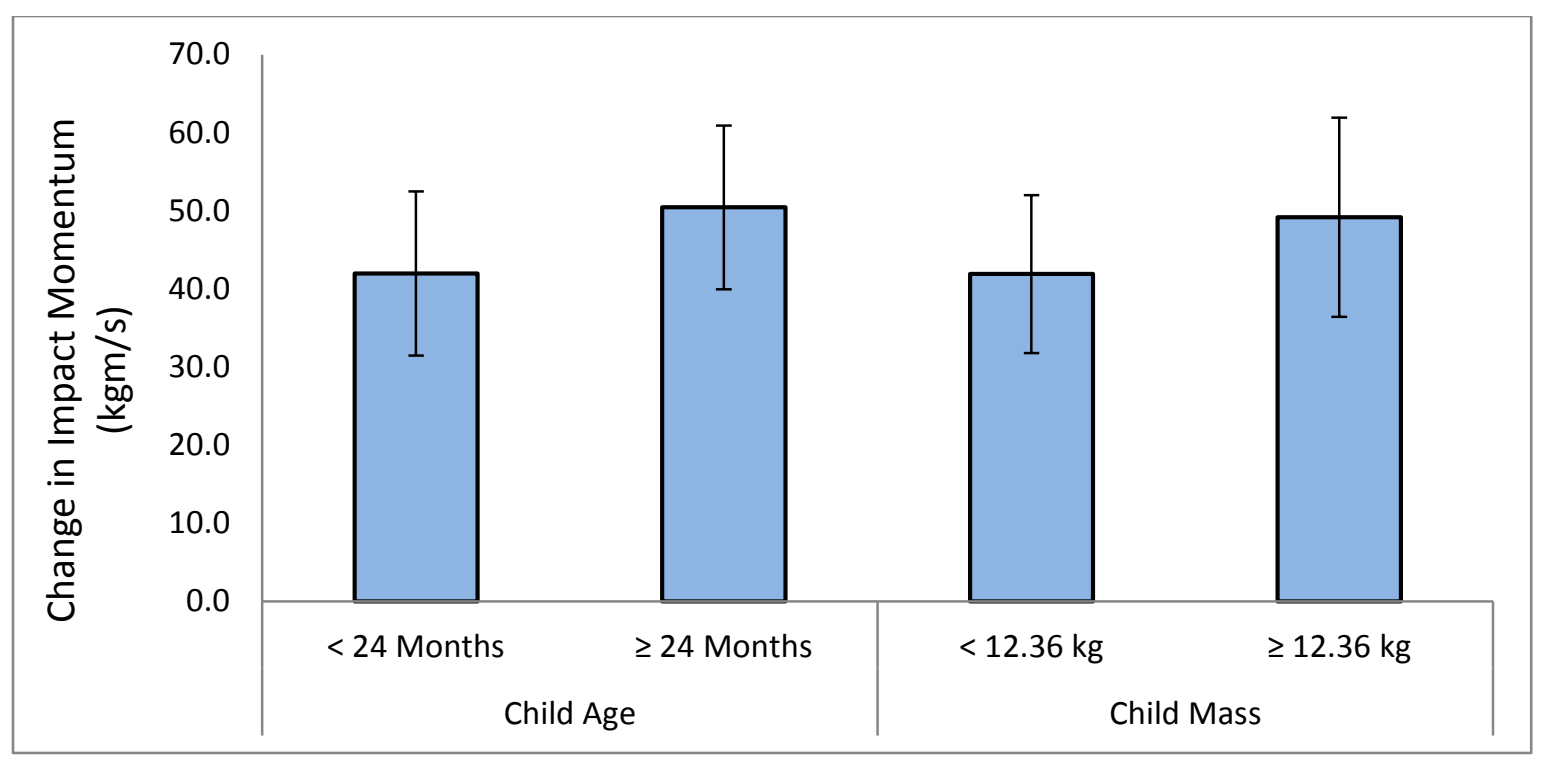

FIGURE 18 - Mean Change in Impact Momentum Based on Child Characteristics. Error Bars Represent \pm SD

\section{Potential Energy}

Mean potential energy based on child age and mass can be seen in FIGURE 19. Child age did not have an effect on potential energy $F(1,98)=1.22, p=0.272$ indicating that there was no significant difference between children younger than 24-months (Mean=35.10 Nm \pm 16.12 ) and children 24-months and older (Mean=42.86 Nm \pm 15.21$)$. Child mass did not have an effect on potential energy $F(1,98)=0.02, p=0.884$. Mean potential energy for children less than $12.36 \mathrm{~kg}$ was $35.20 \mathrm{Nm}( \pm 15.83 \mathrm{Nm})$ and mean potential energy for children greater than or equal to $12.36 \mathrm{~kg}$ was $40.86 \mathrm{Nm}( \pm 17.50$ $\mathrm{Nm}$ ). When considered together, child characteristics did not have an effect on potential energy $F(1,98)=2.53, p=0.115$ 


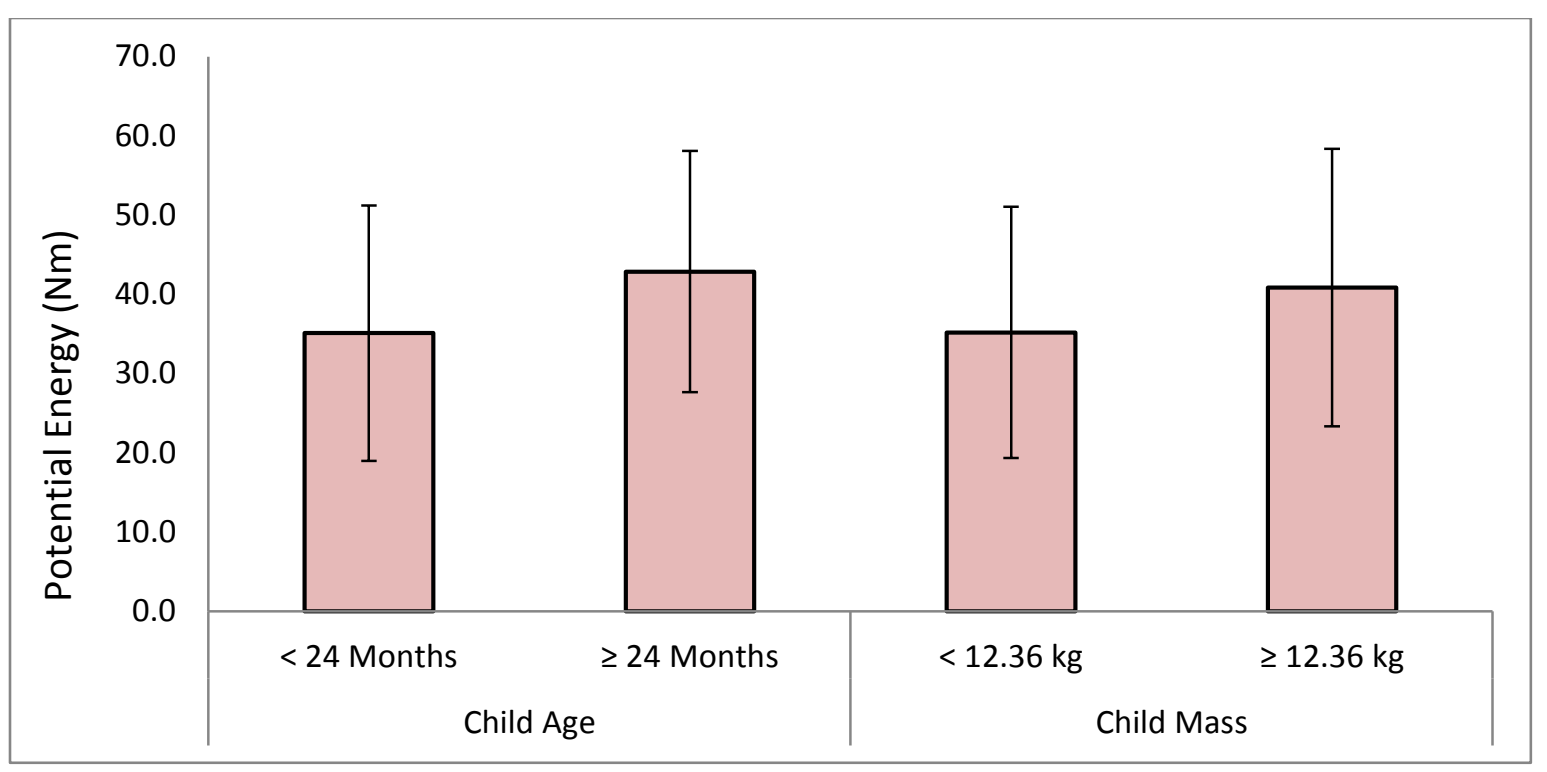

FIGURE 19 - Mean Potential Energy Based on Child Characteristics. Error Bars Represent \pm SD

\section{E. Biomechanical Measures Based on Fall Characteristics}

The number of falls for fall characteristic factors and interactions can be seen in

\section{TABLE V.}


TABLE V

NUMBER OF FALLS FOR FALL CHARACTERISTICS

\begin{tabular}{|c|c|c|}
\hline Fall Characteristics & Group & $\mathrm{N}$ \\
\hline \multirow{2}{*}{ Fall Type } & Ground Based & 87 \\
\hline & From Height & 15 \\
\hline \multirow{2}{*}{ Head Impact } & Non-Head Impact & 76 \\
\hline & Head Impact & 26 \\
\hline \multirow{2}{*}{ Impact Surface } & $\mathrm{COR}<0.43$ & 41 \\
\hline & $\mathrm{COR} \geq 0.43$ & 61 \\
\hline \multirow{4}{*}{$\begin{array}{c}\text { Fall Type and Head or Non- } \\
\text { Head Impact }\end{array}$} & $\begin{array}{l}\text { Ground Based, Non-Head } \\
\text { Impact }\end{array}$ & 70 \\
\hline & Ground Based, Head Impact & 17 \\
\hline & $\begin{array}{l}\text { From Height, Non-Head } \\
\text { Impact }\end{array}$ & 6 \\
\hline & From Height, Head Impact & 9 \\
\hline \multirow{4}{*}{$\begin{array}{l}\text { Fall Type and Impact } \\
\text { Surface COR }\end{array}$} & Ground Based, COR $<0.43$ & 36 \\
\hline & Ground Based, COR $\geq 0.43$ & 51 \\
\hline & From Height, COR $<0.43$ & 5 \\
\hline & From Height, COR $\geq 0.43$ & 10 \\
\hline \multirow{4}{*}{$\begin{array}{l}\text { Head or Non-Head Impact } \\
\text { and Impact Surface COR }\end{array}$} & $\begin{array}{c}\text { Non-Head Impact, COR < } \\
0.43\end{array}$ & 29 \\
\hline & $\begin{array}{l}\text { Non-Head Impact, COR } \geq \\
0.43\end{array}$ & 47 \\
\hline & Head Impact, COR < 0.43 & 12 \\
\hline & Head Impact, COR $\geq 0.43$ & 14 \\
\hline \multirow{8}{*}{$\begin{array}{l}\text { Fall Type, Head or Non- } \\
\text { Head Impact, and Impact } \\
\text { Surface COR }\end{array}$} & $\begin{array}{l}\text { Ground Based, Non-Head } \\
\text { Impact, COR }<0.43\end{array}$ & 27 \\
\hline & $\begin{array}{l}\text { Ground Based, Non-Head } \\
\text { Impact, COR } \geq 0.43\end{array}$ & 43 \\
\hline & $\begin{array}{l}\text { Ground Based, Head } \\
\text { Impact, COR }<0.43\end{array}$ & 9 \\
\hline & $\begin{array}{l}\text { Ground Based, Head } \\
\text { Impact, COR } \geq 0.43\end{array}$ & 8 \\
\hline & $\begin{array}{l}\text { From Height, Non-Head } \\
\text { Impact, COR }<0.43\end{array}$ & 2 \\
\hline & $\begin{array}{l}\text { From Height, Non-Head } \\
\text { Impact, COR } \geq 0.43\end{array}$ & 4 \\
\hline & $\begin{array}{c}\text { From Height, Head Impact, } \\
\text { COR < } 0.43\end{array}$ & 3 \\
\hline & $\begin{array}{l}\text { From Height, Head Impact, } \\
\text { COR } \geq 0.43\end{array}$ & 6 \\
\hline
\end{tabular}




\section{Linear Head Acceleration}

Mean peak resultant linear head acceleration based on fall type, head or non-head impact, and impact surface COR can be seen in FIGURE 20. Fall type did not have an effect on peak resultant linear acceleration $\mathrm{F}(1,94)=0.14, \mathrm{p}=0.707$ indicating that there was no significant difference between ground based falls (Mean=16.60 $\mathrm{g} \pm 5.66)$ and falls from a height (Mean=17.78 $\mathrm{g} \pm 5.31$ ). Whether there was head or no head impacts for falls had an effect on peak linear head acceleration $F(1,94)=0.024$. Post-hoc Tukey tests revealed that falls with head impacts (Mean=20.57 $\mathrm{g} \pm 9.35$ ) were significantly greater than falls without head impacts (Mean=15.47 $\mathrm{g} \pm 2.26)$. Falls onto surfaces with low and high COR had an effect on peak linear resultant head acceleration $\mathrm{F}(1,94)=5.05, \mathrm{p}=$ 0.027. Falls onto surfaces with lower COR (Mean=18.67 $\mathrm{g} \pm 7.78$ ) were associated with significantly greater peak resultant linear head acceleration than falls onto surfaces with higher COR (Mean=15.50 g \pm 2.60$)$. When considered together, interactions of fall characteristics did not have an effect on peak resultant linear head acceleration $(p>0.05)$. 


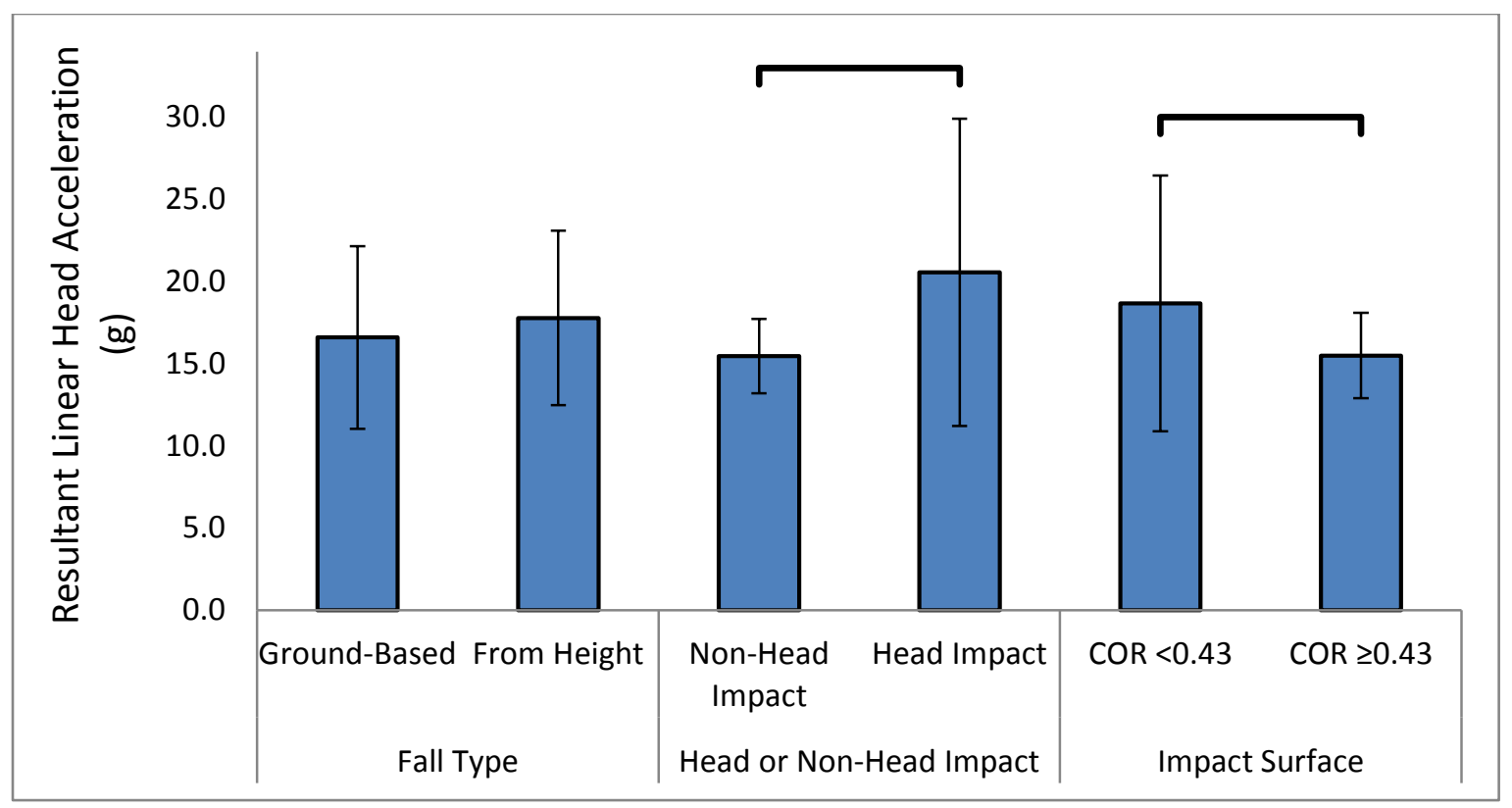

FIGURE 20 - Mean Peak Resultant Linear Head Acceleration Based on Fall Characteristics. Error Bars Represent \pm SD. Brackets Represent Significant Differences $(\mathrm{p}<0.05)$

\section{Rotational Head Acceleration}

Mean values for peak resultant rotational head acceleration based on fall type, head or non-head impact, and impact surface COR can be seen in FIGURE 21. Fall type did not have an effect on peak resultant rotational head acceleration $\mathrm{F}(1,94)=1.14, \mathrm{p}=$ 0.288 indicating that there was no significant difference between ground based falls (Mean=1,829 rad $/ \mathrm{s}^{2} \pm 1,013$ ) and falls from a height (Mean=1,740 rad $/ \mathrm{s}^{2} \pm 1,015$ ).

Whether there was head or not head impacts for falls had an effect on peak rotational head acceleration $\mathrm{F}(1,94)=8.33, \mathrm{p}=0.005$. Falls with head impacts $\left(\mathrm{Mean}=2,265 \mathrm{rad} / \mathrm{s}^{2}\right.$ $\pm 1,423$ ) were significantly greater than falls without head impacts (Mean $=1,662 \mathrm{rad} / \mathrm{s}^{2}$ \pm 776 ). Falls onto surfaces with lower COR (Mean $\left.=1,839 \mathrm{rad} / \mathrm{s}^{2} \pm 1,169\right)$ had approximately similar means with falls onto surfaces with higher COR (Mean=1,800 $\mathrm{rad} / \mathrm{s}^{2} \pm 896$ ). Impact surface COR did not have an effect on peak resultant rotational head 
acceleration $\mathrm{F}(1,94)=0.69, \mathrm{p}=0.409$. The interaction between fall characteristics did not have a significant effect on peak resultant rotational head acceleration $(p>0.05)$.

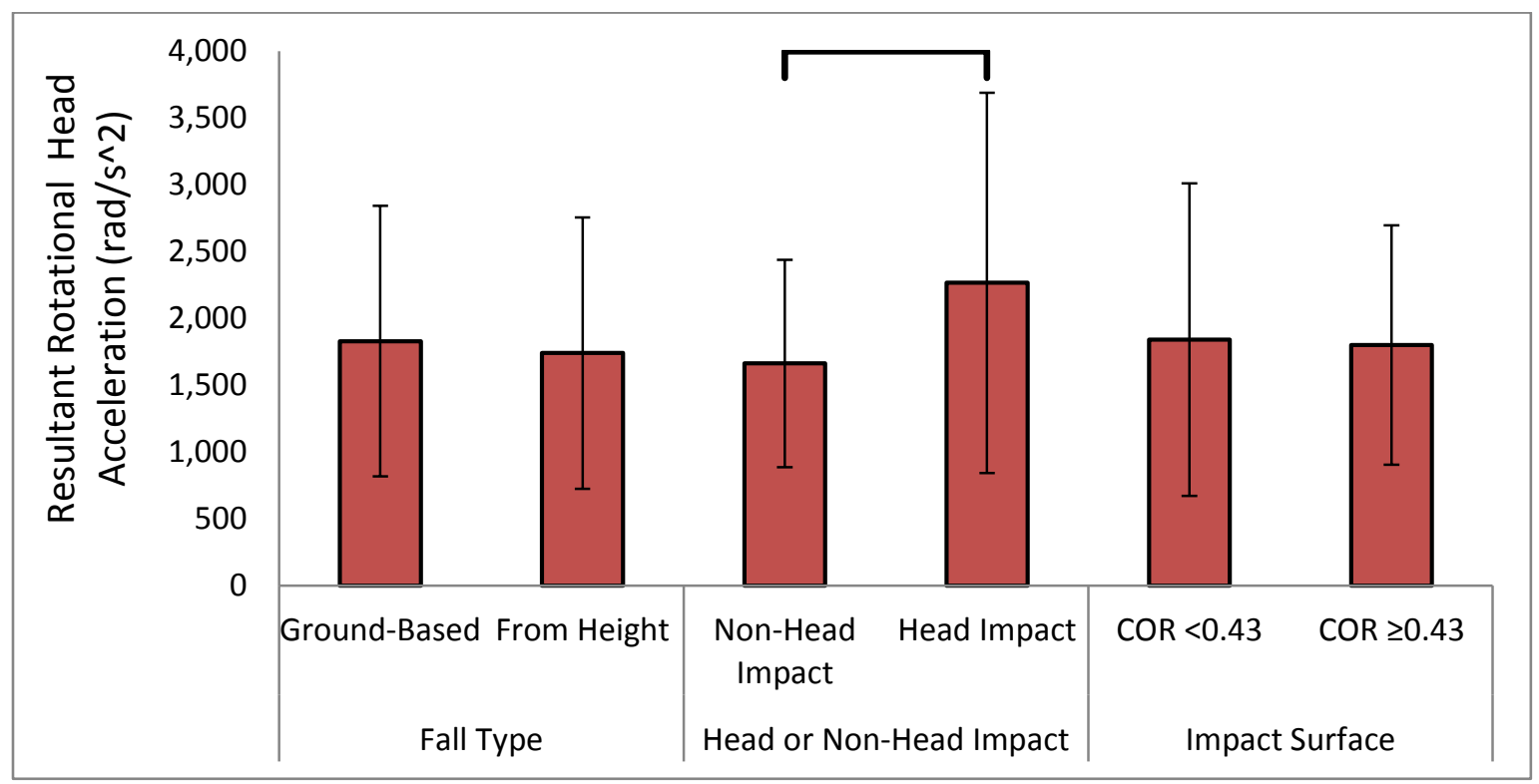

FIGURE 21 - Mean Peak Resultant Rotational Head Acceleration Based on Fall Characteristics. Error Bars Represent \pm SD. Brackets Represent Significant Differences $(\mathrm{p}<0.05)$

\section{Linear Head Velocity}

Mean values for peak resultant linear head velocity based of fall type, head or non-head impact, and impact surface COR can be seen in Fig. 18. Mean peak resultant linear head velocity for ground based falls was $1.97 \mathrm{~m} / \mathrm{s}( \pm 0.73 \mathrm{~m} / \mathrm{s})$ and the mean peak linear head velocity for falls from height was $1.85 \mathrm{~m} / \mathrm{s}( \pm 0.66 \mathrm{~m} / \mathrm{s})$. Fall type did not have an effect on peak resultant linear head velocity $\mathrm{F}(1,94)=1.32, \mathrm{p}=0.253$. Falls with head or non-head impacts did have an effect on peak resultant linear head velocity $\mathrm{F}(1,94)=$ $19.89, \mathrm{p}<0.001$. Conversely to peak resultant linear and rotational head acceleration, falls without head impacts (Mean $=2.16 \mathrm{~m} / \mathrm{s} \pm 0.61$ ) were significantly greater than falls with head impacts (Mean=1.35 m/s \pm 0.67 ). Mean peak resultant linear head velocity for 
falls onto surfaces with lower COR was $2.04 \mathrm{~m} / \mathrm{s}( \pm 0.77 \mathrm{~m} / \mathrm{s})$ and mean peak linear head velocity for falls onto surfaces with higher COR was $1.89 \mathrm{~m} / \mathrm{s}( \pm 0.68 \mathrm{~m} / \mathrm{s})$. Impact surface COR did not have an effect on peak resultant linear head velocity $\mathrm{F}(1,94)=0.58$, $p=0.449$. No interactions for fall characteristics were found to be significant on peak resultant linear head velocity $(\mathrm{p}>0.05)$.

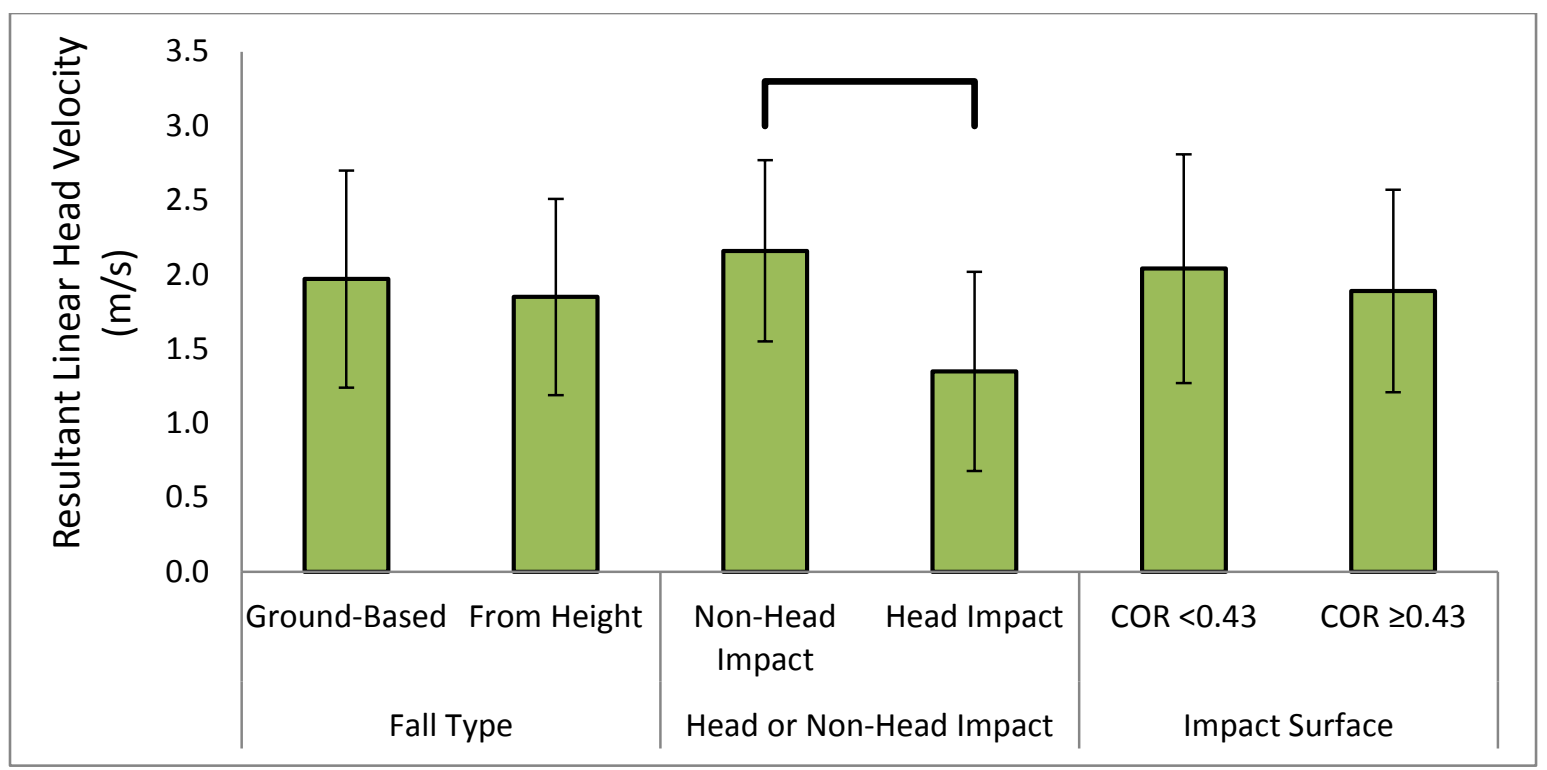

FIGURE 22 - Mean Peak Resultant Linear Head Velocity Based on Fall Characteristics. Error Bars Represent \pm SD. Brackets Represent Significant Differences $(\mathrm{p}<0.05)$

\section{Rotational Head Velocity}

Mean values for peak resultant rotational head velocity for main effects of fall type, head or non-head impact, and impact surface COR can be seen in FIGURE 23. Mean peak resultant rotational head velocity for ground based falls was $9.82 \mathrm{rad} / \mathrm{s}( \pm 4.45$ $\mathrm{rad} / \mathrm{s}$ ) and mean peak resultant rotational head velocity values for falls from height was $9.41 \mathrm{rad} / \mathrm{s}( \pm 4.65 \mathrm{rad} / \mathrm{s})$. Fall type did not have an effect on peak resultant rotational head velocity $\mathrm{F}(1,94)=0.54, \mathrm{p}=0.466$. Mean peak resultant rotational head velocity for falls with head impacts was $9.42 \mathrm{rad} / \mathrm{s}( \pm 4.28 \mathrm{rad} / \mathrm{s})$ and mean peak resultant rotational head 
velocity for falls with head impact was $10.76 \mathrm{rad} / \mathrm{s}( \pm 4.91 \mathrm{rad} / \mathrm{s})$. Whether falls had head or non-head impacts did not have an effect on peak resultant rotational head velocity $\mathrm{F}(1,94)=3.46, \mathrm{p}=0.066$. Mean peak resultant rotational head velocity for falls onto surfaces with lower COR was $9.15 \mathrm{rad} / \mathrm{s}( \pm 3.51 \mathrm{rad} / \mathrm{s})$ and mean peak resultant rotational head velocity for fall onto surface with higher COR was $10.18 \mathrm{rad} / \mathrm{s}( \pm 4.99 \mathrm{rad} / \mathrm{s})$. Impact surface COR did not have an effect on peak resultant rotational head velocity $\mathrm{F}(1,94)<$ $0.01, p=0.986$. When considered together, fall characteristics did not have an effect on peak resultant rotational head velocity $(\mathrm{p}>0.05)$.

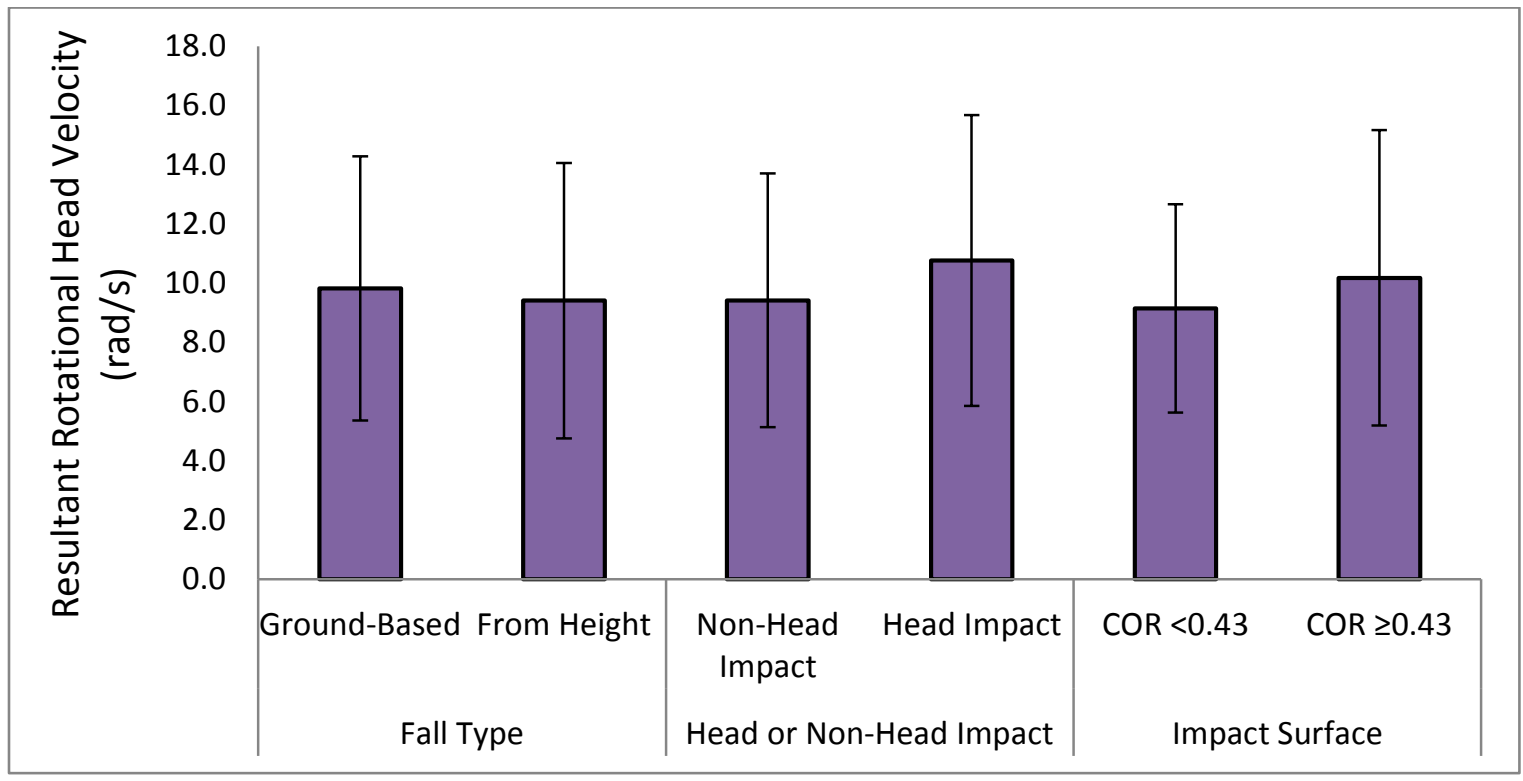

FIGURE 23 - Mean Peak Resultant Rotational Head Velocity Based on Fall Characteristics. Error Bars Represent \pm SD.

\section{Head Injury Criteria}

Mean values for $\mathrm{HIC}_{15}$ based on fall type, head or non-head impact, and impact surface COR can be seen in FIGURE 24. Mean $\mathrm{HIC}_{15}$ values for ground based falls was $8.33( \pm 5.31)$ and mean $\mathrm{HIC}_{15}$ for falls from height was $8.11( \pm 4.04)$. Fall type did not have an effect on $\mathrm{HIC}_{15} \mathrm{~F}(1,94)=0.58, \mathrm{p}=0.446$. Mean $\mathrm{HIC}_{15}$ for falls without a head 
impact was $8.06( \pm 3.77)$ and mean $\mathrm{HIC}_{15}$ for falls with a head impact was $9.00( \pm 7.93)$. Whether falls occurred with or without head impacts did not have an effect on $\mathrm{HIC}_{15}$ $\mathrm{F}(1,94)=1.05, \mathrm{p}=0.307$. However, impact surface COR had an effect on $\mathrm{HIC}_{15} \mathrm{~F}(1,94)$ $=6.31, \mathrm{p}=0.014$. Falls onto surfaces with lower COR $($ Mean $=10.01 \pm 6.17)$ were associated with significantly greater $\mathrm{HIC}_{15}$ values than falls onto surfaces with higher $\mathrm{COR}$ (Mean=7.15 \pm 3.94 ). No interactions for fall characteristics had an effect on $\mathrm{HIC}_{15}$ $(\mathrm{p}>0.05)$

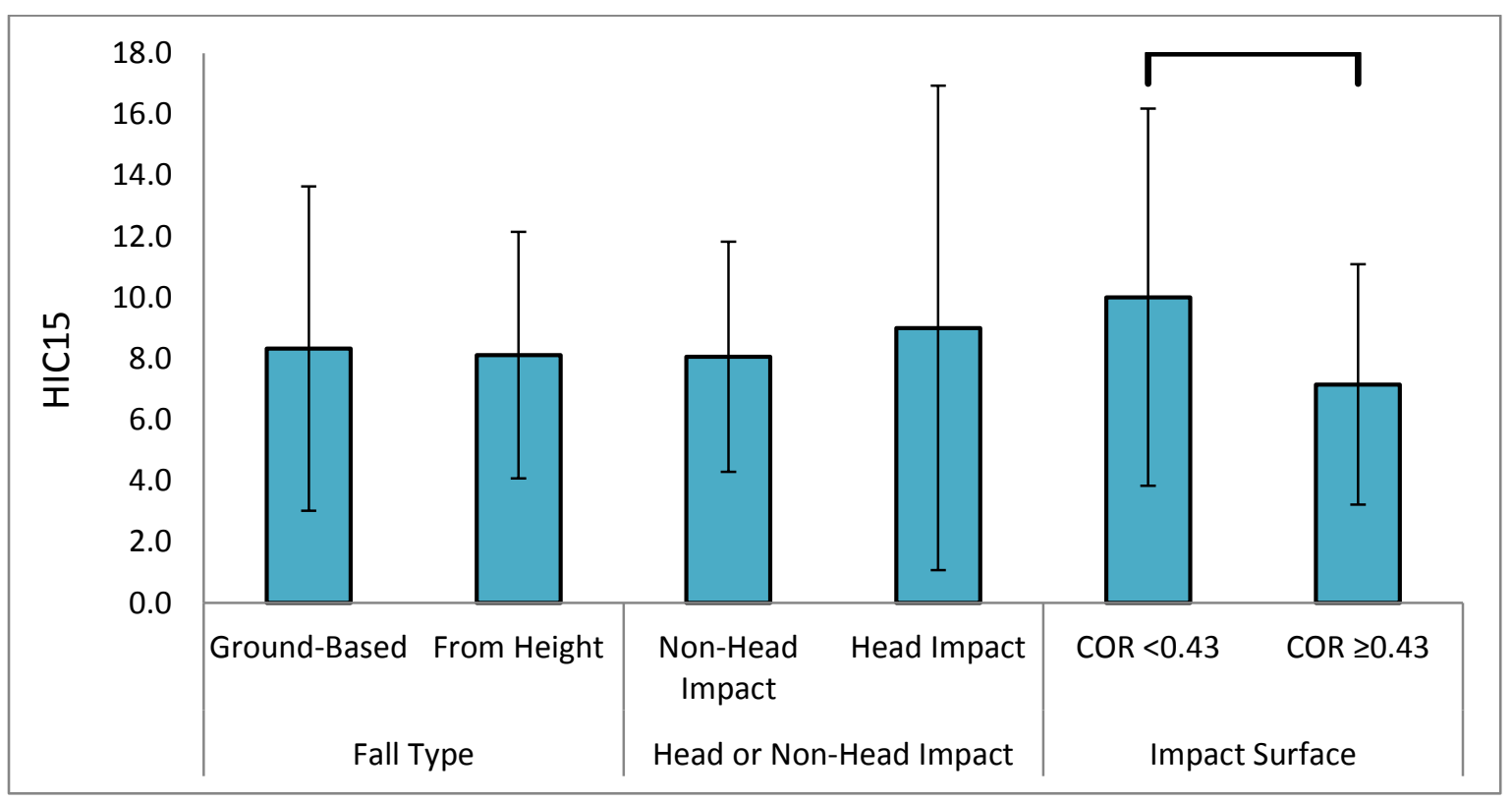

FIGURE 24 - Mean $\mathrm{HIC}_{15}$ Values Based on Fall Characteristics. Error Bars Represent \pm SD. Brackets Represent Significant Differences ( $p<0.05$ )

\section{Impact Duration}

Mean values for impact duration based on fall type, head or non-head impact, and impact surface COR can be seen in FIGURE 25. Mean impact duration for ground based falls was $21.25 \mathrm{~ms}( \pm 6.22 \mathrm{~ms})$ and the mead impact duration for falls from height was $19.73 \mathrm{~ms}( \pm 6.79 \mathrm{~ms})$. Fall type did not have an effect on impact duration $\mathrm{F}(1,94)=1.30$, 
$\mathrm{p}=0.257$. Whether falls occurred with a head or a non-head impact was significant on impact duration $\mathrm{F}(1,94)=37.56, \mathrm{p}<0.001$. Falls without head impacts $($ Mean $=23.24 \mathrm{~ms}$ \pm 4.82 ) were significantly greater than falls with head impacts (Mean=14.58 $\mathrm{ms} \pm 5.67$ ). Mean impact duration for falls onto surfaces with lower COR was $21.20 \mathrm{~ms}( \pm 7.41 \mathrm{~ms})$ and mean impact duration for falls onto surfaces with higher COR was $20.92 \mathrm{~ms}( \pm 5.48$ ms). Impact surface COR did not have an effect on impact duration $\mathrm{F}(1,94)=0.27, \mathrm{p}=$ 0.607). One interaction, head or non-head impact and impact surface COR, for fall characteristics had an effect on impact duration $\mathrm{F}(1,94)=6.62, \mathrm{p}=0.012$.

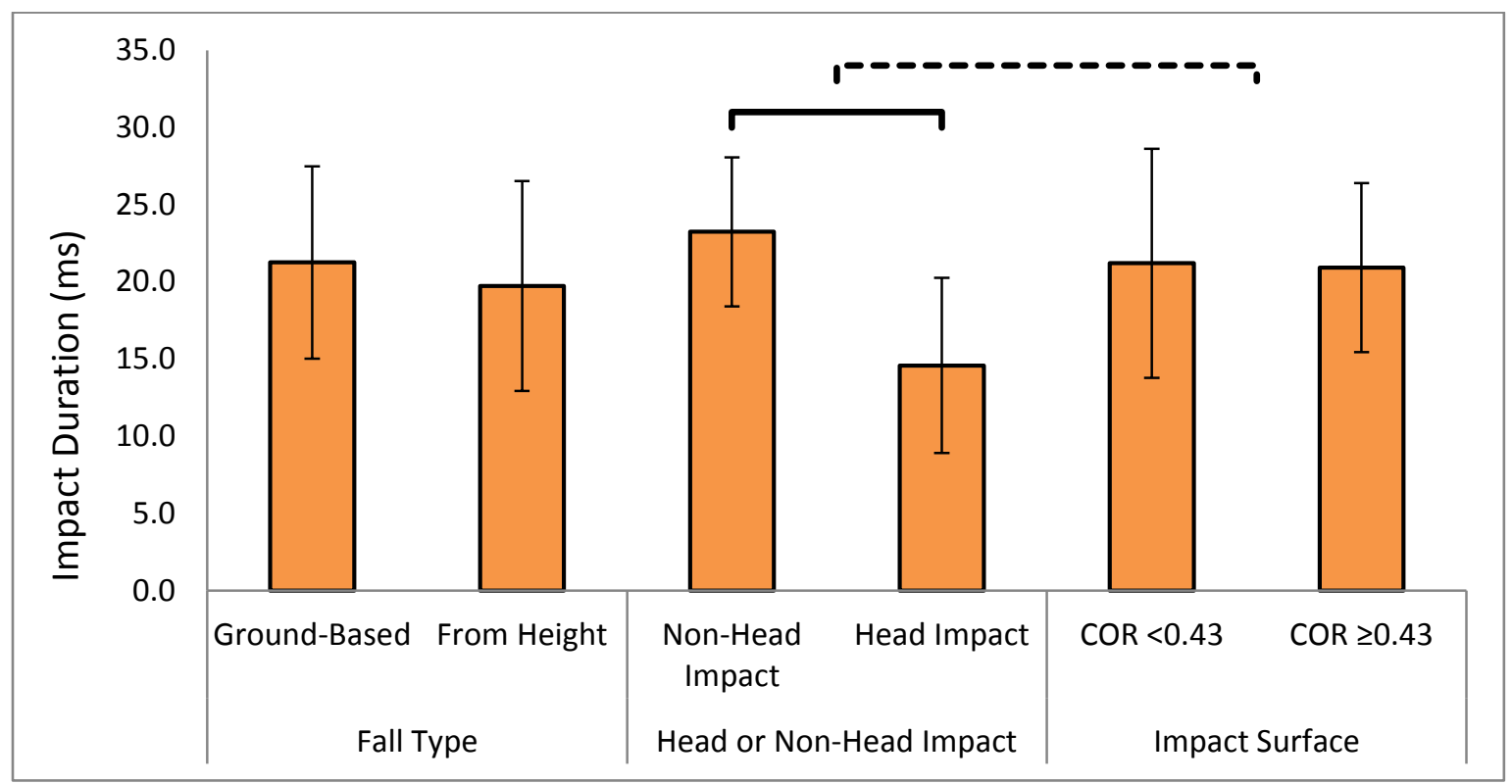

FIGURE 25 - Mean Impact Duration Based on Fall Characteristics. Error Bars Represent \pm SD. Solid Brackets Represent Significant Differences for Main Effects and Dashed Brackets Represent Significant Interactions $(\mathrm{p}<0.05)$

\section{Whole-Body Impact Velocity}

Mean values for whole-body impact velocity based on fall type, head or non-head impact, and impact surface COR can be seen in FIGURE 26. Fall type had an effect on whole-body impact velocity $F(1,94)=17.44, p<0.001$. Falls from heights $($ Mean=3.03 
$\mathrm{m} / \mathrm{s} \pm 0.732$ ) were associated with significantly greater impact velocities than ground based falls (Mean=2.29 m/s \pm 0.37 ). Additionally, impact surface COR had an effect on whole-body impact velocity $\mathrm{F}(1,94)=5.92, \mathrm{p}=0.017$. Falls onto surfaces with high COR (Mean=2.52 m/s \pm 0.55 ) had significantly greater impact velocities than falls onto surfaces with low COR (Mean=2.23 m/s \pm 0.39 ). However, falls with head or non-head impacts did not have an effect on whole-body impact velocity $F(1,94)=0.05, p=0.823$. The mean whole-body impact velocity for falls with head impacts was $2.64 \mathrm{~m} / \mathrm{s}( \pm 0.64$ $\mathrm{m} / \mathrm{s}$ ) and mean whole-body impact velocity for falls without head impacts was $2.32 \mathrm{~m} / \mathrm{s}$ $( \pm 0.43 \mathrm{~m} / \mathrm{s})$. The interaction of falls with head or non-head impacts and impact surface COR did have an effect on whole-body impact velocity $\mathrm{F}(1,94)=6.60, \mathrm{p}=0.012$. Additionally, the interaction of fall type, head or non-head impact, and impact surface COR had an effect on whole-body impact velocity $\mathrm{F}(1,94)=5.10, \mathrm{p}=0.026$.

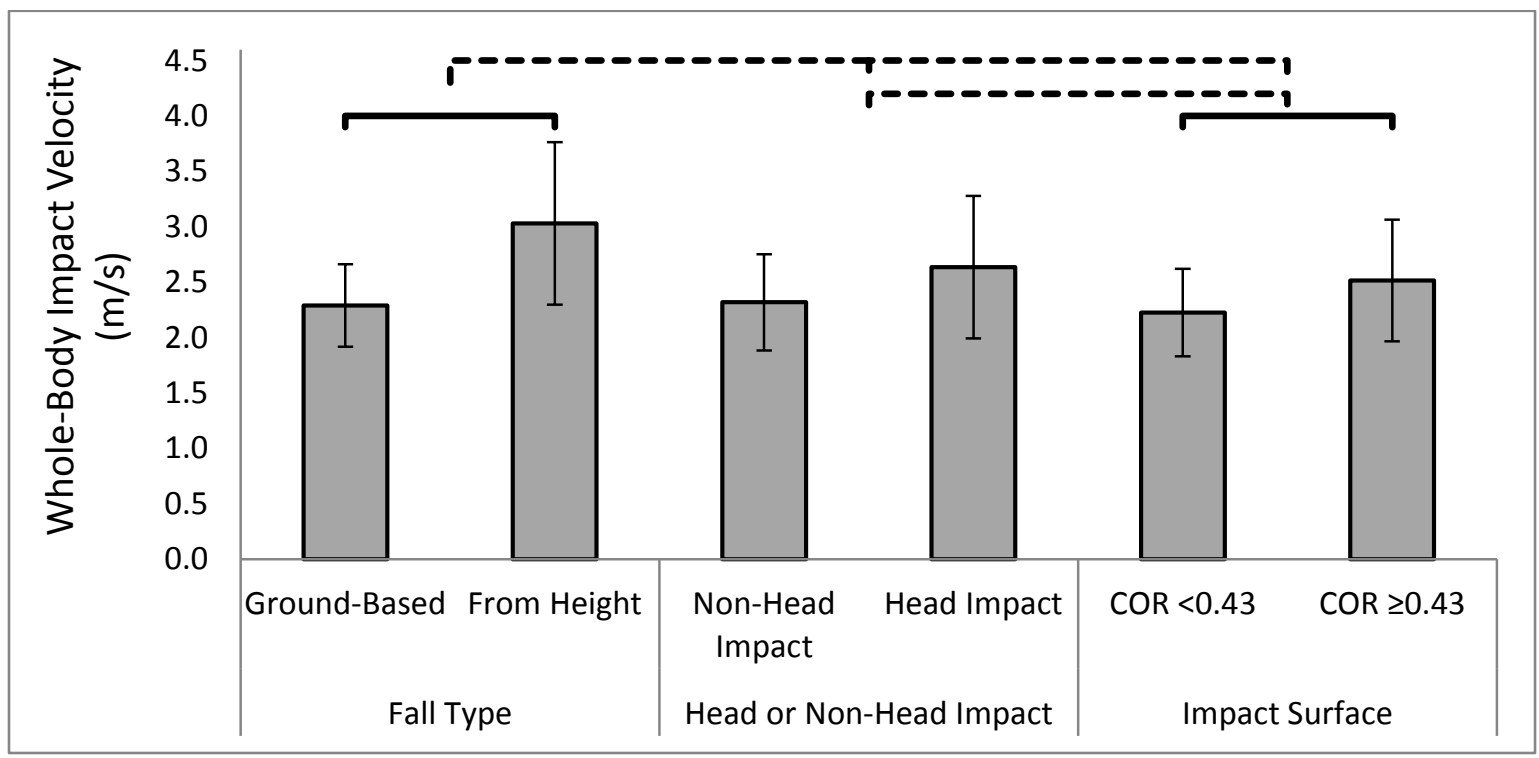

FIGURE 26 - Mean Whole-Body Impact Velocity Based on Fall Characteristics. Error Bars Represent \pm SD. Solid Brackets Represent Significant Differences for Main Effects and Dashed Brackets Represent Significant Interactions $(\mathrm{p}<0.05)$ 


\section{Change in Impact Momentum}

Mean values for change in impact momentum based on fall type, head or nonhead impact, and impact surface COR can be seen in FIGURE 27. Fall type F(1,94)= 16.83, $\mathrm{p}<0.001$ and impact surface COR F $(1,94)=10.15, \mathrm{p}=0.002$ had an effect on change in impact momentum. Falls from height (Mean=54.55 kgm/s \pm 14.18 ) were associated with significantly greater change in impact momentums than ground based falls (Mean=41.08 kgm/s \pm 8.83 ). Falls onto surfaces with high COR (Mean=46.86 kgm/s \pm 10.40 ) had significantly greater change in impact momentums than falls onto surfaces with low COR (Mean=37.41 kgm/s \pm 8.89 ). However, whether falls had head or non-head impacts did not have an effect on change in impact momentum $F(1,94)=1.38, p=0.243$. Mean change in impact momentum for falls with head impacts was $45.92 \mathrm{kgm} / \mathrm{s}( \pm 12.82$ $\mathrm{kgm} / \mathrm{s}$ ) and mean change in impact momentum for falls without head impacts was 42.08 $\mathrm{kgm} / \mathrm{s}( \pm 9.96 \mathrm{kgm} / \mathrm{s})$. The interaction of fall type and falls with head or non-head impact $\mathrm{F}(1,94)=4.67, \mathrm{p}=0.033$ and the interaction of falls with head or non-head impact and impact surface COR $F(1,94)=7.81, \mathrm{p}=0.006$ had an effect on change in impact momentum. Additionally, the interaction of fall type, head or non-head impact, and impact surface COR had an effect on change in impact momentum $\mathrm{F}(1,94)=8.72, \mathrm{p}=$ 0.004 . 


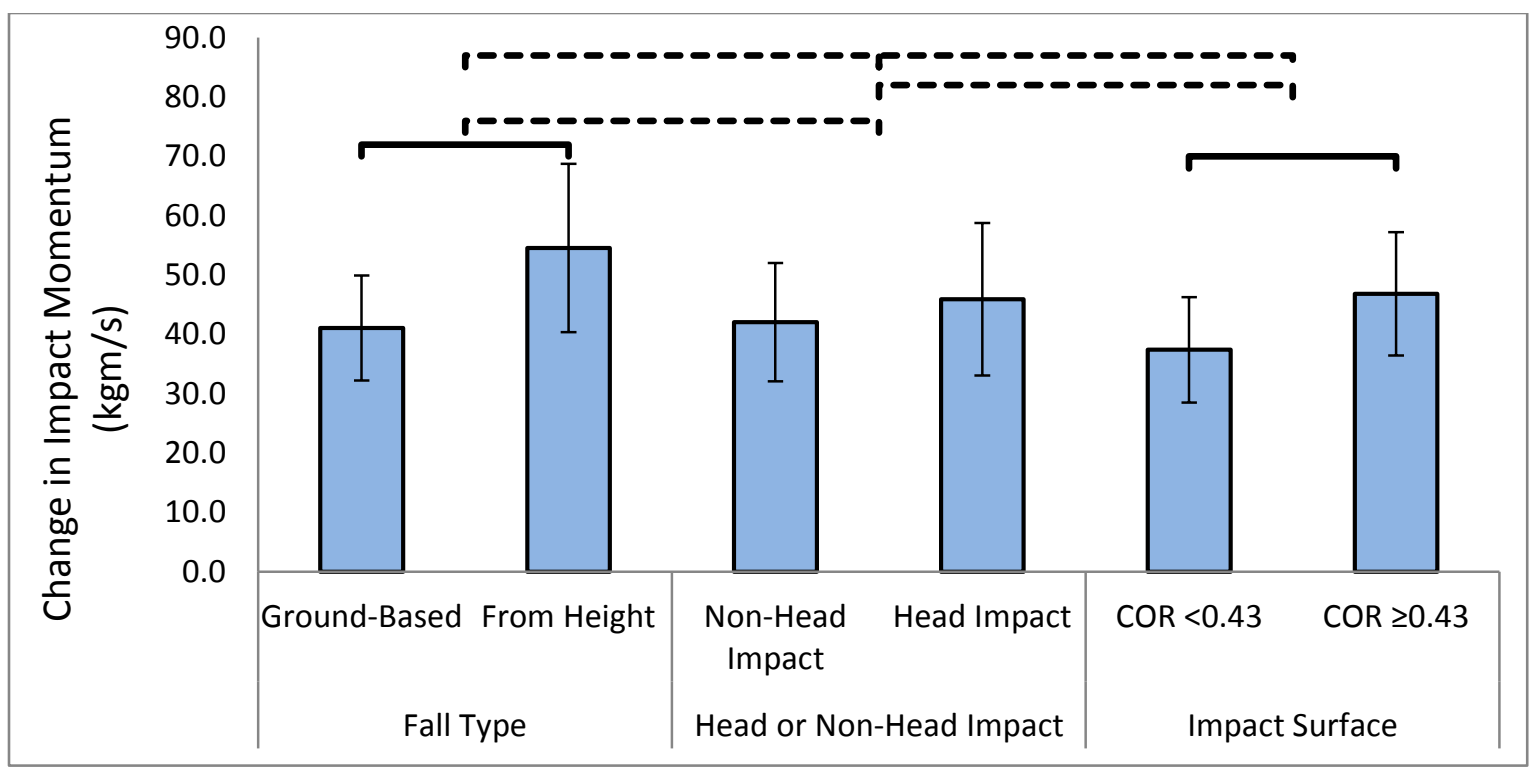

FIGURE 27 - Mean Change in Impact Momentum Based on Fall Characteristics. Error Bars Represent \pm SD. Solid Brackets Represent Significant Differences for Main Effects and Dashed Brackets Represent Significant Interactions $(\mathrm{p}<0.05)$

\section{Potential Energy}

Mean values for potential energy based on fall type, head or non-head impact, and impact surface COR can be seen in FIGURE 28. Fall type had an effect on potential energy $F(1,94)=17.21(p<0.001)$. Falls from heights $($ Mean=57.19 Nm \pm 24.26$)$ were associated with significantly greater potential energies than ground based falls (Mean=32.45 Nm \pm 10.92 ). Falls with head or without head impacts $F(1,94)=0.35, p=$ 0.557 and impact surface COR $\mathrm{F}(1,94)=3.65, \mathrm{p}=0.059$ did not have an effect on potential energy. Mean potential energy for falls with head impacts was $43.23 \mathrm{Nm}$ $( \pm 20.55 \mathrm{Nm})$ and mean potentially energy for falls without head impacts was $33.64 \mathrm{Nm}$ $( \pm 13.66 \mathrm{Nm})$. Mean potential energy for falls onto surfaces with low COR was $30.94 \mathrm{Nm}$ $( \pm 13.23 \mathrm{Nm})$ and mean potential energy for falls onto surfaces with high COR was 39.55 $\mathrm{Nm}( \pm 17.09 \mathrm{Nm})$. The interaction of fall type and head or non-head impact $\mathrm{F}(1,94)=$ $5.13, \mathrm{p}=0.026$ and the interaction of head or non-head impact and impact surface COR 
$\mathrm{F}(1,94)=7.19, \mathrm{p}=0.009$ had an effect on potential energy. Additionally, the interaction of fall type, head or non-impact, and impact surface COR had an effect on potential energy $F(1,94)=8.25, p=0.005$.

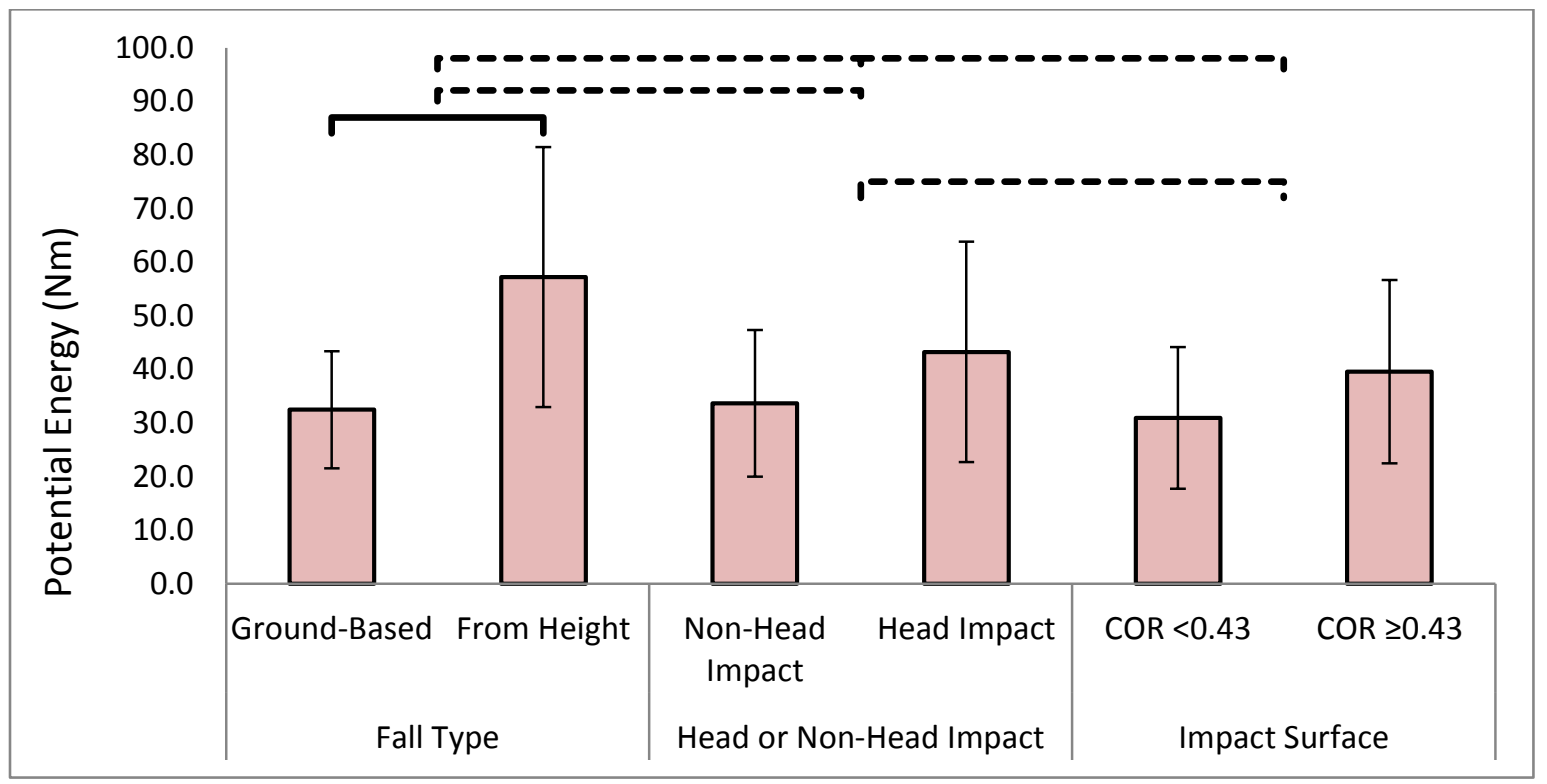

FIGURE 28 - Mean Potential Energy Based on Fall Characteristics. Error Bars Represent \pm SD. Solid Brackets Represent Significant Differences for Main Effects and Dashed Brackets Represent Significant Interactions ( $p<0.05$ )

\section{$\underline{\text { F. Impeded Falls }}$}

There were 9 impeded fall events with biomechanical data that resulted in a child impacting an object prior to impacting the ground in a fall. For impeded falls, the child came into contact with objects such as room furniture, room walls, the playground slide, the playground slide metal support pole, or playground "mushrooms" (FIGURE 29). 


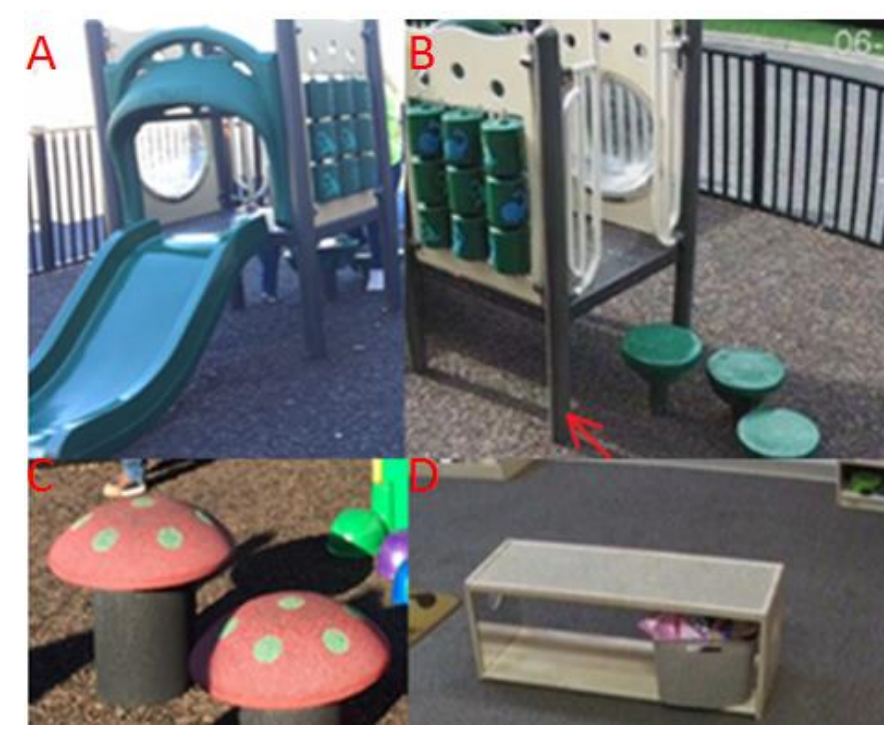

FIGURE 29 - Impacted Objects for Impeded Falls. (A) Playground Slide, (B) Playground Metal Support Pole, (C) Playground Mushrooms, (D) Room Furniture

All of these falls had head impacts. For the objects that the children came into contact with, the surface COR values were lower than all ground surfaces with the exception of the playground "mushrooms". The majority of impeded falls were ground based (78\%). In comparison of impeded and non-impeded falls (TABLE VI), mean head biomechanical measures for impeded falls were greater for peak resultant linear head acceleration, peak resultant rotational head acceleration, peak resultant rotational head velocity, and $\mathrm{HIC}_{15}$, while mean impact duration was considerably shorter (FIGURE 30). 
TABLE VI

MEAN, SD, AND RANGE OF HEAD BIOMECHANICAL MEASURES FOR IMPEDED FALLS AND NON-IMPEDED FALLS (FREE FALLS)

\begin{tabular}{|c|c|c|c|c|}
\hline & \multicolumn{2}{|c|}{ Impeded Falls } & \multicolumn{2}{c|}{ Non-Impeded Falls } \\
\hline & \multicolumn{2}{|c|}{$\mathrm{N}=9$} & \multicolumn{2}{c|}{$\mathrm{N}=93$} \\
\hline $\begin{array}{c}\text { Biomechanical } \\
\text { Measure }\end{array}$ & Mean \pm SD & Range & Mean \pm SD & Range \\
\hline $\begin{array}{c}\text { Peak Resultant } \\
\text { Linear Head } \\
\text { Acceleration (g) }\end{array}$ & $26.40 \pm 12.87$ & $12.00-50.20$ & $15.84 \pm 3.00$ & $12.00-30.90$ \\
\hline $\begin{array}{c}\text { Peak Resultant } \\
\text { Rotational Head } \\
\text { Acceleration } \\
\text { (rad/s^2) }\end{array}$ & $2978 \pm 1950$ & $1000-6800$ & $1703 \pm 801$ & $500-4300$ \\
\hline $\begin{array}{c}\text { Peak Resultant } \\
\text { Linear Head } \\
\text { Velocity (m/s) }\end{array}$ & $1.76 \pm 0.61$ & $0.90-3.40$ & $2.33 \pm 0.67$ & $0.60-3.90$ \\
\hline $\begin{array}{c}\text { Peak Resultant } \\
\text { Rotational Head } \\
\text { Velocity (rad/s) }\end{array}$ & $11.68 \pm 5.54$ & $3.60-23.50$ & $9.58 \pm 4.34$ & $2.60-21.60$ \\
\hline \multicolumn{1}{|c|}{ HIC15 } & $14.02 \pm 10.13$ & $2.20-34.90$ & $7.74 \pm 4.05$ & $1.30-17.40$ \\
\hline $\begin{array}{c}\text { Impact Duration } \\
\text { (ms) }\end{array}$ & $12.00 \pm 5.10$ & $6.00-20.00$ & $21.90 \pm 5.70$ & $6.00-33.00$ \\
\hline
\end{tabular}




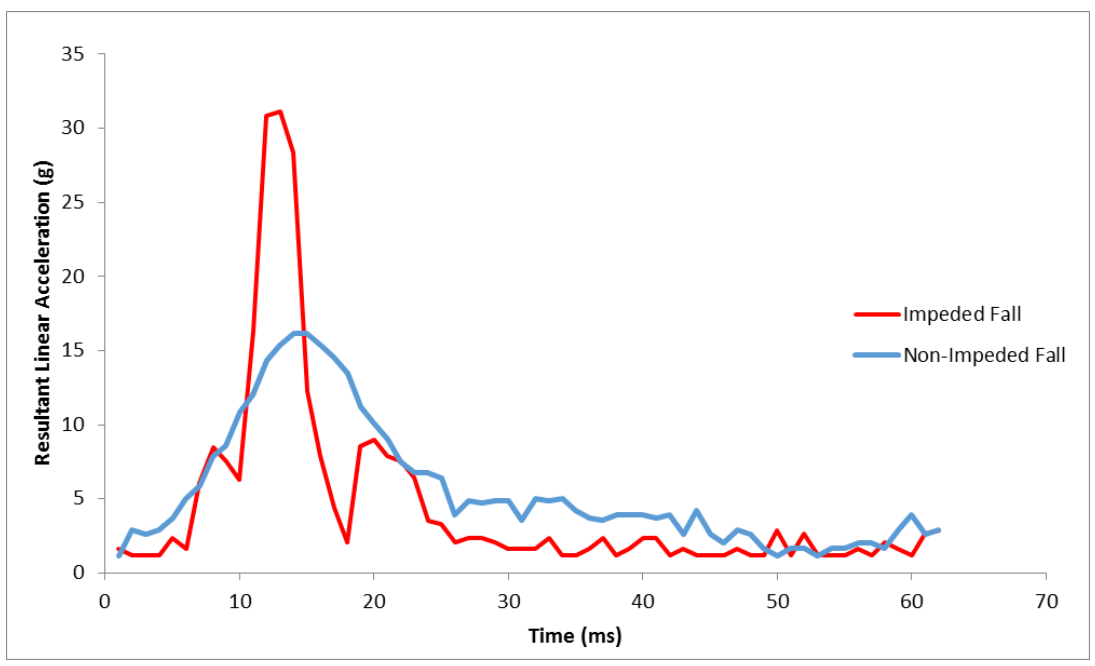

FIGURE 30 - Representative Resultant Linear Head Acceleration Time History for Impeded Fall versus Non-Impeded Fall (Free Fall)

In this study maximum values of peak resultant linear head acceleration, rotational head acceleration, rotational head velocity, and $\mathrm{HIC}_{15}$ occurred in impeded falls. The maximum peak resultant linear head acceleration (50.2 g) occurred in a ground based fall when a subject made head contact with room furniture (FIGURE 31) during descent. 


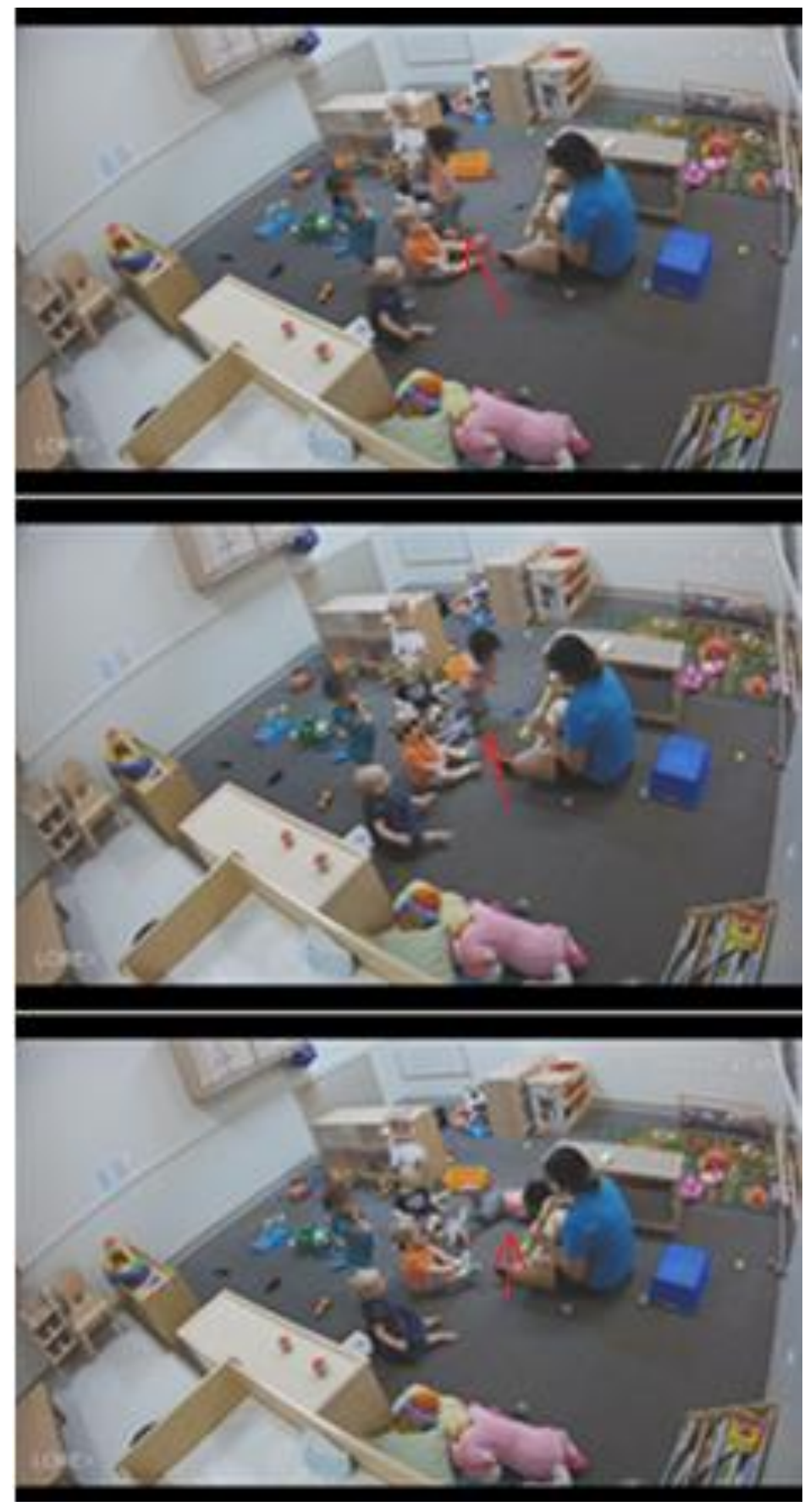

FIGURE 31 - Fall Event that Resulted in Maximum Peak Resultant Linear Head Acceleration

The maximum values for peak resultant rotational head acceleration, rotational head velocity, and $\mathrm{HIC}_{15}$ occurred during a different impeded fall event, a ground based fall when a subject made posterior head contact with the playground slide. 


\section{DISCUSSION}

\section{A. Head Injury Outcomes and Head Injury Risk}

This was the first in situ study to evaluate head biomechanics in children involved in falls. In over one hundred (102) video-recorded falls involving young children in a childcare setting, no head injuries were observed that required medical attention or that led to incident reports generated by daycare center staff.. This is an important finding since controversy exists regarding whether severe head injuries can result from shortdistance falls involving children. In the observed falls, mean and maximum values obtained for biomechanical measures associated with head injury risk such as peak resultant linear accelerations, peak resultant rotational head accelerations, and Head Injury Criteria (HIC) values were well below proposed injury tolerance limits for children. Therefore, head injuries would not be expected in these common short-distance falls.

Peak resultant linear head acceleration is often used as predictive tool for assessing focal type head injuries in children, and is frequently measured in numerous studies. There have been several tolerance limits of peak linear head acceleration proposed for children based on accident reconstructions or pediatric head-first fall experiments. Cory proposed peak linear acceleration limits for children (age unspecified) between $50-200 \mathrm{~g}$ (Cory, 2001). Where $50 \mathrm{~g}$ is the maximum value before injury can occur and $200 \mathrm{~g}$ is the value for fatal injury. Sturtz proposed limits of $86 \mathrm{~g}$ for a 3-yearold (Stürtz, 1980). The limit represents the value where moderate or serious head injuries could occur. Mohan proposed limits of $200-250 \mathrm{~g}$ for ages between 1-10-years-old (Mohan, 1979). All falls in this study resulted in peak resultant linear head accelerations 
below limits proposed by Mohan and Sturtz. In this study, one fall where the child made anterior head contact with room furniture in a ground based fall produced a maximum linear head acceleration value of $50.2 \mathrm{~g}$ which was slightly above the threshold value before injury proposed by Cory (2001). This maximum value suggests that there was a possibility of head injury, but the child did not sustain any head injury. Since peak acceleration values were below linear acceleration tolerance limits, focal type head injuries would not be expected in these common short-distance falls.

HIC is a measure of the likelihood of head injury for head impacts and was initially developed to assess head injury risk in motor vehicle crash testing, but is also used in assessing head injury risk in falls. HIC values are based on resultant linear head acceleration and impact duration. Injury thresholds for children of different ages are available for a 6-year-old, 3-year-old, and 1-year-old child. The $\mathrm{HIC}_{15}$ limits established for the 6, 3, and 1-year-old are 700, 570, and 390 respectively (Eppinger, 1999). All $\mathrm{HIC}_{15}$ values for falls in this study were well below the proposed injury limits. The maximum value of 35 was $9 \%$ of the limit for a 12 -month-old and was $6 \%$ of the limit for a 3-year-old. Therefore, contact type head injuries would not be expected in common short-distance falls observed in this study.

Similar to linear head acceleration being associated with focal type head injuries, rotational head accelerations have been associated with diffuse head injuries such as concussion and diffuse axonal injury (DAI). Ommaya estimated rotational head accelerations associated with concussion and severe DAI for adults, young children, and infants (Ommaya, 2002). Estimated values for concussion were $4,500 \mathrm{rad} / \mathrm{s}^{2}$ for adults and $10,000 \mathrm{rad} / \mathrm{s}^{2}$ for infants. Estimated values for severe DAI were $18,000 \mathrm{rad} / \mathrm{s}^{2}$ for 
young children and $40,000 \mathrm{rad} / \mathrm{s}^{2}$ for infants. In addition to proposing peak linear head acceleration tolerance limits, Sturtz proposed rotational head acceleration tolerance limits of $9,100 \mathrm{rad} / \mathrm{s}^{2}$ for head impacts less than $10 \mathrm{~ms}$. All values obtained for rotational head acceleration in this study were well below proposed limits by Ommaya and Sturtz for children and infants. However, two impeded falls with head contact prior to impact with the ground produced peak rotational head acceleration values of 5,400 $\mathrm{rad} / \mathrm{s}^{2}$ and 6,800 $\mathrm{rad} / \mathrm{s}^{2}$ (maximum value), which resulted in peak rotational head accelerations above Ommaya's proposed limit for concussion in adults of $4,500 \mathrm{rad} / \mathrm{s}^{2}$. No falls resulted in rotational accelerations exceeding 7,000 rad/s $\mathrm{s}^{2}$ which indicate that diffuse head injuries would not be expected in common short-distance falls in this study.

\section{$\underline{\text { B. Head Biomechanical Measures }}$}

Impeded falls (i.e. where the head impacted an object during fall decent) that resulted in head impacts with relatively stiff surfaces (e.g. furniture, metal support pole, playground slide, drywall) were associated with greater head injury risk than all other falls observed. Although impeded falls produced maximum values for multiple biomechanical measures associated with head injury risk, no child sustained a head injury, and biomechanical measures were still below published injury tolerance limits for children. Mean values for peak resultant linear head acceleration, peak resultant rotational head acceleration, and $\mathrm{HIC}_{15}$ were approximately $70 \%$ greater than the mean values associated with non-impeded falls. Mean impact duration was approximately half of the mean impact duration for non-impeded falls. No previous study has evaluated biomechanical measures in impeded falls involving children. Previous anthropomorphic testing device (ATD) fall studies have not evaluated falls that impact surfaces other than 
the ground during the fall. Comparing head biomechanical measures between impeded and non-impeded falls suggests that fall dynamics have an effect on head biomechanical measures and thus, potentially head injury risk.

For fall characteristics examined, whether falls occurred with head or without head impact had the greatest effect on biomechanical head measures. Falls with head impact were associated with greater peak accelerations and shorter impact durations than falls without head impact. Unlike previous fall studies, this study examined differences in biomechanical measures for falls with and without head impact. A majority of previous pediatric fall studies examined head contact with different ground surfaces in fall experiments using ATDs. Unlike fall experiments with ATDs where fall dynamics and head impact can be controlled, this study could not control fall dynamics and whether head impact occurred while monitoring falls involving human subjects. The results of this study indicate that falls with head impact were associated with greater mean peak resultant linear head accelerations, greater mean peak resultant rotational head accelerations, and shorter impact durations than falls without head impact. Mean peak linear and rotational head acceleration values for head impacts were over $30 \%$ greater than non-head impacts. Both fall events that produced the maximum linear and rotational head acceleration were falls that occurred with head impact. Impact durations for head impacts were approximately $37 \%$ shorter than falls without head impact, which can be attributed to the abrupt stop of the head at impact. Shorter impact durations were associated with greater accelerations than longer impact durations. Longer durations allow for the impact to be spread over a longer time duration, which lowers peak acceleration values. When examining linear head velocity based on falls with and without 
head impact, there was an unexpected finding; falls without head impact were associated with significantly greater linear head velocities than falls with head impact. These findings can be explained by the method used to obtain linear head velocity, which was integration of peak linear head acceleration. Although falls with head impacts had greater peak accelerations than non-head impacts, the peak durations were shorter than non-head impacts. Therefore, the acceleration time history curve area for falls without head impacts was greater than the area for falls with head impact. This larger area led to greater linear head velocities than for falls with head impacts.

Falls onto surfaces with low coefficient of restitution (COR) (ex: furniture) were associated with greater head injury risk than falls onto surfaces with high COR (ex: playground synthetic mulch). COR measurements were conducted to quantify the elasticity of the surface, where surfaces with higher COR have greater elasticity than surfaces with lower COR. Surfaces with higher elasticity will have greater deformations during impact and will absorb and return energy during rebound. Greater deformations during impact leads to increases in impact duration and thus, lower peak acceleration values, which was consistent with the study's findings. Surfaces with low COR (i.e. less elastic) were associated with having greater accelerations and shorter impact durations than surfaces with high COR (i.e. more elastic). Greater peak linear accelerations occurred for falls onto surfaces with lower COR $(18.67 \mathrm{~g} \pm 7.78)$ than falls onto surfaces with higher COR $(15.50 \mathrm{~g} \pm 2.60)$. Similarly, previous studies have also shown that there is an increase in peak linear head acceleration for surfaces with lower COR. Thompson conducted a study that examined head injury risk in feet-first fall experiments with a 12month-old ATD and found that less resilient surfaces such as linoleum over concrete, 
linoleum over wood, and wood were associated with greater peak linear head accelerations, peak anterior-posterior rotational head accelerations, $\mathrm{HIC}_{15}$, and shorter impact duration than more resilient surfaces such as padded carpet and playground foam (Thompson, 2009). Additionally, Bertocci found that there was in increase in peak linear head accelerations and $\mathrm{HIC}_{15}$ for bed fall experiments with a Hybrid-II-3-year-old ATD for surfaces with lower COR such as wood than surfaces with greater COR such as playground foam (Bertocci, 2003). Prange conducted fall experiments with a 1.5-monthold ATD and similarly to Thompson, found that falls onto less elastic surfaces resulted in greater peak rotational head accelerations than falls onto more elastic surfaces (Prange, 2003). Findings in our study are similar, less elastic surfaces were associated with greater peak linear head accelerations and $\mathrm{HIC}_{15}$ values than that for more elastic surfaces. However, our findings showed that impact surface COR did not have an effect on impact duration alone, but that the interaction between head or non-head impacts and impact surface COR had a significant effect on impact duration. The findings indicate that falls occurring with head impacts onto less elastic surfaces were associated with the shortest impact durations. Our findings showed that mean peak rotational head acceleration was greater for falls onto surfaces with lower COR than falls onto surfaces with higher COR, but they were not significantly greater. The lack of significance may be due to the high standard deviation and wide range of peak rotational head acceleration for falls onto both high and low COR surfaces. Peak rotational head acceleration ranged from $600-6800 \mathrm{rad} / \mathrm{s}^{2}$. However, the maximum value of peak rotational head acceleration occurred with a fall impacting a surface with low COR. Impact surface was found to have a significant effect on head biomechanical measures, whereas falls onto low COR 
surfaces were associated with greater biomechanical measures associated with head injury risk.

Fall type did not have a significant effect on head biomechanical measures associated with head injury risk. Previous ATD fall studies have conflicting findings on whether increases in height lead to increases in biomechanical head measures. Coats found a significant increase in peak rotational acceleration with increased fall heights in head-first fall experiments using a 1.5-month-old ATD (Coats, 2008). Bertocci found that increase in height resulted in an increase in peak linear head acceleration and head injury risk for experimental feet-first falls using a Hybrid II-3-year-old ATD (Bertocci, 2004). Similar to Coats, Ibrahim found that rotational head acceleration nearly doubled for falls from $0.6 \mathrm{~m}$ compared to $0.3 \mathrm{~m}$ for head-first fall experiments using an 18-month-old ATD (Ibrahim, 2010). Conversely, Thompson (2009) found that the shortest fall height tested, a ground based fall $(0.46 \mathrm{~m})$, produced greater peak linear and rotational head acceleration and shorter impact durations than falls from heights $(0.69 \mathrm{~m}$ and $1.20 \mathrm{~m})$ in feet-first fall experiments using a 12-month-old ATD. Thompson attributed the differences in findings to the fall dynamics and initial position of the ATD. Feet-first falls from heights resulted in knee and hip flexion which absorbed greater amounts of energy than ground based falls. The results of our study indicate there were no significant differences in head biomechanical measures for different fall types (ground based vs. falls from heights). Mean peak linear head accelerations were greater for falls from a height compared to ground based falls, but this difference was not significant. Additionally, mean impact duration for falls from heights was shorter than ground based falls, but this difference was not significant. The lack of significance in head 
biomechanical measures based on fall type could be attributed to the sample size and severity of falls between groups. The majority of falls were ground based (85\%) and a majority of the impeded falls (associated with greater head biomechanical measures) were also ground based falls (78\%). Additionally, the mean fall height for non-ground based falls was relatively low $(0.49 \mathrm{~m} \pm 0.22)$. A more even distribution of falls across groups and if falls occurred at greater heights may have led to significant differences in head biomechanical measures based on fall type.

In this study child characteristics were not found to have an effect on head biomechanical measures. However, previous studies have indicated an increase in head biomechanical measures for different ATD characteristics (i.e. varying ATD age representations). Ibrahim found that toddler surrogate head accelerations were more than doubled that previously measured infant surrogates under the same head-first fall conditions. Bertocci (2004) reported linear head acceleration up to six times greater when using a 3-year-old ATD compared to Thompson (2009) using a 12-month-old ATD in feet-first experiments. The increase in acceleration was likely due to the different age representation and size of the ATDs, Bertocci used a larger ATD (Hybrid II-3-year-old) than Thompson (12-month-old CRABI ATD). In our study child characteristics did not have an effect on head biomechanical measures. Mean biomechanical measures obtained in this study were similar across child age groups ( $<24$ vs. $\geq 24$ months $)$ and child mass groups ( $<12.36$ vs. $\geq 12.36 \mathrm{~kg}$ ). The lack of difference in biomechanical measures may be attributed to the lower number of falls involving the older age group ( $\geq 24$ months) and greater mass $(\geq 12.26 \mathrm{~kg})$ in this study. The majority of falls occurred in the younger age group $(87.3 \%)$ and in the lesser mass group $(84.3 \%)$. 
Previous ATD fall studies have reported greater head accelerations and $\mathrm{HIC}_{15}$ values across multiple fall test conditions than the values obtained in this study.

Thompson's feet-first falls study (2009) reported greater mean and maximum peak linear head acceleration, peak rotational head acceleration, and $\mathrm{HIC}_{15}$ values. Estimated mean values in Thompson's study for the shortest fall height tested $(0.46 \mathrm{~m}$ from COM to ground), which was closest to mean fall height of this study, were compared to mean values for falls with head impacts (TABLE VII).

TABLE VII

COMPARISON OF MEAN HEAD BIOMECHANICAL MEASURES FROM THOMPSON'S FEET-FIRST FALL STUDY (2009)

\begin{tabular}{|c|c|c|}
\hline Measure & $\begin{array}{c}\text { Thompson (2009) } \\
0.46 \text { m Fall Heights }\end{array}$ & $\begin{array}{c}\text { Falls with Head } \\
\text { Impacts in This } \\
\text { Study }\end{array}$ \\
\hline Fall Height (m) & Mean & Mean \\
\hline $\begin{array}{c}\text { Peak Linear Head } \\
\text { Acceleration (g) }\end{array}$ & 0.46 & 0.37 \\
\hline $\begin{array}{c}\text { Peak Rotational } \\
\text { Head Acceleration } \\
\left(\text { rad/s }{ }^{2}\right)\end{array}$ & 58.2 & 20.6 \\
\hline $\begin{array}{c}\text { HIC } \\
\text { 15 }\end{array}$ & 4,740 & 2,265 \\
\hline $\begin{array}{c}\text { Impact Duration } \\
(\mathrm{ms})\end{array}$ & 83.0 & 9.0 \\
\hline
\end{tabular}


The mean peak linear head acceleration for $0.46 \mathrm{~m}$ fall experiments from Thompson was nearly triple (58.2 g vs. $20.6 \mathrm{~g}$ ) and the peak rotational head acceleration was more than double $\left(4,740 \mathrm{rad} / \mathrm{s}^{2}\right.$ vs. $\left.2,265 \mathrm{rad} / \mathrm{s}^{2}\right)$ the mean value for falls with head impacts obtained in this study. The mean $\mathrm{HIC}_{15}$ in Thompson's experiment for $0.46 \mathrm{~m}$ falls was over nine times greater than the mean HIC for falls with head impacts in this study (83 vs 9). Additionally, Thompson reported a mean impact duration for $0.49 \mathrm{~m}$ falls that was longer than the mean impact duration for falls with head impacts in this study (19.4 ms vs 14.6 ms). Longer durations in Thompson's findings could be attributed to differences in fall dynamics and/or differences in head and neck properties of an ATD compared to that of a child. Bertocci's feet-first fall study with a 3-year-old ATD (2004) reported a mean linear head acceleration of $80 \mathrm{~g}$ for $0.69 \mathrm{~m}$ falls. In comparison, Bertocci's mean linear head acceleration was over four times greater than the mean linear head acceleration for falls from height with head impacts $($ Mean $=0.50 \mathrm{~m})$ obtained in this study $(19.3 \mathrm{~g})$ (rotational head acceleration was not reported). Bertocci (2003) conducted bed fall experiments at $0.68 \mathrm{~m}$ and reported mean peak linear head acceleration and $\mathrm{HIC}_{15}$ values greater than the mean values for falls from height with head impacts obtained in this study. The mean linear head acceleration was over nine times greater (179.8 g vs. $19.3 \mathrm{~g}$ ) and $\mathrm{HIC}_{15}$ values were approximately 19 times greater (155.3 vs. 8.2) for falls from height with head impacts obtained in this study. Prange (2003) examined rotational head acceleration in head-first falls with a 1.5-month-old ATD and reported mean rotational head accelerations for $0.3 \mathrm{~m}$ onto carpet $\left(>25,000 \mathrm{rad} / \mathrm{s}^{2}\right)$ and onto concrete $(>35,000$ $\mathrm{rad} / \mathrm{s}^{2}$ ). Prange's mean rotational head acceleration values for $0.3 \mathrm{~m}$ falls, which was similar to the mean fall height of this study $(0.31 \mathrm{~m})$, were greater than the mean value 
for falls with head impacts in this study. Prange's mean value for rotational head acceleration was over 11 times greater for falls onto carpet and was over 15 times greater than the mean value for falls with head impacts found in this study $\left(2,265 \mathrm{rad} / \mathrm{s}^{2}\right)$. There are several explanations for differences in head biomechanical measures in this study compared to previous ATD fall studies. One explanation is the difference in fall test conditions. ATD fall studies control the initial position and fall height of the ATD which influences fall dynamics. Mean peak values could be greater due to the consistency of repeated falls and that ATD fall studies generally tested falls from greater heights than the heights observed in this study. Additionally, some ATD studies oriented the ATD such that head-first impact occurred, whereas in our falls children typically impacted another body region before head impact with the ground. The differences in ATD characteristics versus human subjects could also explain the differences in findings. The lack of ATD biofidelity could lead to biomechanical measurements that differ from those involving actual children. Specifically, ATDs skull stiffness and neck stiffness likely differ from that of a human child (Pierce, 2006). Inaccurate ATD representations of children could lead to inaccurate results. This study was able to avoid these concerns by obtaining head biomechanical measures on human subjects. Additionally, human subjects have the ability to brace themselves during a fall (active muscle response) while an ATD cannot. Currently, ATD fall experiments are often used to assess biomechanical measures in forensic investigations with a stated fall history. If biomechanical measures are consistently greater for ATD experiments compared to the measures obtained from actual children under the same conditions, assessments of injury risk could be inaccurate and misleading.. 


\section{Whole-Body Biomechanical Measures}

Whole-body biomechanical measures have been analyzed in previous studies to determine if they are associated with injury severity. Lyons \& Oats conducted a study to determine if estimated impact momentum was different for falls that resulted in injuries and falls that resulted in no injuries to children (Lyons, 1993). The study did not find any significant differences in impact momentum between injured and non-injured subjects. An additional study that focused on whole-body biomechanical measures effect on injuries in children during falls came from Thompson (Thompson, 2011). Detailed casebased biomechanical assessments of short-distance household falls for children presenting to the Emergency Department (ED) were used to determine the types and severity of injuries and to investigate the influence of fall environment and biomechanical measures on injury outcomes. Whole-body impact velocity, change in impact moment, and potential energy were estimated for each case to further characterize the fall and were compared between non-injured and injured children. Thompson found that only wholebody impact velocity was different between non-injured and injured children. In comparison to Thompson's findings, this study found mean values of whole-body biomechanical measures such as peak whole-body impact velocity and potential energy that were considerably lower (TABLE VIII). 
TABLE VIII

COMPARISON OF MEAN WHOLE-BODY BIOMECHANICAL MEASURES FROM

THOMPSON'S HOUSEHOLD FALLS STUDY (2011)

\begin{tabular}{|c|c|c|c|c|c|c|}
\hline & \multicolumn{4}{|c|}{ Thompson (2011) } & \multicolumn{2}{|c|}{ This Study } \\
\hline Measure & $\begin{array}{c}\mathrm{N} \\
\text { (Non- } \\
\text { Injured) }\end{array}$ & $\begin{array}{c}\text { Non- } \\
\text { Injured }\end{array}$ & $\begin{array}{c}\mathrm{N} \\
\text { (Injured) }\end{array}$ & Injured & $\begin{array}{c}\text { All Falls } \\
(\mathrm{N}=102)\end{array}$ & $\begin{array}{c}\text { Only Falls from } \\
\text { Height } \\
(\mathrm{N}=15)\end{array}$ \\
\hline Fall Height (m) & 60 & 0.80 & 19 & 0.91 & 0.31 & 0.49 \\
\hline $\begin{array}{c}\text { Whole-Body } \\
\text { Impact Velocity } \\
(\mathrm{m} / \mathrm{s})\end{array}$ & 60 & 4.0 & 19 & 4.3 & 2.4 & 3.03 \\
\hline $\begin{array}{c}\text { Change in } \\
\text { Impact } \\
\text { Momentum } \\
\text { (kgm/s) }\end{array}$ & 26 & 56.2 & 11 & 57.8 & 43.06 & 54.55 \\
\hline $\begin{array}{c}\text { Potential Energy } \\
(\mathrm{Nm})\end{array}$ & 60 & 91.3 & 19 & 107.3 & 36.09 & 57.19 \\
\hline
\end{tabular}

Mean fall height in Thompson's study for both non-injured and injured children was considerably greater than the mean fall height for all falls and the mean fall height for non-ground based falls obtained in this study. In Thompson's study, non-injured children fell at approximately $63 \%$ and injured children fell at approximately $86 \%$ greater heights than the mean height for non-ground based falls in this study $(0.49 \mathrm{~m})$. Mean whole-body impact velocity in Thompson's study for non-injured children was $32 \%$ greater and mean whole-body impact velocity for injured children was $42 \%$ greater than the mean wholebody impact velocity for falls from a height in this study $(3.03 \mathrm{~m} / \mathrm{s})$. Mean change in impact momentum in Thompson's study for both non-injured and injured children had similar values to mean change in impact momentum for falls from a height obtained in this study $(54.55 \mathrm{kgm} / \mathrm{s})$. Mean potential energy for non-injured children was $60 \%$ greater and mean potential energy for injured children was $88 \%$ greater in Thompson's study 
than the mean potential energy for falls from a height in this study $(36.09 \mathrm{Nm})$. The difference in findings may be due to Thompson evaluating falls for children presenting to the ED, which represents a biased sample given that children are typically injured, and the difference in height measurements. Thompson predicted fall heights based on estimates from caregivers which has the potential for inaccuracies. Additionally, Thompson measured fall height from child COM at the beginning of the fall to ground. In this study, fall height was determined by examining video-recordings and height was estimated from child COM at the beginning of the fall (initial position) to child COM at the end of the fall (final position).

The results of our study indicate that falls from height were associated with significantly greater impact velocities, change in impact momentums, and potential energies compared to ground based falls. These findings were expected due to wholebody biomechanical measures being dependent on fall height. The average fall height for non-ground based falls was $0.49 \mathrm{~m}$ while the average height for ground based falls was $0.27 \mathrm{~m}$. These results suggest that there is increase in injury risk for falls from height compared to ground based falls.

Impact surface COR had an effect on whole-body impact velocity and change in impact momentum. Falls onto surfaces with high COR were associated with greater impact velocities and changes in impact momentum than falls onto surfaces with low COR. Change in impact momentum is dependent on COR and increasing COR leads to greater change in impact momentums. Additionally, mean fall heights were greater for surfaces with high COR than surfaces with low COR. A majority of the falls from height occurred on the playground $(73.3 \%)$, which has a relatively higher COR surface. Mean 
fall height for surfaces with high COR was $0.34 \mathrm{~m}$, while mean fall height for surfaces with low COR was $0.26 \mathrm{~m}$.

Several interaction effects were found on whole-body biomechanical measures. There was a significant interaction effect of head or non-head impact and impact surface COR on all whole-body biomechanical measures. These findings could possibly be attributed to the fall height associated with head impact and different COR surfaces. Typically, head impacts onto surfaces with low COR were frequently ground based falls, while head impacts onto surfaces with high COR typically occurred at a greater height due to falls on the playground having a high COR. Increase in fall height would have an increase in potential energy and whole-body impact velocity which would increase change in impact momentum. The three-way interaction of fall type, head or non-head impact, and impact surface COR was significant on all whole-body biomechanical measures. Fall events that occurred at greater heights and onto surfaces with higher COR would produce the greatest whole-body biomechanical measures. Increase in height would increase whole-body impact velocity, change in impact momentum, potential energy, and higher CORs will increase change in impact momentum. Additionally, mean fall height for falls with head impact $(0.37 \mathrm{~m})$ was greater than falls without head impact $(0.28 \mathrm{~m})$. Therefore, whole-body biomechanical measures would be expected to be greatest for falls from height with head impact and onto surfaces with high COR.

\section{Hypotheses Evaluation}

HO1 - There will be an increase in linear and rotational head acceleration and velocity, $H_{15}$, whole-body impact velocity, change in impact momentum, and potential energy for falls from height compared to ground based falls. 
Falls from height were associated with significantly greater whole-body impact velocities, change in impact momentums, and potential energies than ground based falls. However, there were no significant differences in head biomechanical measures based on fall type. The lack of a significant difference could be attributed to the sample size for falls from a height and that fall heights were relatively low for non-ground based falls ( $0.49 \mathrm{~m}$ for non-ground based vs. $0.27 \mathrm{~m}$ for ground based). Thus, there is evidence to reject $\mathrm{H} 01$.

HO2 - There will be a decrease in impact duration and an increase in the remaining head biomechanical measures for falls onto surfaces with lower COR.

Falls onto surfaces with lower COR were only found to be significantly greater for peak linear head acceleration and $\mathrm{HIC}_{15}$ than falls onto surfaces with higher $\mathrm{COR}$. However, the interaction effect between falls with head and non-head impacts and impact surface COR was found to be significant, indicating that head impacts onto surfaces with lower COR were associated with the shortest impact durations. The lack of a significant difference in linear head velocity could be attributed to the shorter impact durations associated for surfaces with lower COR. Shorter impact durations decrease area under the peak, which would result in lower linear head velocities than surfaces wit high COR. The lack of a significant difference in peak rotational head acceleration and velocity between impact surface COR could be attributed to the high standard deviation and wide range for both surfaces. Thus, there is evidence to reject $\mathrm{H} 02$.

H03 - There will be an increase in linear and rotational head acceleration, linear and rotational head velocity, and $\mathrm{HIC}_{15}$ for head impacts compared to non-head impacts. 
Head Impacts were associated with significantly greater peak linear and peak rotational head accelerations than falls without head impacts. Falls with head impacts were associated with greater mean $\mathrm{HIC}_{15}$ and peak rotational head velocities than falls without head impacts, but were not found to be significantly different. Thus, there is evidence to reject $\mathrm{H} 03$. The lack of a significant difference could be attributed to the high standard deviations and wide ranges in both measures for falls with head impacts due to differences in severities of head impacts observed. There was an unexpected finding when examining linear head velocity, where falls without head impacts were associated with greater linear head velocities than falls with head impacts. The findings can be attributed to the shorter impact durations for falls with head impacts than falls without head impacts. Since linear head velocity was determined by integrating peak resultant linear head acceleration, longer impact durations would lead to greater areas under the curve, and thus greater linear head velocities for falls without head impacts compared to falls with head impacts.

\section{E. Clinical and Judicial Relevance}

This study found video-recorded pediatric short-distance falls did not lead to head injuries in children and that fall biomechanical measures were associated with a low likelihood of head injury risk. Differences in biomechanical measures based on fall characteristics suggests that fall characteristics must be considered when evaluating injury risk for a given fall. Falls that resulted in head contact with less resilient objects were associated with greater head biomechanical measures suggesting a higher level of head injury risk. The results of this study could aid forensic investigations in determining if a stated fall history could account for a child's presenting injuries. Additionally, the 
results of this study indicate the importance of documenting fall characteristics such as fall type, impact surface, and whether head impact occurred in falls involving children since they were found to influence biomechanical measures.

\section{$\underline{\text { F. Limitations }}$}

There are several limitations to this study. One limitation is that biomechanical data for all video-recorded falls in this study were not obtained. The SIM G only recorded biomechanical data when peak linear head acceleration met or exceeded a $12 \mathrm{~g}$ threshold. This means falls where head acceleration was below $12 \mathrm{~g}$ would not have SIM G data. There were 456 falls where the SIM G was positioned on the child but were not included in this study due to not obtaining biomechanical data because the SIM G threshold was not met or exceeded. Another potential limitation with the biometric sensor was the possibility of inaccurate head acceleration and velocity data. Inaccurate biomechanical data could have been obtained if a headband was not snuggly fit on the child's head. Headbands were not customized for a single individual but different sizes (i.e. small, medium, large) were fabricated based on head percentile measurements for the child age in this study. Head circumference measurements obtained during the anthropometric measurements were used to approximate the best headband fit for each subject.

There were also some limitations with the video surveillance system at the daycare facility. A small percentage of falls that potentially had biomechanical data were not included in the study due to either the fall not occurring in a monitored area, or that the camera view was blocked. Falls frequently occurred in the daycare center hallway, which was not video monitored, while subjects were being transferred to the playground. A total of 50 falls were excluded due to limitations of video. Of the 50 falls, 9 had 
possible biomechanical data but were not confidently associated with video-recorded falls since the time stamp was not documented. However, none of these falls resulted in injuries to the child.

COR measurements of daycare surfaces may be inaccurate when surfaces were not level and the rebounding ball contacted the side of the tube during testing. Additionally, some COR values were estimated based upon material construction. For example, due to the lack of a flat surface for the slide structural support pole, the COR was not directly obtained from that surface. Instead, COR measurements were conducted on a flat metal surface and were used to estimate COR values of the pole. However, the values would still be expected to be in the same low impact surface COR group.

Another limitation of this study is the estimation of fall heights. Although video recordings of the fall allowed for estimations of the height, exact accuracy of height could be in question. Fall heights were based on the initial COM of the child to the final $\mathrm{COM}$ of the child. However, falls do not always start from a standing position and end in a prone or supine position. Initial and final positions of the fall were frequently from or to knees, knees and hands, buttocks, side, and combinations thereof. Furthermore, any inaccuracy with fall height estimation could potentially have led to errors in estimations for impact velocities, change in impact momentums, and potential energies. An additional limitation with the estimation of whole-body biomechanical measures was that initial velocities of the child prior to the fall were not accounted for; initial velocity was assumed to be zero. This would tend to lead to an underestimation of biomechanical measures in cases where the child had initial motion. Another limitation with the estimation of whole-body biomechanical measures was that the child was modeled as a 
lumped mass, which may not be an accurate representation of a child during a fall. There are fall events where particular body segments could make contact with the ground while others do not. A more appropriate model would be a multi-body model representing body segments.

Another limitation was that given that this was a pilot study, a power analysis to determine the adequate sample of falls was not conducted; data from this study should be used to perform a power analysis as a next step. Additionally, while examining interactions of fall characteristics on biomechanical measures, the sample size was low for certain factor combinations, which could lead to inaccurate findings. Moreover, some biomechanical measures used in the analysis failed to meet analysis of variance (ANOVA) assumptions of normality or homogeneity of variance. While examining effects of child characteristics on biomechanical measures, whole-body impact velocity and potential energy violated ANOVA assumptions. Additionally, while examining the effects of fall characteristics on biomechanical measures, $\mathrm{HIC}_{15}$, whole-body impact velocity, and potential energy violated ANOVA assumptions.

\section{G. Future Work and Recommendations}

This pilot study is the first step in a broader study in evaluating biomechanical measures experienced in video monitored falls involving children. Data from this pilot study included a quarter of the data that will be used for the larger study; this study will provide preliminary findings for the larger study. The larger study will continue data collection at the same daycare facility with the same methods described. Biomechanical data will be continued to be collected with the same SIM G biometric device. Future work will have an emphasis on injury outcomes and will determine the rate of head injury 
for falls. A predictive model will be developed to estimate head impact acceleration and velocity based upon fall, environment, and child characteristics. Additionally, a searchable web-based knowledge base will be developed to determine if fall histories are consisted with the stated cause through biomechanical assessment.

The on-going larger study will address a majority of the limitations that occurred in this pilot study. A power analysis will be conducted to determine an adequate sample size of falls and this number of falls will be obtained. The larger study will investigate the role that fall dynamics have on biomechanical measures and injury risk. Improvements on estimating whole-body biomechanical measures will be made. Since all falls do not have the same fall dynamics, whole-body biomechanical measures will be modeled accordingly. Additionally, motion capture/analysis will be examined to verify estimates of subject initial velocities. 


\section{CONCLUSION}

This pilot study obtained and examined biomechanical measures for naturally occurring pediatric falls in a video monitored setting. The effect of child characteristics (child age and child mass) and fall characteristics (fall type, head or non-head impact, and impact surface) on head and whole-body biomechanical measures were assessed. Significant differences in biomechanical measures based on child and fall characteristics were evaluated to determine which factors were associated with greater biomechanical measures associated with injury risk. Falls involving head impacts were associated with greater head accelerations with shorter impact durations and thus, would be associated with an increased likelihood of injury risk than falls without head impacts. Head biomechanical measures also increased for falls onto stiffer surfaces (lower COR) by producing greater $\mathrm{HIC}_{15}$ values than falls onto less stiff surfaces. Falls from height resulted in an increase in whole-body biomechanical measures such as whole-body impact velocity, change in impact momentum, and potential energy. This study also reported head biomechanical measures for fall events that resulted in impacts with objects prior to impact with the ground during the fall. These falls had higher levels of head biomechanical measures than any other falls. However, no falls in this study resulted in injury to any child hat required medical care or that caused an incident report to be generated by daycare center staff. Thus, these falls have a low level of injury risk. The findings of this study indicate the importance of accounting for fall characteristics such as, fall type, whether there was head impact, impact surface properties, and fall dynamics when evaluating biomechanical measures and injury risk for short-distance falls. 
Outcomes of this study have the capability to aid forensic investigations in determining if a stated fall history could account for a child's presenting injuries. 


\section{REFERENCES CITED}

Barlow, B., Niemirska, M., Gandhi, R. P., and Leblanc, W. 1983. Ten years of experience with falls from a height in children. J Pediatr Surg. 18: 509-11.

Bechtel, K., Stoessel, K., Leventhal, J. M., Ogle, E., Teague, B., Lavietes, S., Banyas, B., Allen, K., Dziura, J., and Duncan, C. 2004. Characteristics that distinguish accidental from abusive injury in hospitalized young children with head trauma. Pediatrics. 114: 165-8.

Bertocci, G. E., Pierce, M. C., Deemer, E., Aguel, F., Janosky, J. E., and Vogeley, E. 2003. Using test dummy experiments to investigate pediatric injury risk in simulated short-distance falls. Arch Pediatr Adolesc Med. 157: 480-6.

Bertocci, G. E., Pierce, M. C., Deemer, E., Aguel, F., Janosky, J. E., and Vogeley, E. 2004. Influence of fall height and impact surface on biomechanics of feet-first free falls in children. Injury. 35: 417-24.

Billmire, M. E., and Myers, P. A. 1985. Serious head injury in infants: accident or abuse? Pediatrics. 75: 340-2.

Caffey, J. 1974. The whiplash shaken infant syndrome: manual shaking by the extremities with whiplash-induced intracranial and intraocular bleedings, linked with residual permanent brain damage and mental retardation. Pediatrics. 54: 396-403.

Chadwick, D. L., Bertocci, G., Castillo, E., Frasier, L., Guenther, E., Hansen, K., Herman, B., and Krous, H. F. 2008. Annual risk of death resulting from short falls among young children: less than 1 in 1 million. Pediatrics. 121: 1213-24.

Choi, W. J., Wakeling, J. M., and Robinovitch, S. N. 2015. Kinematic analysis of videocaptured falls experienced by older adults in long-term care. J Biomech. 48: 91120 .

Coats, Brittany, and Margulies, Susan S. 2008. Potential for head injuries in infants from low-height falls. Journal of Neurosurgery: Pediatrics. 2: 321-30.

Cory, C. Z., and Jones, B. M. 2003. Can shaking alone cause fatal brain injury? A biomechanical assessment of the Duhaime shaken baby syndrome model. Med Sci Law. 43: 317-33.

Cory, C. Z., Jones, M. D., James, D. S., Leadbeatter, S., and Nokes, L. D. 2001. The potential and limitations of utilising head impact injury models to assess the 
likelihood of significant head injury in infants after a fall. Forensic Sci Int. 123: 89-106.

Duhaime, A. C., Alario, A. J., Lewander, W. J., Schut, L., Sutton, L. N., Seidl, T. S., Nudelman, S., Budenz, D., Hertle, R., Tsiaras, W., and et al. 1992. Head injury in very young children: mechanisms, injury types, and ophthalmologic findings in 100 hospitalized patients younger than 2 years of age. Pediatrics. 90: 179-85.

Duhaime, A. C., Gennarelli, T. A., Thibault, L. E., Bruce, D. A., Margulies, S. S., and Wiser, R. 1987. The shaken baby syndrome. A clinical, pathological, and biomechanical study. J Neurosurg. 66: 409-15.

Duma, S. M., Manoogian, S. J., Bussone, W. R., Brolinson, P. G., Goforth, M. W., Donnenwerth, J. J., Greenwald, R. M., Chu, J. J., and Crisco, J. J. 2005. Analysis of real-time head accelerations in collegiate football players. Clin J Sport Med. 15: 3-8.

Eppinger, Rolf, Sun, Emily, Bandak, Faris, Haffner, Mark, Khaewpong, Nopporn, Maltese, Matt, Kuppa, Shashi, Nguyen, Thuvan, Takhounts, Erik, and Tannous, Rabih. 1999. Development of improved injury criteria for the assessment of advanced automotive restraint systems-II. National Highway Traffic Safety Administration. 1-70.

Fang, X., Brown, D. S., Florence, C. S., and Mercy, J. A. 2012. The economic burden of child maltreatment in the United States and implications for prevention. Child Abuse Negl. 36: 156-65.

Feldman, K. W., Bethel, R., Shugerman, R. P., Grossman, D. C., Grady, M. S., and Ellenbogen, R. G. 2001. The cause of infant and toddler subdural hemorrhage: a prospective study. Pediatrics. 108: 636-46.

Geddes, J. F., Hackshaw, A. K., Vowles, G. H., Nickols, C. D., and Whitwell, H. L. 2001. Neuropathology of inflicted head injury in children. I. Patterns of brain damage. Brain. 124: 1290-8.

Geddes, J. F., Vowles, G. H., Hackshaw, A. K., Nickols, C. D., Scott, I. S., and Whitwell, H. L. 2001. Neuropathology of inflicted head injury in children. II. Microscopic brain injury in infants. Brain. 124: 1299-306.

Helfer, Ray E., Slovis, Thomas L., and Black, Mary. 1977. Injuries Resulting When Small Children Fall Out of Bed. Pediatrics. 60: 533-35.

Ibrahim, Nicole G. , and Margulies, Susan S. . 2010. Biomechanics of the toddler head during low-height falls: an anthropomorphic dummy analysis. Journal of Neurosurgery: Pediatrics. 6: 57-68. 
Joyce, T., and Huecker, M. R. 2018. 'Pediatric Abusive Head Trauma (Shaken Baby Syndrome).' in, StatPearls (StatPearls Publishing: Treasure Island (FL)).

Kakara, H., Nishida, Y., Yoon, S. M., Miyazaki, Y., Koizumi, Y., Mizoguchi, H., and Yamanaka, T. 2013. Development of childhood fall motion database and browser based on behavior measurements. Accid Anal Prev. 59: 432-42.

Karibe, H., Kameyama, M., Hayashi, T., Narisawa, A., and Tominaga, T. 2016. Acute Subdural Hematoma in Infants with Abusive Head Trauma: A Literature Review. Neurol Med Chir (Tokyo). 56: 264-73.

Kelley, M. E., Kane, J. M., Espeland, M. A., Miller, L. E., Powers, A. K., Stitzel, J. D., and Urban, J. E. 2017. Head impact exposure measured in a single youth football team during practice drills. J Neurosurg Pediatr. 20: 489-97.

Kivlin, J. D. 2001. Manifestations of the shaken baby syndrome. Curr Opin Ophthalmol. 12: $158-63$.

Kraus, J. F., Rock, A., and Hemyari, P. 1990. Brain injuries among infants, children, adolescents, and young adults. American Journal of Diseases of Children. 144: 684-91.

Lyons, T. J., and Oates, R. K. 1993. Falling out of bed: a relatively benign occurrence. Pediatrics. 92: 125-7.

Maguire, S., Pickerd, N., Farewell, D., Mann, M., Tempest, V., and Kemp, A. M. 2009. Which clinical features distinguish inflicted from non-inflicted brain injury? A systematic review. Arch Dis Child. 94: 860-7.

Margulies, S. S., and Thibault, L. E. 1992. A proposed tolerance criterion for diffuse axonal injury in man. J Biomech. 25: 917-23.

Mohan, D., Bowman, B. M., Snyder, R. G., and Foust, D. R. 1979. A Biomechanical Analysis of Head Impact Injuries to Children. Journal of Biomechanical Engineering. 101: 250-60.

Nadarasa, J., Deck, C., Meyer, F., Willinger, R., and Raul, J. S. 2014. Update on injury mechanisms in abusive head trauma--shaken baby syndrome. Pediatr Radiol. 44 Suppl 4: S565-70.

Ommaya, A. K., Goldsmith, W., and Thibault, L. 2002. Biomechanics and neuropathology of adult and paediatric head injury. Br J Neurosurg. 16: 220-42.

Ommaya, A. K., and Hirsch, A. E. 1971. Tolerances for cerebral concussion from head impact and whiplash in primates. J Biomech. 4: 13-21. 
Paiva, W. S., Soares, M. S., Amorim, R. L., de Andrade, A. F., Matushita, H., and Teixeira, M. J. 2011. Traumatic brain injury and shaken baby syndrome. Acta Med Port. 24: 805-8.

Paul, A. R., and Adamo, M. A. 2014. Non-accidental trauma in pediatric patients: a review of epidemiology, pathophysiology, diagnosis and treatment. Transl Pediatr. 3: 195-207.

Peterson, C., Xu, L., Florence, C., and Parks, S. E. 2015. Annual Cost of U.S. Hospital Visits for Pediatric Abusive Head Trauma. Child Maltreat. 20: 162-9.

Peterson, C., Xu, L., Florence, C., Parks, S. E., Miller, T. R., Barr, R. G., Barr, M., and Steinbeigle, R. 2014. The medical cost of abusive head trauma in the United States. Pediatrics. 134: 91-9.

Pierce, MC, and Bertocci, Gina. 2006. Injury Biomechanics and Child Abuse (Annual Review of Biomedical Engineering).

Plunkett, J. 2001. Fatal pediatric head injuries caused by short-distance falls. Am J Forensic Med Pathol. 22: 1-12.

Prange, M. T., Coats, B., Duhaime, A. C., and Margulies, S. S. 2003. Anthropomorphic simulations of falls, shakes, and inflicted impacts in infants. J Neurosurg. 99: 143-50.

Raghupathi, R., and Margulies, S. S. 2002. Traumatic axonal injury after closed head injury in the neonatal pig. J Neurotrauma. 19: 843-53.

Rivara, Frederick P., Kamitsuka, Michael D., and Quan, Linda. 1988. Injuries to Children Younger Than 1 Year of Age. Pediatrics. 81: 93-97.

Roach, J. P., Acker, S. N., Bensard, D. D., Sirotnak, A. P., Karrer, F. M., and Partrick, D. A. 2014. Head injury pattern in children can help differentiate accidental from non-accidental trauma. Pediatr Surg Int. 30: 1103-6.

Smith, D. H., Nonaka, M., Miller, R., Leoni, M., Chen, X. H., Alsop, D., and Meaney, D. F. 2000. Immediate coma following inertial brain injury dependent on axonal damage in the brainstem. J Neurosurg. 93: 315-22.

Stürtz, G. 1980. Biomechanical Data of Children. SAE International.

Thompson, A., and Bertocci, G. 2014. Pediatric bed fall computer simulation model: parametric sensitivity analysis. Med Eng Phys. 36: 110-8. 
Thompson, A., Bertocci, G., and Smalley, C. 2018. Femur loading in feet-first fall experiments using an anthropomorphic test device. J Forensic Leg Med. 58: 2533.

Thompson, A. K., and Bertocci, G. E. 2013. Paediatric bed fall computer simulation model development and validation. Comput Methods Biomech Biomed Engin. 16: $592-601$.

Thompson, A. K., Bertocci, G., and Pierce, M. C. 2009. Assessment of head injury risk associated with feet-first free falls in 12-month-old children using an anthropomorphic test device. J Trauma. 66: 1019-29.

Thompson, A. K., Bertocci, G., Rice, W., and Pierce, M. C. 2011. Pediatric shortdistance household falls: biomechanics and associated injury severity. Accid Anal Prev. 43: 143-50.

U.S. Department of Health \& Human Services, Administration for Children and Families, Administration on, and Children, Youth and Families, Children's Bureau. 2018. Child maltreatment 2016.

Wolfson, D. R., McNally, D. S., Clifford, M. J., and Vloeberghs, M. 2005. Rigid-body modelling of shaken baby syndrome. Proc Inst Mech Eng H. 219: 63-70. 


\section{APPENDIX I}

\section{A. SIM G/SKYi Verification}

Replicate fall experiments of Thompson's ATD feet first falls study (Thompson, 2018) have been conducted to assess SIM G accuracy. Thompson's data for falls onto carpet $(n=13)$ and linoleum $(n=13)$ were obtained. Each individual fall from the previous experiments were categorized into one of three different fall dynamics by the authors. For replicate falls each fall was video reviewed and categorized into one of the three fall dynamics described by Thompson (FIGURE 32). Replicate falls onto linoleum resulted in 5 of 7 falls with the same fall dynamics as 11 previous falls. Replicate falls onto carpet resulted in 7 of 7 falls with the same fall dynamics as only 1 previous fall. Based on the lack of similar fall dynamics onto the carpet surface, only replicate falls onto linoleum were used for analysis.

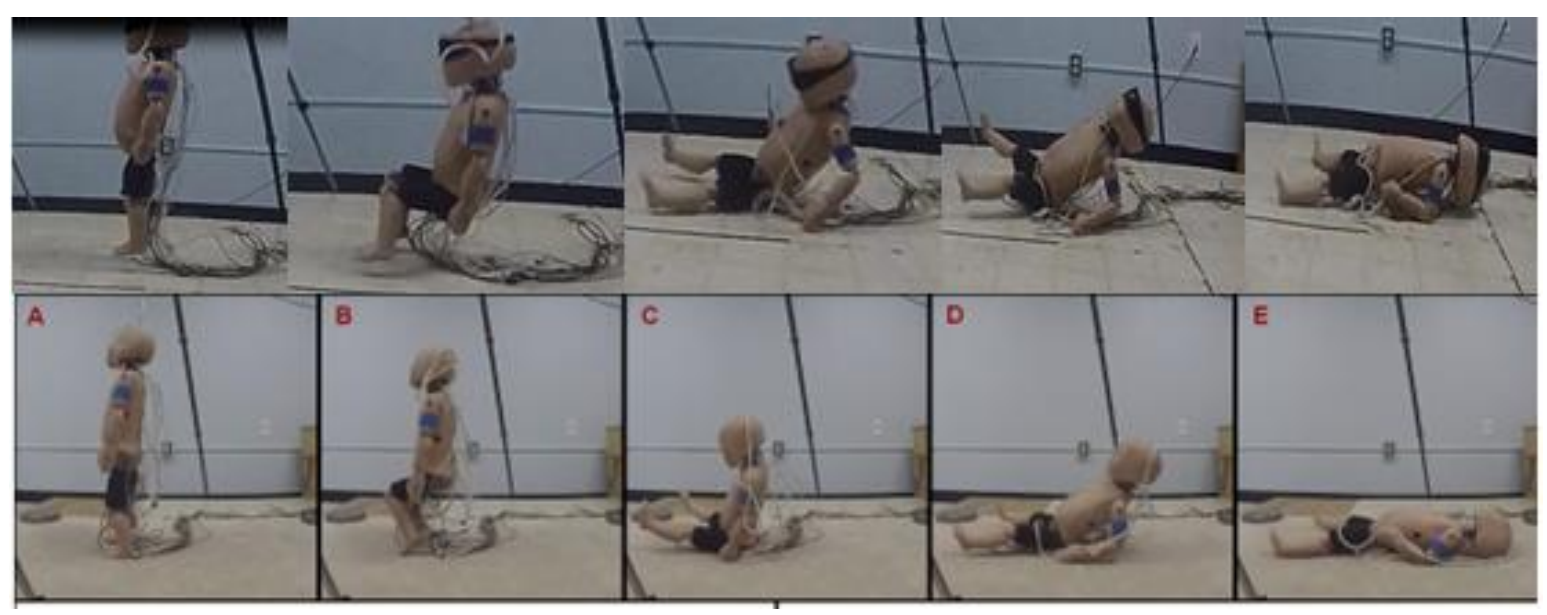

FIGURE 32 - Video Capture of Fall Dynamic Sequence for Replicated Falls (Top) and Previous Falls (Bottom) 
Mean peak resultant values for linear head acceleration, rotational head acceleration, and rotational head velocity and mean impact duration was determined for Thompson's experiments and for replicate experiments with the SIM G (TABLE IX). All measures were found not to be significantly different ( $\mathrm{p}$ value $>0.05$ )

TABLE IX

ATD ONBOARD INSTRUMENTATION AND SIM G COMPARISON

\begin{tabular}{|c|c|c|c|c|c|}
\cline { 2 - 6 } \multicolumn{1}{c|}{} & \multicolumn{2}{c|}{$\begin{array}{c}\text { ATD Onboard } \\
\text { Instrumentation(n=11) }\end{array}$} & \multicolumn{2}{c|}{ SIM G (n=5) } & \\
\hline & Mean \pm SD & Range & Mean \pm SD & Range & p value \\
\hline $\begin{array}{c}\text { Peak resultant } \\
\text { linear head } \\
\text { acceleration (g) }\end{array}$ & $32.73 \pm 9.20$ & $25.14-47.77$ & $31.02 \pm 1.37$ & $29.44-33.22$ & 0.571 \\
\hline $\begin{array}{c}\text { Peak resultant } \\
\text { rotational head } \\
\text { acceleration } \\
\text { (krad/s }\end{array}$ \\
$\begin{array}{c}\text { atrad } \\
\text { Peak resultant } \\
\text { rotational head } \\
\text { velocity (rad/s) }\end{array}$ & $12.51 \pm 3.53$ & $7.58-18.31$ & $13.53 \pm 2.55$ & $10.27-15.79$ & 0.574 \\
\hline $\begin{array}{c}\text { Impact } \\
\text { Duration (ms) }\end{array}$ & $16.09 \pm 1.58$ & $13.00-17.00$ & $16.80 \pm 1.48$ & $15.00-19.00$ & 0.734 \\
\hline
\end{tabular}

\section{Linear Head Acceleration}

The mean peak resultant linear head acceleration obtained by the ATD onboard accelerometers from Thompson's experiments was $32.73 \mathrm{~g}$ with a 95\% confidence interval (CI) of $(26.55,38.91)$. The mean peak resultant linear head acceleration obtained by the SIM G from the replicated falls was $31.02 \mathrm{~g}$ with a $95 \% \mathrm{CI}$ of $(29.32,32.72)$ (FIGURE 33). Resultant linear head acceleration from both falls was tested for normal distribution and found that the peak resultant linear head acceleration from the ATD 
onboard accelerometers was not normally distributed. A non-parametric Mann Whitney U-Test was performed and found that peak resultant linear head acceleration between the SIM G and the ATD onboard accelerometers were not significantly different $(\mathrm{p}=0.571)$.

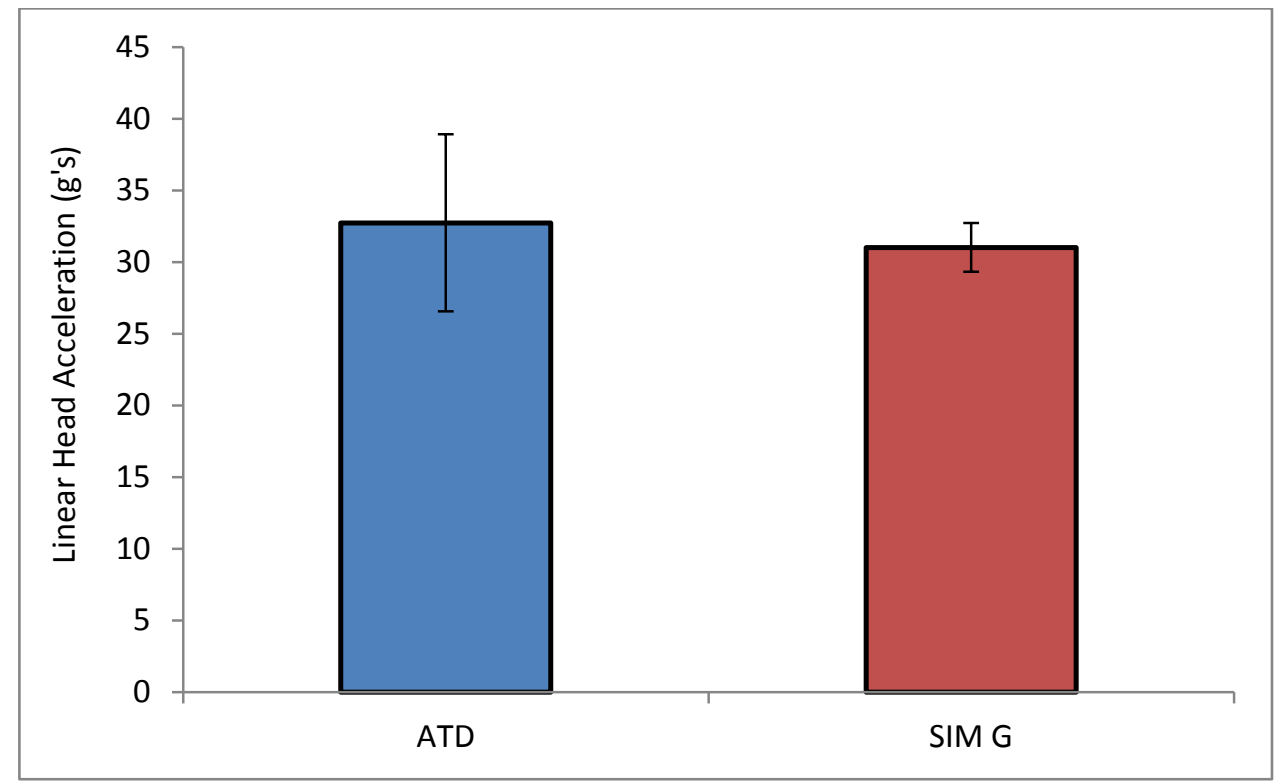

FIGURE 33 - SIM G Verification: Mean Peak Resultant Linear Head Acceleration. Error Bars Represent 95\% CI

\section{Rotational Head Acceleration}

The mean peak resultant rotational head acceleration from Thompson's experiments was $3.23 \mathrm{krad} / \mathrm{s}^{2}$ with a $95 \% \mathrm{CI}$ of $(2.44,4.01)$. The mean peak resultant rotational head acceleration obtained by the SIM G for replicated falls was $2.60 \mathrm{krad} / \mathrm{s}^{2}$ with a $95 \%$ CI of $(2.01,3.18)$ (FIGURE 34). A two sample t-test was performed and found that peak resultant rotational head acceleration between the SIM G and the ATD onboard accelerometers were not significantly different $(\mathrm{p}=0.270)$. 


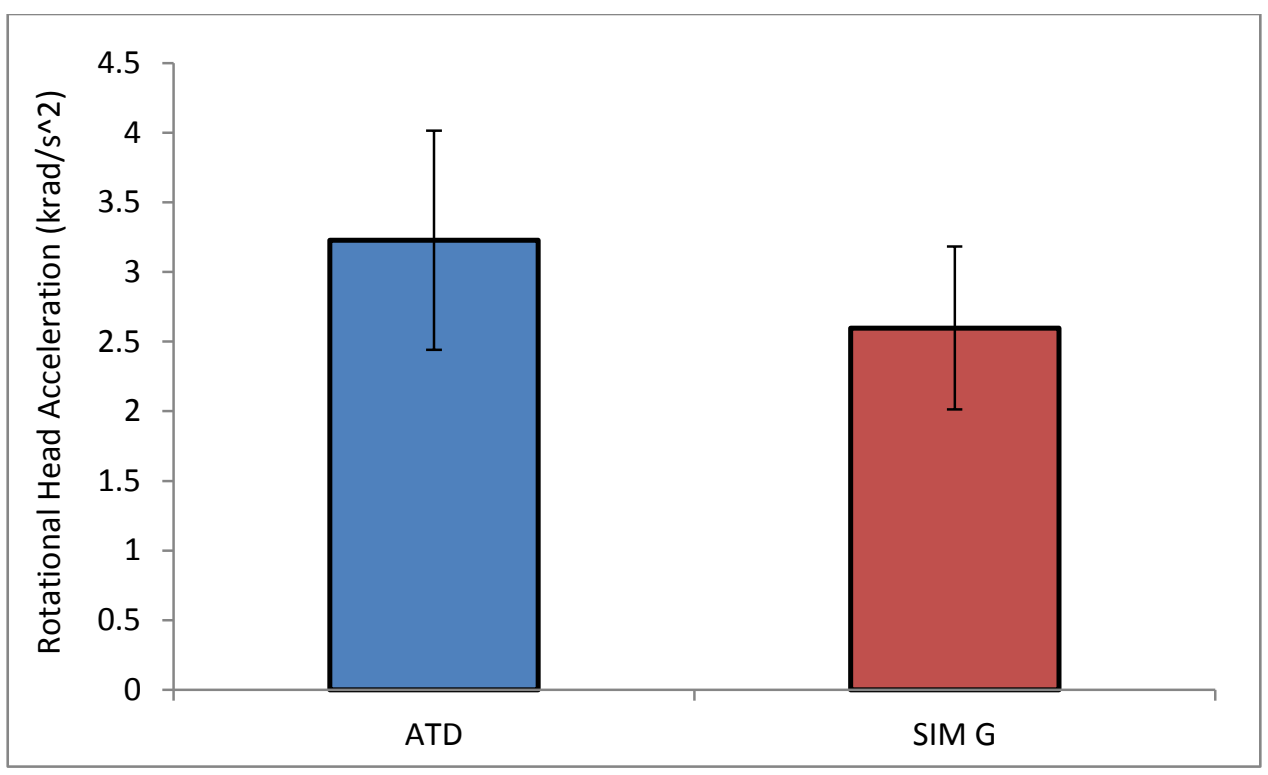

FIGURE 34 - SIM G Verification: Mean Peak Resultant Rotational Head Acceleration. Error Bars Represent 95\% CI

\section{Rotational Head Velocity}

The mean peak resultant rotational head velocity from Thompson's experiments was $12.51 \mathrm{rad} / \mathrm{s}$ with a $95 \%$ CI of $(10.14,14.88)$. The mean peak resultant rotational head velocity obtained by the SIMG for replicated falls was $13.53 \mathrm{rad} / \mathrm{s}$ with a $95 \% \mathrm{CI}$ of $(10.35,16.70)$ (FIGURE 35). Resultant rotational head velocity from the ATD onboard instrumentation and the SIM G were found to be normally distributed. A two sample ttest was performed and found that peak resultant rotational head velocity between the SIM G and the ATD onboard instrumentation were not significantly different $(\mathrm{p}=0.574)$. 


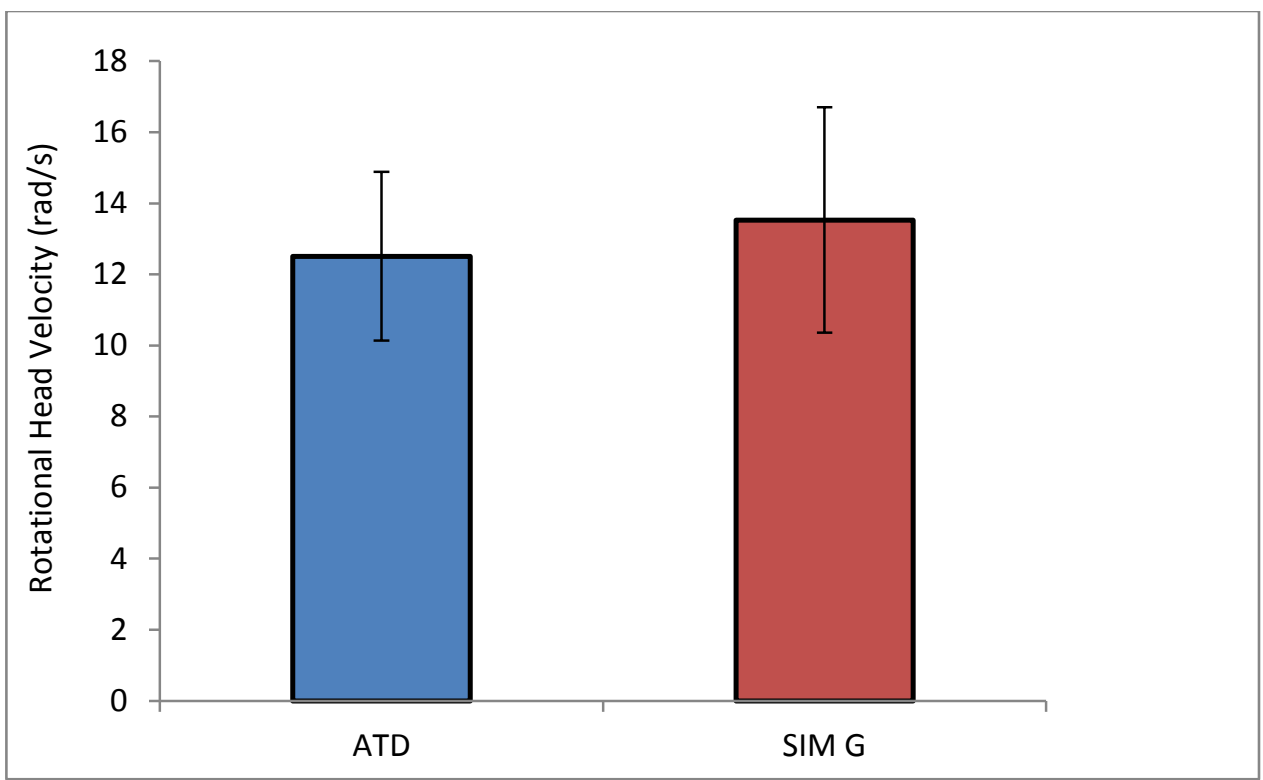

FIGURE 35 - SIM G Verification: Mean Peak Resultant Rotational Head Velocity. Error Bars Represent 95\% CI.

\section{Impact Duration}

Mean impact duration from Thompson's experiments was $16.09 \mathrm{~ms}$ with a CI of $(15.03,17.15)$. Mean impact duration for replicated falls was $16.80 \mathrm{~ms}$ with a CI of $(14.96,18.64)$ (FIGURE 36). Impact durations from both falls were tested for normal distribution and found that impact durations from Thompson's experiment was not normally distributed. A non-parametric Mann Whitney U-Test was performed and found that impact durations between the SIM G and the ATD were not significantly different ( $p$ $=0.734)$. 


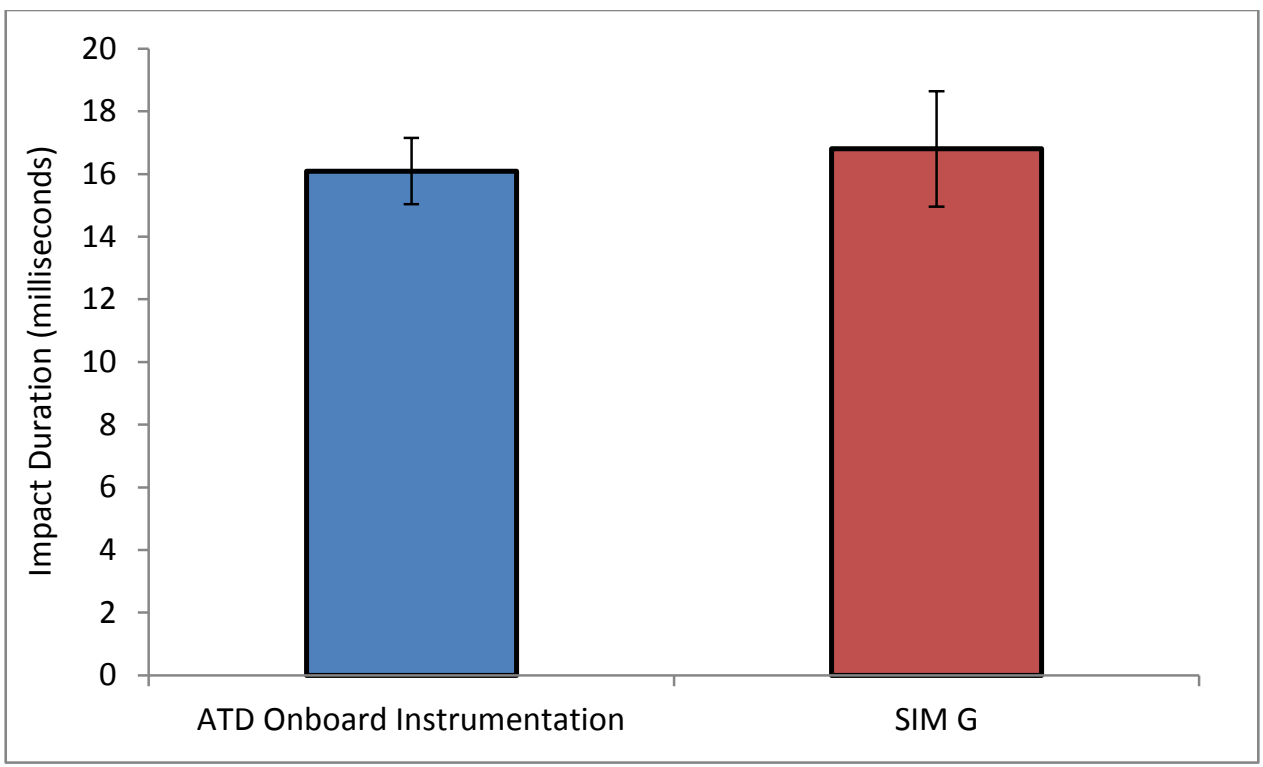

FIGURE 36 - SIM G Verification: Mean Impact Duration. Error Bars Represent 95\% CI. 
VITA

BRET HILT

\section{EDUCATION}

M.Eng. in Bioengineering

University of Louisville, J. B. Speed School of Engineering, Louisville, KY

5/17 - Expected 12/18

B.S. in Bioengineering

University of Louisville, J. B. Speed School of Engineering, Louisville, KY $8 / 12-5 / 17$

\section{EXPERIENCE}

BFW Inc. Louisville, KY

Operations Associate

5/17 - Present

- Responsible for testing and troubleshooting of customer returned products.

- Provide customer service to diagnose and resolve equipment and technical issues

- Involved with technical training for equipment use

- Involved with optimize process flow for shipping, receiving, and product distribution.

Catalent Pharma Solutions; Winchester, KY

ProcessEngineer Co-op

8/15, 5/16, 1/17

- Primary Project: Resolve site equipment issues by providing cost effective solutions. Involved research and collaboration with outside vendors to resolve compatibility issues. Oversaw purchases of and lead implementation of the equipment.

University of Louisville - Bioengineering Undergraduate Research

Fall 2017

- Senior Design Project: Worked as a team leader to design and develop a prototype insole that assists patients in initiating a gait cycle. The initial prototype was researched, designed, manufactured, and was used for further development after completion. 